\title{
DISCLAIMER
}

This report was prepared as an arcount of work sponsored by an agency of the United States Government. Neither the Urited States Government nor any agency thereof, nor any of their employees, makes any warranty, express or implied, or assumes any legal liability or responsibility for the accuracy, completeness, or usefulness of any information, apparatus, product, or process disclosed, or represents that its use would not infringe privately owned rights. Referenze herein to any specific commercial product, process, or service by trade name, trademark, manufacturer, or otherwise does not necessarily constitute or imply its endorsement, recommondation, or favoring by the United States Government or any agency thereof. The views and opinions of authors expressed herein do not necessarily state or reflect those of tine United States Government or any agency thereof.

\section{ANAL YTICAL AND NUMERICAL MODELS \\ FOR ESTIMATING THE EFFECT OF \\ EXHAUST VENTILATION ON RADON ENTRY IN \\ HOUSES WITH BASEMENTS OR CRAWL SPACES}

by

Robert J. Mowris

B.S. University of Wisconsin, 1977

LBL -22067

B.S.M.E. University of Wisconsin, 1983

DE87 000936

A thesis submitced to the

Faculty of the Graduate School of the

University of Colorado in partial fulfillment

of the requirements for the degree of

Master of Science

Department of Civil, Environmental, \& Architectural Engineering

1986

\author{
Lawrence Berkeley Laboratory \\ University of California \\ Berkeley, California 94720
}


Mowris, Robert J. (M.S., Civil Engineering)

Analytical and Numerical Models for Estimating the Effect of Exhaust Ventilation on Radon Entry in Houses with Basements or Crawl Spaces

Thesis directed by Associate Professor Dr. David Claridge, and William J. Fisk, Staff Scientist, Indoor Environıment Program, Lawrence Berkeley Laboratory, Berkeley, CA

Mechanical exhaust ventilation systems are being installed in newer, energy-efficient houses and their operation can increase the indoor-outdoor pressure differences that drive soil gas and thus radon entry. This thesis presents simplified models for estimating the pressure driven flow of radon into houses with basements or crawl spaces, diue to underpressures induced by indoor-outdoor temperature differences, wind, or exhaust ventilation. A two-dimensional finite difference model is presented and used to calculate the pressure field and soil gas flow rate into a basement situated in soil of uniform permeability. A simplified analytical model is compared to the finite difference model with generally very good aggreement. Another simplified model is presented for houses with a crawl space. Literature on radon research is also reviewed to show why pressure driven flow of soil gas is considered to be the major source of radon entry in houses with higher-than-average indoor radon concentrations.

Comparisons of measured vs. calculated indoor radon concentrations for a house with a basement showed the simplified basement model underpredicting on average by $25 \%$. For a house with a crawl space the simplified crawl space model overpredicted by $23 \%$ when the crawl space vents are open and $48 \%$ when the crawl space vents are sealed.

For a house with a basement, the exhaust ventilation sysiem is shown to reduce indoor radon concentrations by from $12 \%$ to $30 \%$ below the levels expected for the same house, 
soil conditions, and no mechanical ventilation system. The combined effects of "tightening" the building envelope and installing an exhaust ventilation system are shown to generally increase indoor radon concentrations by as much as a factor of two. The increased radon entry rate due to these effects may be countered by sealing penetrations in the basement substructure so that the resistance to fow through the substructure is increased. For a house with a vented crawl space and evenly distributed effective leakage area, the exhaust system is shown to reduce indoor radon levels by from $29 \%$ to $58 \%$ below the levels expected for the same house without the system. The combination of exhaust ventilation with house "tightening" messures, which include "tightening" the floor above the crawl space, is shown to reduce indoor radon concentrations by from $28 \%$ to $58 \%$ below levels expected for a house with the same crawl space radon concentration. 


\section{To Kaki}




\section{ACKNOWLEDGEMENTS ${ }^{\dagger}$}

I would like to express my appreciation to all of the fine people in the Indoor Environment Program at Lawrence Berkeley Laboratory for their financial support, patience, assistance and guidance throughout the course of this research. I would especially like to thank William Fisk for his invaluable support throughout the research and writing, David Grimsrud, Barbara Moed, Tony Nero, Rich Prill, Brad Turk, Richard Sextro, and Henrik Wallman for their suggestions and advice, and Ken Revzan for helping me in the computer modeling. I would aiso like to thank the members of the Energy Performance of Buildings Group; Brian Smith for helping with the computer graphics, and especially Mark Modera and Helmut Feustel for sharing with me their knowledge of wind induced pressures in buildings. Others that must be thanked include: Claudette Lederer, Nancy Powers, Sandy Sampson, Cindy Sverrisson, Rebecca Palmer, and especially Mirriam Schwartz for her patience and wonderful artistic skill in completing the figures.

I would aiso like to thank the fine people in the Civil, Environmental, \& Architectural Engineering Department at the University of Colorado for their assistance and guidance during my first year there as a graduate student, and in helping me continue my education for this past year, while working in Berkeley at LBL. I especially want to thank my advisor Dr. David Claridge, for his advice and support, and Florence Petersen for her invaluable help during these past two years.

I would also like to express my deepest appreciation to my family and friends for their ever present love and support.

In closing, I want to thank my friend and lover, Kathleen Carlson, for her kindness, affection, love, and support, while writing this thesis.

'This work was supported by the Assistant Secretary for Conservation and Renewable Energy, Office of Building Energy Research and Development, Building Systems Division of the U.S. Department of Energy under contract NO. DE-AC03-76SF00098. 


\section{CONTENTS}

\section{CHAPTER}

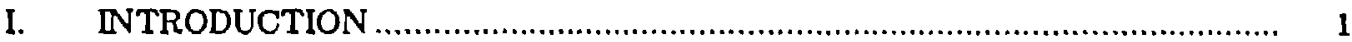

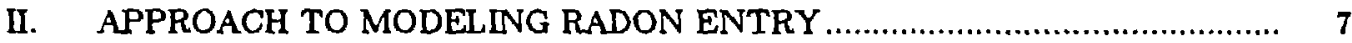

Background and Literature Review ................................................ 9

Forces Driving Soil Gas Flow and Radon Entry ............................... 12

Stack Effect Pressures ............................................................ 12

Wind Induced Pressure.............................................................. 14

Crawl Space Pressure ................................................................... 21

Pressure Resulting from Mechanical Ventilation.............................. 23

Combining the Underpressures Driving Radon Entry .......................... 24

III. ANALYTICAL MODEL OF SOII GAS FLOW INTO BASEMENTS ............... 26

Resistance to Soil Gas Flow Through Soil ........................................... 26

Resistance to Soil Gas Flow Through Basoment Gaps and Cracks ............... 31

Analytical Model of Soil Gas Flow for a Basement Gap or Crack................ 37

IV. NUMERICAL MODEL OF SOL GAS FLOW INTO BASEMENTS................ 40

Mathematical Model of Soil Gas Flow ............................................. 40

Mass Transfer of Radon Through Soil ............................................... 43

Radon Entry Rate into a Basement............................................ 46

2-dimensional Finite Difference Computer Programming Description ............ 50

Analytical vs. Numerical Model of Soil Gas Flow ............................... 62

iseasured vs. Calculated Radon Entry Rate into Basements..................... 66 
V. SIMPLE MODEL OF RADON ENTRY

INTO HOUSES FROM CRAWL SPACES

Measured vs. Calculated Radon Entry into Houses from Crawl Spaces.

VI. THE EFFECT OF EXHAUST VENTILATION ON SOIL GAS ENTRY, RADON ENTRY, AND INDOOR RADON CONCENTRATIONS

Effect of Exhaust Ventilation in Houses with Basements

Effect of Exhaust Ventilation in the Spokane House with a Basement.......

Effect of Exhaust Ventilation in Basement

Houses with Other Soil Conditions.

Effect of Exhaust Ventilation in Houses with Crawl Spaces

Conclusions Regarding the Effect of Exhaust Ventilation

Systems in Houses with Basements or Crawl Spaces.

BIBLIOGRAPHY

\section{APPENDDX}

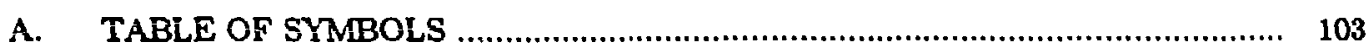

B. LBL MODEL TERFAIN AND SHIELDING COEFFICIENTS ........................... 107

C. 2-DIMENSIONAL FINITE DIFFERENCE COMPUTER PROGRAM ............... 108 


\section{TABLES}

Table

1. Comparison of calculated pressure drop, $\Delta P$, across gaps and cracks in a concrete slab

2. Sensitivity of the basement and soil resistances and the soil gas flow rate with variations in permeability, width and length of the basement gap or crack, and depth of the basement

3. Pressure field boundary conditions for the soil surrounding a basement shown in Figure 6

4. Radon concentration field boundary conditions

for the soil surrounding a basement shown in Figure 6

5. Physical characteristics of the Spokane, WA and

the Portland, OR house used in the sample calculations.

6. Basement House, Spokane, WA. Measured vs. calculated values of Indoor Radon Concentration.

7. Crawl Space House, Portland, OR. Measured vs. calculated values of indoor radon concentration

8. The effect of exhaust ventilation, gap size, and effective leakage area, on soil gas entry and indoor radon concentration in a house with a basement.

9. The effect of exhaust ventilution, soil permeability, soil gas radon concentration, and effective leakage area on soil gas entry and indoor radon concentration, house with a basement.

10. The effect of exhaust ventilation, crawl space radon concentration, and effective leakage areas, on radon entry rates and indoor radon concentrations, in a house with a crawl space 


\section{FIGURES}

\section{Figure}

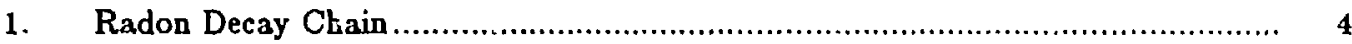

2. Pathways for radon entry into houses

with basement or crawl space substructures

3. Interior pressure coefficient vs. Envelope Permeability Ratio......................... 20

4a. Cross-sectional view of a house with a

basement having a poured concrete wall and floor

4b. The simplified geometry assumed for the basement house showing the streamlines of pressure driven soil gas flow into the basement.

5. Lines of heat-low between an isothermal surface and a horizontal cylinder, imledded into a homogeneous thermally conductive medium of uniform conductivity

6. Cross-sectional view of a typical basement and soil block showing boundary regions for the 2-dimensional finite difference model

7a. A 2-dimensional simple nodal network

7b. 2-rimensional pressure field finite difference approximation

8. Variable spaced grid and coordinate system used to model the 2-dimensional basement geometry

8. Typical 2-dimensional fine grid spacing used near the gap region

10. Soil gas pressure field for a basement section with homogeneous permeability, a gap size of $1 \mathrm{~mm}$, $\Delta P=-3.5 \mathrm{~Pa}$, and model geometry extending $14 \mathrm{~m}$

11. Soil gas pressure field for a basement section with homogeneous permeability, a gap size of $1 \mathrm{~mm}$, $\Delta P=-3.5 \mathrm{~Pa}$, and model geometry extending $30 \mathrm{~m}$

12. Soil gas pressure fielf for a basement section with homogeneous permeability, a gap size of $10 \mathrm{~mm}$, $\Delta \mathrm{P}=-3.5 P a$, and model geometry extending $14 \mathrm{~m}$ 
13. Close-up view of the soil gas pressure field

14. A comparison of the simple analytical model to the numerical model of soil gas flow rate vs. basement wall-floor gap size for a basement underpressure of $\triangle \mathrm{P}=-3.5 \mathrm{~Pa}$. and soil permeabilities of $10^{-4}, 10^{-7}$, and $10^{-10} \mathrm{~cm}^{2}$.

15. A comparison of the simple analytical model to the numerical model of soil gas flow rate vs. basement wall-floor gap size for a basement underpressure of $\triangle \mathrm{P}=-0.3 \mathrm{~Pa}$ and soil permeabilities of $10^{-4}, 10^{7}$, and $10^{-10} \mathrm{~cm}^{2}$.

16. A comparison of the simple analytical model to the numerical model of soil gas flow rate vs. basement wall-toor gap size for a basement underpressure of $\Delta \mathrm{P}=-10 \mathrm{~Pa}$ and soil permeabilities of $10^{-4}, 10^{7}$, and $10^{-10} \mathrm{~cm}^{2}$

17. Plan view of the Spokane, WA house

18. Spokane, WA house with basement (ESP108C), measured vs. calculated indoor radon concentrations, and calculated soil gas entry rates for the period of October 28 through Novemeber 2,1985 ..

19. Spokane, WA house with basement (ESP108C), measured vs. calculated indoor radon concentrations, and calculated soil gas entry rates for the period of December 13 through December 18, 1985

20. Spokane, WA house (ESP111), Messured data from

a period from November 23 through December 14, 1985

21. Plan view of the Portland, OR house

which has a vented crawl space substructure

22. The effect of exhsust ventilation, effective leakage area, and wall-floor gap width on indoor radon concentration in a house with a basement

23. Permeability $\left(\mathrm{cm}^{2}\right)$ of representative soils

24. The effect of exhaust ventilation, crawl space radon concentration, and effective leakage area on indoor radon concentration in a house with a vented crawl space 


\section{CHAPTER I}

\section{INTRODUCTION}

Simplified methods of estimating soil gas entry, and hence radon entry, ihe residential buildings are necessary in order to assess the impact on indoor radon concentration caused by:

1) installing mechanical exhaust ventilation systems,

2) constructing new houses in regions known to have high radon concentrations or high soil permeabilities, and

3) reducing infitration rates by "tightening" measures designed to save energy.

Efforts have been made recently to characterize and map the United States in order to locate areas where radium content in the soil and high soil permeability might suggest potential problems of higher-than-average indoor radon concentrations in houses (Na85). ihese date can be used as inputs to a simnlified model of radon entry to quickly estimate whether houses in certain locations might have radon problems. This paper is concerned with the development of two such models:

1) a simplified model to predict soil gas flow, and hence radon entry into houses with basements, and

2) a simplified model to predict radon entry into houses with crawl spaces.

An understanding of the health risks associated with radon exposure and where radon comes from is necessary before describing the approach and deveiopment, of the simplified models.

Exposure to the decay products of radon $\left({ }^{222} \mathrm{Rn}\right)$ in the indoor air of residential buildings poses a potentially serious lung cancer risk. The relationship between exposure to radon 
decay products and lung cancer was first noticed in uranium mine workers. Extensive epidemiological studies on uranium and other miners by the United Nations Scientific Committee on the Effects of Atomic Radiation, the U.S. Environmental Protection Agency, and others have resulted in the establishment of dose-response factors for exposure to radon decay products (UN77,Ne83,Ra84). Extrapolating from dose-response factors given in the United Nations study, Nero has estimated that between 2000 and 20,000 cases of lung cancer per year may result from exposure to radon decay products in residential buildings amonis the entire United States population of 225 million people ( $\mathrm{Ne} 83, \mathrm{Ne} 86)$. This estimate is based on an average indoor radon concentration of $1 \mathrm{pCi} / /^{1}$ which is the geometric mean of measured values from 38 regions covering 21 of the contiguous United States (Ne84). Approximately 1 million houses in the U.S. have indoor radon concentrations exceeding $8 p C i / l(\mathrm{Ne}$ ) for people living in these so called "hot" houses, the lifetime lung cancer risk from exposure to radon decay products may be greater than 1 in 50.

The radon isotopes ${ }^{222} \mathrm{Rn}$ and ${ }^{220} \mathrm{Rn}$ naturally occur from the decay of uranium-238 and thorium-232 respectively. The half-life of ${ }^{238} \mathrm{U}$ is 4.5 billion years, which is approximately the age of the earth, and the half-life of ${ }^{232} \mathrm{Th}$ is 13.9 billion years. Both ${ }^{238} \mathrm{U}$ and ${ }^{232} \mathrm{Th}$, and their decay products, including ${ }^{220} \mathrm{Ra}$ and ${ }^{224} \mathrm{Ra}$, are widely distributed in nature, and exist in trace amounts in all rocks, sand, and soil. In ordinary back-yard soil, each cubic meter contains from 0.2 to $6 \mu C i$ of radium, which decays at a constant rate into radon, maintaining a constant activity of from 200 to $6000 \mathrm{pCi} / \mathrm{l}$ of soil (Ev68,Na84). The average soil gas concentration of radon is approximately $540 \mathrm{pCi} / \mathrm{l}(\mathrm{Na} 84)$. Radon is the only element in the uranium and thorium decay series that is a gas at ambient temperatures $(>-69 C)$, and because all rock and soil is somewhat porous, radon can travel either by diffusion or convection through the soil, and into:

'The SI unit of radioactive decay is the Becquerel, which is defined as $1 B q=1$ dis/see, and $1 \mathrm{pCi} / \mathrm{I}=37 \mathrm{~Bq} / \mathrm{m}^{3}$. 
1) the atmosphere where typical radon background concentrations in the outdoor air range from 0.1 to $0.7 \mathrm{pCi} / /$ (Ev69), depending on radium concentration and soil permeability, or

2) a house through entry paths in basements, crawl spaces, or slab floors, where indoor radon concentrations in U.S. homes range from 1 to $1000, \mathrm{Ci} / \mathrm{l}(\mathrm{Ne} 84)$.

For simplicity the discussion of the details of the decay products of radon will be limited to the ${ }^{272} \mathrm{Rn}$ isotope which has a half-life of 3.8 days compared to the very short half-life of 55 seconds for ${ }^{20} \mathrm{Rn}$. This shorter half-life limits the indoor concentration and average dose to the lung from ${ }^{200} \mathrm{Rn}$ progeny to about $25 \%$ of that from ${ }^{222} \mathrm{Rn}$ progeny (UN82).

The health risk from radon arises from the alpha decay of its short-lived progeny polonium ${ }^{218} \mathrm{Po}$ and ${ }^{214} \mathrm{Po}$. Figure 1 shows the ${ }^{228} \mathrm{Ra},{ }^{222} \mathrm{Rn}$ decay chain from the ${ }^{238} \mathrm{U}$ decay series. The radon progeny polonium $\left({ }^{218} \mathrm{Po}\right)$, lead $\left({ }^{214} \mathrm{~Pb}\right)$, and bismuth $\left({ }^{214} \mathrm{Bi}\right)$, which have half-lives of $3.05,26.8$, and $19.7 \mathrm{~min}$ respectively, can be inhaled and cause subsequent alpha doses to the basal tissue where bronchogenic lung cancer is assumed to originate. These radon progeny (also called daughters) are chemically active unlike their inert radon parent and can attach to surfaces of particles, room walls, and lung tissue. Raton daughters attached to particles are mainly deposited in the pulmonary region of the lung, and unattached daughters are deposited in the upper respiratory tract due to their higher diffusion coefficienc. Unattached daughiers are typically $0.002 \mu \mathrm{mm}$ in size, and attached daughters typically range in size from between 0.03 to $0.09 \mu \mathrm{m}$, but may be larger or smaller depending on the distribution of indoor aerosols. The small size of unattached daughters allows them to pass deeper into the bronchi where their estimated alpha dose is thought to be from 9 to 35 times greater than the estimated dose from attached daughters $(\mathrm{Ja} \mathbf{8 1})$. 


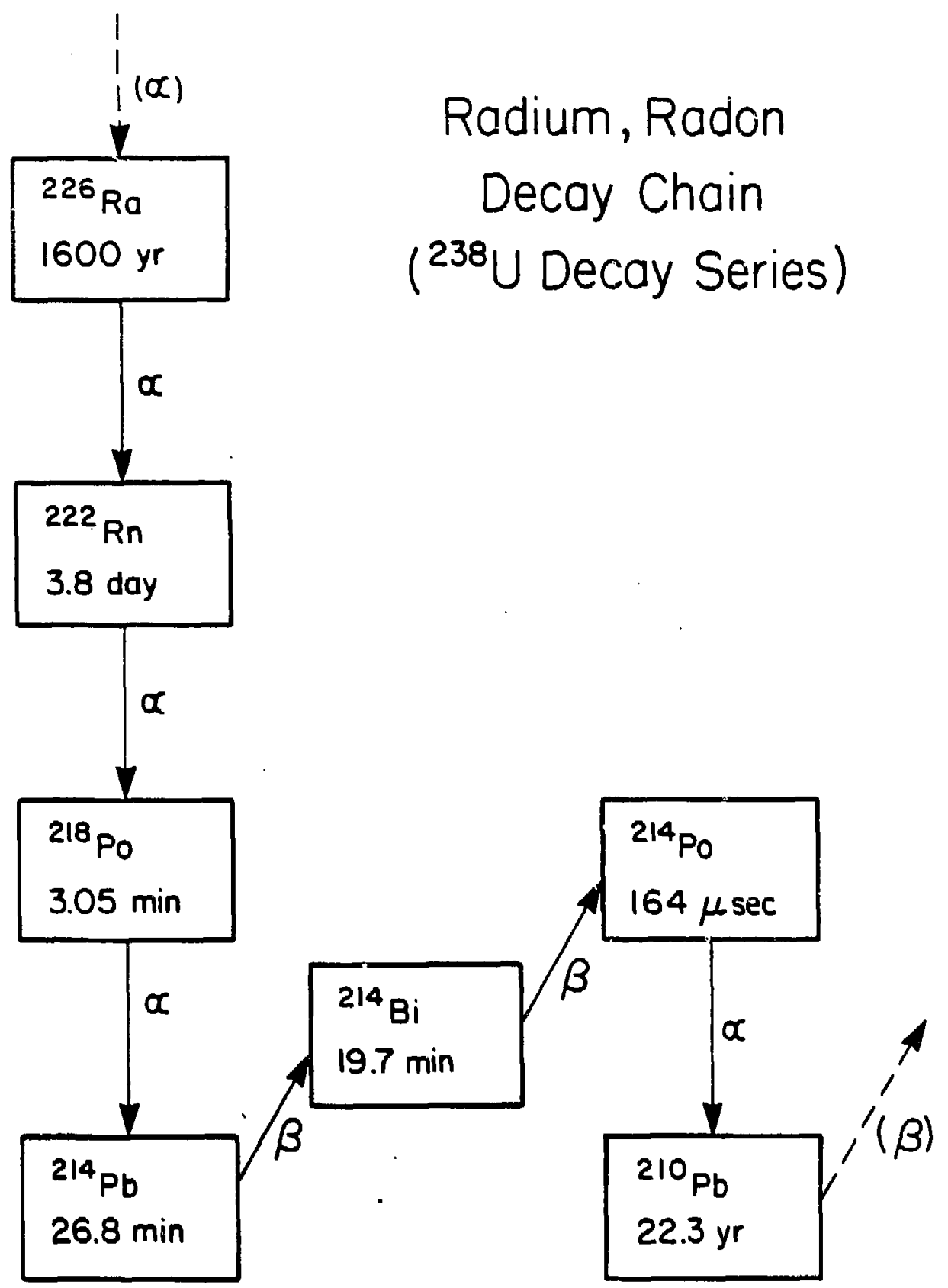

XBL 853-10395

Figure 1. Radon Decay Chain. The nuclides ${ }^{218} \mathrm{Po},{ }^{214} \mathrm{~Pb}$, and ${ }^{214} \mathrm{Bi}$ are of primary radiological concern due to inhalation and susequent alpha decay. 
Since the problem of exposure to radon daughters was first noticed in the mining industry, the potential alpha energy concentration (PAEC) of radon decay products has traditionally been described in units of Working Levels ${ }^{2}(W L)$. One working level used to be the highest radiation concentration allowed in the workplace. It is defined as any combination of short-lived radon decay products in one liter of air which result in the emission of 1.3 $\times 10^{5} \mathrm{MeV}$ of alpha-particle energy. In an "ideal" indoor environment with no plate-out of radon daughters onto walls or other surfaces, and no ventilation, the "ideal" ? $\hat{A E C}$ will be $1 \mathrm{WL}$ if the radon concentration is $100 \mathrm{pCi} / \mathrm{l}$. To adjust for the presence of plaie-out and ventilation in residential buildings an equilibrium factor is used which is defined as the ratio of "actual" PAEC divided by the "ideal" PAEC. The equilibrium factor in residential buildings is typically 0.5 , and a house with a measured radon concentration of $5 p C i / l$ would have a PAEC of $0.025 W L$. The radiological dose to the lung is given in Working Level Months ( $W L M$ ) and is defined as the cumulative radi slogical exposure to a concentration of radon decay products in air of 1 working level $(W L)$, over an average working month of 170 hours, at a mean breathing rate of $1200 \mathrm{l} / \mathrm{hr}$. The current occupational limit for exposure to radon decay products is four WLM/year (NC84b).

The 1981 American Society of Heating, Refrigerating, and Air-Conditioning Engineers (ASHRAE) guidelins recommends indoor levels of radon concentration not to exceed 0.01 WL. Nero et al. have shown that $20 \%$ of houses in the United States may be expected to exceeed the ASHRAE quideline (Ne84). The National Council on Radiation Protection (NCRP) has recently proposed a higher guideline of $0.04 W L$, or $8 p C i / l$ (NC84), but approximately $1 \%$ to $2 \%$ of U.S. houses ( 1 to 2 million homes) may be expected to exceed even this higher guideline ( $\mathrm{Ne84})$.

${ }^{2}$ The SI equivalent units of $W L$ and $W L M$ are $2.08 \times 10^{-5} \mathrm{~J} / \mathrm{m}^{3}$ and $4.2 \times 10^{3} \mathrm{~J}$ respectively. 
Radon can enter a home by the process of diffusion or convection. The major diffusive sources in the home are soil around the building substructure, building materials, and domestic water supplies, which contribute an average radon flux of $0.04,0.06$, and 0.03 $p C i / l-h r$ respectively $(\mathrm{Se} 85, \mathrm{Na84b})$. The convective sources are the infiltrating outdoor air and pressure driven thow of soil gas which sweeps radon from the soil around the building substructure and into the house. The contribution from outdoor air is typically $0.3 \mathrm{pCi} / \mathrm{l}-\mathrm{hr}$ $(\mathrm{Na84b})$, but the contribution from pressure driven flow depends on the indoor-outdoor pressure differences, substructure penetrations, soil permeability, and soil radium concentrations. The importance of pressure driven flow, and the factors that influence it, are discussed in Chapter 2. Chapters 3 and 4 discuss simplified models for estimating pressure driven flow of radon into houses with basements, and Chapter 5 discusses a simplified model for estimating pressure driven flow of radon into houses with crawl spaces. Chapter 6 discusses how pressure driven flow, and indoor raton concentration, is affected by the presence of an unbalanced mechanical exhaust ventilation system. 


\section{CHAPTER II}

\section{APPROACH TO MODELING RADON ENTTRY}

In order to approach the problem of modeling radon entry, it is necessary to understand the sources of radon entering the indoor environment of a house. As discussed in Chapter 1, the major sources of radon in typical single family houses are the soil around the building substructure, building materials, domestic water supplies, and infiltrating outdoor air. Figure 2 shows the possible pathways for radon entering houses with basements or crawl spaces (Se85). A mass balance approuch can be used to model the rate of change of indoor radon concentration, $R n_{i}(t)$, with respect to time, $t$, as

$$
\frac{d R n_{i}(t)}{d t}=\sigma_{d}(t)+\sigma_{j}(t)+\lambda_{,}(t) R_{n_{0}}(t)-R n_{i}(t)\left[\lambda_{1}+\lambda_{R n}\right]
$$

where $\sigma_{d}=$ radon entry rate from diffusion $(p C i / l-h r), \sigma_{f}=$ radon entry rate from convection or soil gas flow $(p C i / l-h r), \lambda_{0}=$ house ventilation rate $\left(h r^{-1}\right), \lambda_{R_{n}}=$ radon decay constant $=0.00756\left(h r^{-1}\right)$, and $R n_{0}=$ outdoor radon concentration (pCi/l-hr). At steadystate Equation (2.1) may be written as

$$
R n_{i}=\frac{\sigma_{d}+\sigma_{f}+\lambda_{i} R n_{0}^{\dagger}}{\lambda_{1}+\lambda_{R n}}
$$

The rate of removal of radon is dominated by ventilation, and the radon decay constant, $\lambda_{R m}$, is usually ignored. The house ventilation rate can be estimated using the following expression given by Modera (Mo85)

'The term $\lambda, R_{n}$ in the above equations should be corrected to account for air entering the house from gaps or cracks in the foundation of a house with a basement or air entering through the floor of a house with a crawl space (see Errata sheet at end of thesis). 


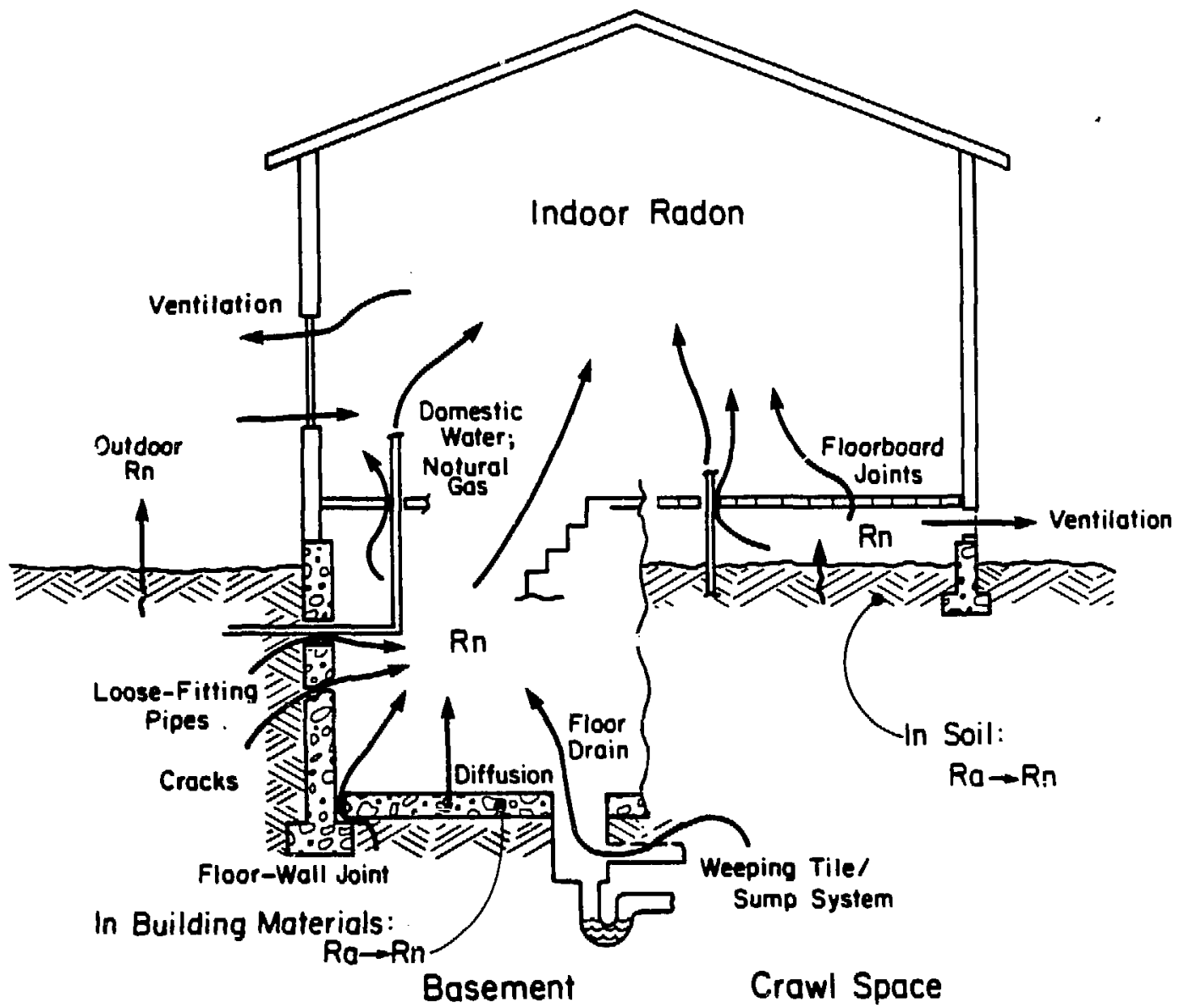

XBL 853-10394

Figure 2. Patbways for radon entry into houses with basement or crawl space substructures. 


$$
\lambda_{v}=\frac{\sqrt{Q_{v^{2}+Q_{u}^{2}+Q_{s m v}^{2}}+Q_{b m v}}}{V}
$$

where volumetric flow rates are represented by $Q\left(\mathrm{~m}^{3} / \mathrm{hr}\right), V=$ house volume $\left(\mathrm{m}^{3}\right)$, and the subscripts are $s=$ stack effect, or temperature induced infiltration, $w=$ wind induced infiltration, $u m v=$ unbalanced mechanical ventilation (ie. exhaust system), and $b m v=$ balanced mechanical ventilation (ie. air-to-air system). Excluding the balanced mechanical ventilation component, the total air change rate is determined by adding the individual rates in quadrature. Increasing the ventilation rate, by the use of a balanced mechanical ventilation system, will typically lower the indoor radon concentration by a proportional amount. Mitigation efforts using balanced ventilation systems, such as an air-to-air heat exchanger, have been effective in reducing indoor radon concentrations by from $50 \%$ to $70 \%$ (Tu86).

\section{Background and Literature Review}

Early work done on mathematical modeling of radon in the soil was done by Clements who studied the effect of atmospheric pressure on the transport of radon from the soil to the atmosphere (Cl74). Clements formulated the mathematical equations describing the mass transfer of radon in the soil which are described in Chapter 4. He also made numerous measurements of radon flux from soil for comparison to predicted radon fluxes. Another mathematical modeling effort by Bates was done to examine the effect of overpressure ventilation on reducing radon concentrations in uranium mines (Ba81). Bates' study showed 50\% reductions in radon flux into average sandstone mines with moderate $2 \%$ increases in pressure. The overpressure technique has been used successfully to mitigate radon entry in houses with higher-than-average radon levels (Tu86). Efforts have been made to model radon entry into houses with basements by Scott $(\mathrm{Sc83a}, \mathrm{Sc85})$ and Nazaroff (Na84a). Scott was the first to develop a simplified model of the resistance in the soil to the flow of soil gas, 
based on an electrical analog. The work done by Scott was limited to modeling the flow of radon in the soil under a basement only, without looking at the resistance to flow in basement cracks or gaps. Scott has done numerical modeling of the steady-state problem (Sc83a) and a quasi-transient problem of radon entry into basements (Sc85). Scott's quasitransient modeling results show the following dependence on wind speed and soil permeablity:

1) for highly permeable soil $\left(\mathrm{k}=10^{-4} \mathrm{~cm}^{2}\right)$ the radon entry rate increases at the beginning of an increase in wind speed and then quickly decreases to a fairly uniform low value for the remainder of the period of high wind, and

2) for low permeability soil $\left(k=10^{-7} \mathrm{~cm}^{2}\right)$ the radon entry rate follows the wind speed in a proportional manner.

The above results indicate that the combined effects of high wind speed $(>5 \mathrm{~m} / \mathrm{s})$ and high permeability cause an immediate pressure perturbation in the soil, sweeping radon into the house on the windward sides and out on the leeward sides, but producing a net temporary increase in radon entry. However, for the remainder of the time during the increase in wind speed, the radon concentration in the soil is reduced due to the wind forcing fresh air into the soil causing a net decrease in radon entry. Nazaroff suggests that the characteristic times for propagation of pressure disturbances in sandy and gravelly soils are on the order of a minute, compared to clay-like soils where the propagation time for a pressure disturbance can take more than a day (Na85). Field studies conducted by Lawrence Berkeley Laboratory in the Spokane River Valley (Tu86) show the same type of correlations between wind speed, high soil permeability (approx. $10^{-6} \mathrm{~cm}^{2}$ ), and radon entry for a number of houses.

Nazaroff and Nero have shown that the dominant source of radon entry in most houses with higher-than-average radon levels is soil gas entering by pressure driven flow through penetrations in either a basement, crawl space, or slab floor (Na84b). The following 
reasons are given for this conclusion:

1) no building material (e.g. masonry) associated with these houses produces sufficient radon to account for the observed levels,

2) water, including well water, usually does not release sufficient radon to account for observed radon entry rates.

3) the rate of radon diffusion through concrete slabs and basement walls is too low to account for observed radon entry rates, and

4) flow-inducing mechanisms that drive infiltration, such 29 wind speed and indooroutdoor temperature differences, can cause sufficienc flow of soil gas through the building substructure to transport radon gas in the amount necessary to account for higher-than-average indoor radon concentrations in houses.

There are exceptions to the first point where high radium content materials such as alumshale concrete was used for construction of buildings in Sweden from 1930 to 1975 (Na84b), or where uranium tailings were used in the construction of houses in Grand Junction, CO (US79). There are also exceptions to the second point where well water in Maine was shown to be a significant source of radon entry (He83). Hess showed that high radon levels in Maine well water, of up to $180,000 \mathrm{pCi} / \mathrm{l}$, may contribute about $0.8 \pm 0.2 \mathrm{pCi} / \mathrm{l}$ of air per $10,000 \mathrm{pCi} / \mathrm{l}$ of water, assuming $1 \mathrm{ACH}$. However, regions with high radon concentrations in well water should be expected to have high radon concentrations in the soil, which could lead to high radon entry rates from pressure driven flow of soil gas.

Further evidence for the importance of pressure driven flow of radon into houses is seen by comparing measured indoor radon concentrations to inferred indocr radon concentrations which would occur if the entire floor area of a house were upen to the soil. Measured radon fluxes from uncovered soil range from 325 to $5,000 \mathrm{pCi} / \mathrm{m}^{2}-\mathrm{hr}$ (Wiz2), and 
inferred indoor radon concentrations ${ }^{1}$ due to this range of radon fux from uncovered soil wculd be

$$
R n_{i, \text { inferred }}=\frac{\left(325 \text { to } 5,000 p C i / m^{2}-h r\right) 140 m^{2}}{1000.1 / m^{3}\left(140 m^{2}\right) 2.3 m\left(0.5 h r^{-1}\right)}=0.28 \text { to } 4.35 p C i / l \text {. }
$$

This range of inferred indoor radon concentrations, due to radon flux from uncovered soil, is not sufficient to account for measured indoor radon concentrations which range from 1 to 1000's of $\mathrm{pCi} / \mathrm{l}(\mathrm{Na84b}, \mathrm{Ne} 84, \mathrm{Ru} 79, \mathrm{Tu} 86)$. Furthermore, Colle, et al have shown that radon flux by diffusion will be reduced by factors or $\mathbf{2 5}$ to 50 for an intact concrete slab (Co81), and Landman showed reductions by a factor of 4 with a severly cracked concrete slab (La82).

Houses with basements have more area in contact with the soil than houses with slab floors and crawl spaces, but the measured data indicate that all house substructure types can have radon entry problems ( $\mathrm{Na83}, \mathrm{Na84a}, \mathrm{Th} 84)$. Understanding the ferces that drive soil gas flow and radon entry will provide a basis for modeling the problem and lead to a better understanding of methods for both prevention and thitigation.

\section{Forces Driving Soil Gas Flow and Radon Entry}

The forces which drive soil gas entry and hence radon entry are indwor-outdoor pressure differences at the floor level of a house. The pressure differences can result from any or all of the following phenomena:

1) indoor-outdoor temperature differences which cause the "stack effect",

2) wind induced pressures, and

${ }^{1}$ Assuming an average floor area of $140 \mathrm{~m}^{2}\left(1500 / \mathrm{t}^{2}\right)$, ceiling height of $2.3 \mathrm{~m}(8 \mathrm{ft})$, and ventilation rate of 0.5 air changes per hour. 
3) mechanical ventilation.

Each of these must be examined to determine their individual or combined influence on radon entry.

\section{Stack Effect Pressureo}

Air is a compressible fluid, acted upon by gravity, and obeys the ideal gas law such that air density is inversely proportional to temperature. Indoor-outdoor temperature differences produce indoor-outdoor density differences resulting in a pressure difference that varies with height across the vertical walls of a house. This pressure difference may be modeled using an expression from hydrostatics which relates a change in the indoor-outdoor pressure difference with respect to height as proportional to the change in indoor-outdoor density difference as follows (Fo78):

$$
\frac{d \Delta P}{d z}=-g \Delta \rho
$$

where $\Delta P=$ indoor-outdoor pressure difference $(P a), z=$ distance from top of ceiling $(m)$; $\Delta p=$ indoor-outdoor air density difference $\left(\mathrm{kq} / \mathrm{m}^{3}\right)$, and $g=$ acceleration of gravity $\left(\mathrm{m} / \mathrm{s}^{2}\right)$. This model assumes that the building interior is a single zone, well mixed volume of air, with approximately uniform temperature. Integrating Equation (2.4), and applying the ideal gas law, we obtain the well known expression for the stack pressure difference

$$
\Delta P_{a}=-\rho g \frac{\Delta T}{T_{0}}(z-N P L)
$$

where $\Delta P_{0}=$ stack pressure difference at any height, $z(P a), \Delta T=$ indoor-outdoor temperature difference $(K), T_{0}=$ outdoor temperature $(K)$, and $N P L=$ neutral pressure level (m). The neutral pressure level, NPL, is defined as the distance from the ceiling to the level where, under calm conditions, no indoor-outdoor pressure difference exists. The distribution of the effective leakage area of the building envelope determines the location of the NPL, 
and NPL is assumed constant unless the leakage distribution is modified (Fe85).

The stack effect contributes a large amount to the air infitration of a house. The amount of underpressure that might be produced by this effect alone during the heating season may be shown by the following sample calculation. A typical house with a $2.5 \mathrm{~m}$ depth basement, a neutral pressure level of $1.25 \mathrm{~m}$ above-ground level (i.e. midway up the above ground wall), an indoor temperature of $295 K$, and an indoor-outdoor temperature difference of $20 \mathrm{~K}$, would produce a pressure at the basement floor level of,

$$
\Delta P_{.}=-1.2(8.81) \frac{20}{295}(2(2.5)-1.25)=-3 P a
$$

For a crawl space or slab floor house, the amount of underpressure at the floor due to the same weather conditions and leakage distribution would be approximately $-1 P a$.

\section{Wind Induced Pressures}

The flow of wind creates a 3 dimensional pressure field around a house that affects both infiltration and radon entry. Wind tunnel measurements of the pressure field around houses show regions of overpressure on the windward side and underpressure on sides leeward and parallel to the wind direction (Fe85). The pressure field on the soil surface extending almost 1 house height away shows the same pattern (Sc85). The pressure field is related to the undisturbed wind dynamic pressure through the use of dimensionless pressure coefficients. The dynamic pressure is eqtal to the theoretical change in kinetic energy which would occur if the undisturbed wind speed were brought to a halt. Neglecting ground shear forces the dynamic pressure for a streamline can be obtained from Bernoulli's equation as follows:

$$
\frac{P_{1}}{\rho}+\frac{v_{1}{ }^{2}}{2}=\frac{P_{2}}{\rho}+\frac{v_{2}{ }^{2}}{2}
$$


Assuming $v_{2}=0$, and defining the dynamic pressure as $\Delta P_{d}=P_{1}-P_{2}$ gives

$$
\Delta P_{d}=-\rho \frac{v^{2}}{2}
$$

where $\Delta P_{\alpha}=$ dynamic pressure $(P a), \rho=$ ai $\cdot$ density $\left(\mathrm{kg} / \mathrm{m}^{3}\right)$, and $v=$ wind speed $(\mathrm{m} / \mathrm{s})$. This relationship between pressure and wind speed, using Bernoulli's equation is derived by integrating Euler's equation written for a streamline. Euler's equation is reduced from the Navier-Stokes equation for the How of incompressible fluids when inertial forces are much greater than viscous forces (i.e. Reynolds number $>1$ ).

The wind speed near the house is related to measured wind speed at a local weather station by terrain factors (macro effects) and a power law relationship given by Sherman and others (Ak79,Ar84,Ay85,Sh80). The pressure coefficients are defined as the ratio of the surface pressure at any point $(x, y, z, \phi)$ divided by the dyamic pressure, and are averaged over a region, $k$, as follows ( $\mathrm{Fe85}$ )

$$
\bar{c}_{k}=\frac{P_{k}-P_{0}}{\Delta P_{d}}
$$

wher:: $\bar{c}_{k}=$ average pressure coeflicient for region $k$ (dimensionless), $P_{k}=$ average surface pressure for region $k(P a)$, and $P_{0}=$ static pressure in the undisturbed wind $(P a)$. The average wind induced pressure on any region or surface $k$ above or below the static pressure is given by combining Equations (2.7) and (2.8)

$$
\Delta P_{h}=\bar{c}_{k}\left[-\rho \frac{v^{2}}{2}\right]
$$

where $\Delta P_{k}:=$ average wind induced pressure on surface $k(P a)$. Aynsley has shown that flow patterns around typical rectangular buildings (bluff bodies), and their corresponding pressure coefficients do not change significantly with large changes in velocity (Ay85). 
The flow rate of air through the envelope of a building is usually described by a power law expression such as

$$
Q=D \Delta P^{n}
$$

where $Q=$ air flow rate $\left(m^{3} / h r\right), D=$ permeability of the building envelope $\left(m^{3} / h r-P a^{n}\right)$, $\Delta P=$ pressure drop across the building envelope $(P a)$, and $n=$ flow exponent (dimensionless). The permeability of the building envelope is mainly determined by the number and size of cracks and gaps between building components. The air permeability and the flow exponent can be measured using the fan pressurization, or blower door, technique. The flow exponent, $n$, will vary between its physical limits of $n=1.0$ for fully developed laminar flow, and $n=0.5$ for fully developed turbulent flow. A study by Sherman measuring the air leakage of 196 houses, using the blower door technique, yielded a mean value of $n=$ 0.66 (Sh84).

Using the continuity equation, Feustel has derived an expression to calculate the wind induced indoor-outdoor pressure difference in a building as a function of the flow exponent, air permeability, and the windward and leeward average pressure coefficients as follows (Fe85):

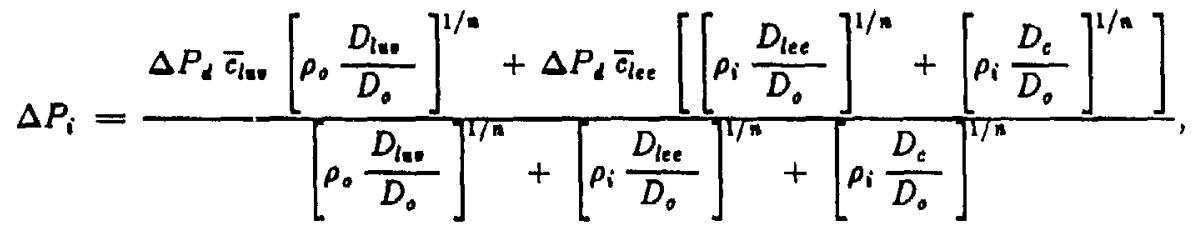

where $\rho_{0}$ and $\rho_{i}=$ the outdoor and indoor air densities $\left(\mathrm{kg} / \mathrm{m}^{3}\right), \bar{c}_{\mathrm{ln}}$ and $\bar{c}_{\overline{l e c}}=$ average pressure coefficients for the windward and leeward sides respectively (dimensionless), $n=$ flow exponent of the building, $D_{0}=$ the total air permeabilty of the building $\left(\mathrm{m}^{3} / \mathrm{hr}-P a^{n}\right)$, and 


$$
\frac{D_{\text {les }}}{D_{0}}, \frac{D_{\text {lee }}}{D_{0}} \text { and } \frac{D_{\epsilon}}{D_{0}}=\text { windward, leeward, and ceiling air permeability ratios. }
$$

Note that the ceiling is assumed to be a leeward surface in this model, and the floor is assumed to be totally shielded from any wind induced pressure effects. Assuming the indoor and outdoor air densities are approximately equal, and dividing both sides of Equation (2.10) by the dynamic wind pressure, $\Delta P_{d}$, gives

$$
\Psi=\frac{\Delta P_{i}}{\Delta P_{d}}=\frac{\bar{c}_{\text {lue }}\left[\frac{D_{\text {lev }}}{D_{0}}\right]^{1 / n}+\bar{c}_{\text {lec }}\left[\left[\frac{D_{\text {les }}}{D_{0}}\right]^{1 / n}+\left[\frac{D_{c}}{D_{0}}\right]^{1 / n}\right]}{\left[\frac{D_{\text {les }}}{D_{0}}\right]^{1 / n}+\left[\frac{D_{\text {lee }}}{D_{0}}\right]^{1 / n}+\left[\frac{D_{c}}{D_{0}}\right]^{1 / n}}
$$

where $\Psi=$ indoor pressure coefficient (dimensionless).

The measured wind speed from the local weather station must be converted to an effective wind speed at the house. This is done using the familiar power law relationship (Sh80)

$$
f_{t}=\frac{\alpha\left[\frac{H}{10}\right]^{\gamma}}{\alpha^{\prime}\left[\frac{H^{\prime}}{10}\right]^{\gamma}}
$$

where $f_{1}=$ terrain factor (dimensionless), $\alpha$ and $\gamma=$ dimensionless terrain coefricients (see Table $1 \mathrm{a}$ in Appendix B), $H=$ building height ( $m$ ), and all primed ( $)$ values are related to the weather measurement station. Combining Equations (2.12) and (2.13) gives a reduced interior pressure coefficient

$$
c_{i}=\Psi \rho_{t}^{2}
$$

The wind induced indoor-outdoor pressure difference in the house may be estimated by combining Equation (2.9) and (2.14) as 


$$
\Delta P_{\omega}=c_{i}\left[\rho \frac{v^{2}}{2}\right]
$$

The sign of $\Delta P$. will depend on the sign of $\Psi$ calculated using Equation (2.12). In the absence of actual measured air permeabilities of the windward and leeward sides of the building, an area weighted value can be used assuming the air permeability is evenly distributed on all building surfaces.

A sample calculation of $\Psi, f_{1}$, and $c_{i}$ will provide insight into the amount of underpressurization a $3 \mathrm{~m} / \mathrm{s}$ wind causes inside a house, assuming the following:

1) evenly distributed permeabilicy for a house with an $8 \times 22 \mathrm{~m}$ floor and $2.3 \mathrm{~m}$ ceiling height,

2) house height is $5 \mathrm{~m}$, weather station height is $10 \mathrm{~m}$, and both terrain classes are III $\left(f_{\ell}=\mathbf{0 . 8 7}\right)$,

3) wind direction of $90^{\circ}$, windward pressure coefficient of 1.0 and leeward pressure coefficient of $\mathbf{- 0 . 3}$ which acts on the 3 leeward sides plus the ceiling,

4) air density, $\rho=1.2041 \mathrm{~kg} / \mathrm{m}^{3}$, and

5) the flow exponent, $n=0.66$, or $1 / n=1 / 0.66=1.5$.

The first assumption, given above, of evenly distributed leakage area, allows us to use area ratios instead of permeability ratios. For a wind impinging at $90^{\circ}$ to one of the $8 \mathrm{~m}$ walls, the windward area is $18.4 \mathrm{~m}^{2}$, the leeward area is $119.6 \mathrm{~m}^{2}$, the ceiling area is $176 \mathrm{~m}^{2}$, and the total area is $490 \mathrm{~m}^{2}$. Using the above values in Equation (2.12) gives

${ }^{2}$ Note that the total area includes $176 \mathrm{~m}^{2}$ of florr area, since $D_{0}$ was assumed to be evenly distributed over the entire building envelope. 
$\Psi_{8}=\frac{\Delta P_{i}}{\Delta P_{d}}=\frac{1.0\left[\frac{18.4}{490}\right]^{1.5}+(-0.3)\left[\left[\frac{119.6}{490}\right]^{1.5}+\left[\frac{176}{490}\right]^{1.5}\right]}{\left[\frac{18.4}{490}\right]^{1.5}+\left[\frac{119.6}{490}\right]^{1.5}+\left[\frac{176}{490}\right]^{1.5}}=-0.27$.

For a wind impinging on the $\mathbf{2 2} \mathbf{m}$ wall, the the value of the interior pressure coefficient is $\Psi_{22}=-0.17$. Using these two values in Equations (2.14) and (2.15) gives reduced interior pressure coefficients of $c_{i, 8}=-0.2, \quad c_{i, 22}=-0.13$, and wind induced indoor-outdoor pressure differences of $\Delta P_{a, 8}=-1.08 \mathrm{~Pa}$, and $\Delta P_{\star, 22}=-0.70 \mathrm{~Pa}$. For a $5 \mathrm{~m} / \mathrm{s}$ wind, the values of the wind induced indoor-outdoor pressure difference would be $\Delta P_{w, 8}=-3.01 P a$ and $\Delta P_{-, 22}=-1.96 \mathrm{~Pa}$. The wind induced pressure is proportional to the square of the wind speed and is greatly affected by increases or decreases in wind speed.

A method for simplifying the calculation proceedure for $\Psi$ can be obtained by using the envelope permeability ratio given as

$$
E P R=\frac{\sum_{i=1}^{k} D_{\text {lee } i}}{\sum_{i=1}^{k} D_{\text {lee } i}+\sum_{j=1}^{m} D_{\text {let } j}}=\frac{\sum_{i=1}^{k}\left[\frac{D_{\text {lee }}}{D_{0}}\right]_{i}}{\sum_{i=1}^{k}\left[\frac{D_{\text {let }}}{D_{0}}\right]_{i}+\sum_{j=1}^{m}\left[\frac{D_{l w i}}{D_{0}}\right]_{j}}
$$

where $E P R=$ envelope permeability ratio (dimensionless). Figure 3. shows values of $\Psi$ calculated for wind directions of $90^{\circ}$ and $45^{\circ}$, and values of EPR Irom 0 to 1 (Fe86). The $90^{\circ}$ curve was calculated using windward and leeward pressure coefficients of 1.0 and -0.3 respectively, and the $45^{\circ}$ curve was calculated using windward and leeward pressure coeficients of 0.6 and -0.4 respectively. These pressure coefficients are weighted averages from wind tunnel measurements done by Krischer and Beck (Kr57). The curves only apply to cases having these average pressure coefficients on windward and leeward sides. Figure 3 allows a quick method for determining the wind induced interior pressure coefficient from estimates of the building envelope permeabilty ratio. This is seen by calculating the effect of 


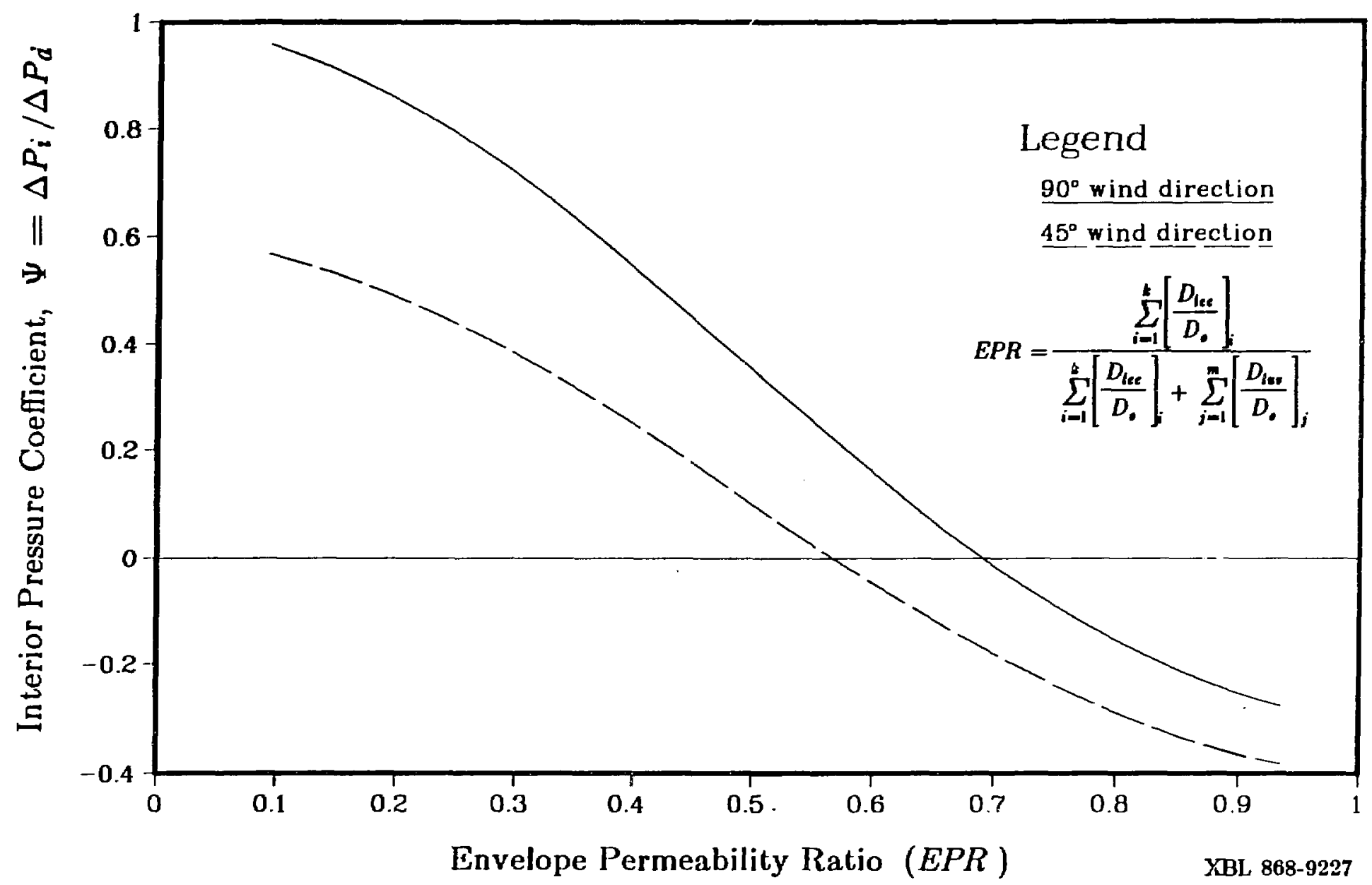

Figure 3. Interior pressure coefficient, $\Psi=\Delta P_{i} / \Delta P_{d}$ vs. Envelope Permeability Ratio $E P R$. The $90^{\circ}$ wind direction values of $\Psi$ are calculated using windward and leeward pressure coefficients of 1.0 and -0.3 respectively, and the $45^{\circ}$ wind direction values are calculated using windward and leeward pressure coefficients of 0.6 and -0.4 respectively. 
a $45^{\circ}$ wind direction on the building in the previous example. For a $45^{\circ}$ wind direction, the windward and leeward air permeability ratios are equal $\left(D_{\text {lso }} / D_{0}=D_{\text {lee }} / D_{0}=0.139\right)$, and the ceiling air permeability ratio remains the same $\left(D_{c} / D_{0}=0.359\right)$. Using these values in Equation (2.16) gives an envelope permeability ratio for $45^{\circ}$ of $E P R=0.78$, and Figure 3 gives an interior pressure coefficient of $\Psi=-0.23$. The wind induced indooroutdoor pressure difference is then

$$
\Delta P_{\star}=-0.23(0.87)^{2}\left[1.2 \frac{3^{2}}{2}\right]=-0.94 P a
$$

This is approximately equal to the the average of the previously calculated values for wind impinging at $90^{\circ}$ to the $8 \mathrm{~m}$ and $22 \mathrm{~m}$ facades of the building. For this building, the wind induced interior pressure coefficient will vary between -0.17 and $-0.27(-0.17 \leq \Psi \leq-0.27)$.

If an unhested garage is attached to the house, the envelope permeability ratio, $E P R$, will be affected depending on the direction of the wind. Any such shielding must be accounted for in this simplified model.

\section{Crawl Space Pressures}

Assuming the floor of the house is insulated, and the crawl space is unheated, it is possible to estimate the crawl space pressure in the same manner as the wind induced pressure in a house. Vented crawl spaces are designed to have much greater leakage area than unvented crawl spaces. Typical crawl space vents range in size from 500 to $1000 \mathrm{~cm}^{2}$, and assuming 1 or 2 are placed on each wall, the leakage area of a vented crawl space can range from 2000 to $8000 \mathrm{~cm}^{2}$. Depending on the number of vents, the leakage area or permeability of the crawl space walls can be about 100 times greater than the crawl space ceiling (house floor). This means that we can neglect the floor permeability when calculating the 
wind induced pressure in a vented crawl space.

A sample calculation will illustrate the magnitude of pressure induced in a vented crawl space from a $3 \mathrm{~m} / \mathrm{s}$ wind with the following assumptions:

1) two $500 \mathrm{~cm}^{2}$ vents are on each wall $\left(E P R_{90^{\circ}}=0.75\right.$ and $\left.E P R_{45^{\circ}}=0.50\right)$, and

2) all other assumptions are the same as for the previous examples.

From Figure 3 , and the above values of $E P R$, we obtain $\Psi_{00^{\circ}}=-0.1, \Psi_{45^{\circ}}=0.1$. With these values for $\Psi$, and using Equations (2.14) and (2.15), we obtain $\Delta P_{\text {ea, } 90^{\circ}}=-0.4 P a$ and $\Delta P_{e, 45^{\circ}}=0.4 P a$. The $45^{\circ}$ wind direction has the effect of reversing the sign of the interior pressure in the crawl space. Since the vents are assumed to be equally spaced around the building (i.e. 2 per wall), the estimated interior pressure coefficients for this vented crawl space range from -0.1 to 0.1 (i.e. $-0.1 \leq \Psi \leq 0.1$ ).

The sample calculation of wind induced pressure in an unvented crawl space from a 3 $\mathrm{m} / \mathrm{w}$ wind is based on the same assumptions as above except that the permeability ratios must be recalculated. Assuming the unvented crawl space walls are built to the same construction standards as the house, the permeability ratios can be area weighted. Using the previously stated floor area of $8 \times 22 \mathrm{~m}^{2}$, and crawl space ceiling height of $0.7 \mathrm{~m}$, the permeability ratios for a wind impinging at $90^{\circ}$ to one of the $8 \mathrm{~m}$ walls are $D_{140} / D_{0}=0.03$, $D_{\text {lee }} / D_{0}=0.17$, and $D_{e} / D_{0}=0.80$.

Figure 3 cannot be used for this case because the pressure coefincient on the unvented crawl space ceiling is different from the coeficients on the leeward walls. In this case we will assume that the coefficient for the crawl space ceiling (house floor) is equal to the previously calculated interior pressure coefficient, $\Psi_{8}$, calculated for a wind impinging on the $8 \mathrm{~m}$ facade of the house (i.e $\bar{c}_{c}=\Psi_{8}=-0.27$ ). Using Equations (2.12), (2.14), and (2.15) we obtain $\Psi_{c e, 8}=-0.26$, and $\Delta P_{\mathrm{ea}, \mathrm{B}}=-1.06 \mathrm{~Pa}$ which is only $2 \%$ greater than the value 
calculated for the wind induced indoor-outdoor pressure difference for the house.

For the case of a wind impinging on the $22 \mathrm{~m}$ facade, the assumption for the crawl space ceiling is the same (i.e. $\bar{c}_{c}=\Psi_{22}=-0.17$ ). This gives a value of the crawl space interior pressure coefficient of $\Psi_{22}=-0.18$, and $\Delta P_{t 0,22}=-0.74 \mathrm{~Pa}$ which is only $6 \%$ less than the value calculated for the wind induced indoor-outdoor pressure difference for the house.

The wind induced underpressure in an unvented crawl space for any wind direction is almost equal to the wind induced underpressure in the house. They are close enough that we can neglect the wind induced component of the floor pressure for a house with an unvented crawl space. Chapter 6 discusses the application of this model to estimating radon entry in houses with crawl spaces.

\section{Preagures Reaulting From Mechanical Ventilation}

Mechanical ventilation systems are being installed in newer energy efficient houses, and their design and operation can affect the indoor-outdoor pressure differences that drive soil gas entry and radon entry. Two common mechanical ventilation systems are used in residences:

\section{1) balanced air-to-air systems, or}

2) exhaust systems.

The balanced system in theory produces no net effect on the inside pressure of the house. The exhaust system, however, produces an underpressure inside the house which may lead to increased radon entry. To understand what effect the exhaust system has, some assumptions must be made concerning the range of possible flow rates for typical exhaust systems. Typical exhaust systems are designed to increase the flow of fresh air into the house up to 
$1 / 2$ air changes per hour. The actual predicted increase in ventilation rate may be calculated using Equation (2.3). For a typical house of $300 \mathrm{~m}^{3}$, and zero natural infiltration, the exhaust flow rate would be $150 \mathrm{~m}^{3} / \mathrm{hr}$. A lower level of ventilation rate might be $100 \mathrm{~m}^{3} / \mathrm{hr}$ which, for a $300 \mathrm{~m}^{3}$ house, would produce $1 / 3$ air changes per hour, in the absence of any other driving forces of wind or temperature. An expression relating this flow rate to the predicted house underpressure is

$$
\Delta P_{\mathrm{vml}}=-\frac{\rho}{2}\left[\frac{Q_{\mathrm{vmv}}}{E L A}\right]^{2}
$$

where $\Delta P_{\text {ume }}=$ pressure difference caused by the presence of the unbalanced mechanical ventilation system $(P a), Q_{m o}=$ unbalanced mechanical ventilation rate $\left(\mathrm{m}^{3} / \mathrm{a}\right)$, and $E L A$ $=$ effective leakage area of the house $\left(\mathrm{m}^{2}\right)$. For an effective leakage area of $0.025 \mathrm{~m}^{2}$ the underpressure, $\Delta P_{\text {amo }}$, due to the exhaust system would be $1.67 P a$ and $0.743 P a$ for 150 and $100 \mathrm{~m}^{3} / \mathrm{hr}$ respectively. The exhaust underpressure is proportional to the square of the ratio of ventilation rate divided by leakage area, meaning very "tightly" built houses may experience large additional underpressure when using an exhaust ventilation system. In "tight" houses additional leakage area, such as operable vents, would reduce the amount of depressurization, and the placement of these vents will have an affect on the neutral pressure level and thus, the pressure at the floor level. If an overpressure system is used to mitigate radon entry Equation (2.17) may be used with a change of sign.

\section{Combining the Underpressures Driving Radon Entry}

The pressures created by the presence of indoor-outdoor temperature differences, wind speed, and mechanical ventilation may simply be added together to arrive at the total effective indoor-outdoor pressure difference at any height. It is important to note that the temperature induced pressure difference is dependent on vertical location. The total indoor- 
outdoor pressure difference at the floor level is

$$
\Delta P_{f}=\Delta P_{\text {, }}+\Delta P_{*}+\Delta P_{\mathrm{sm}}
$$

where $\Delta P_{f}=$ indoor-outdoor pressure difference at the floor level $(P a)$. Neglecting the effect of exhaust ventilation the pressures from the stack and wind effects calculated previously can be added using Equation (2.18). For the basement house the underpressure at the floor varies from 3.7 to $4.1 \mathrm{~Pa}$, depending on the wind direction. For the vented crawl space house the underpressure acrose the floor varies from 1.3 to $2.3 \mathrm{~Pa}$, depending on the wind direction, and for an unvented crawl space, the underpressure is approximately $1 \mathrm{~Pa}$. As was stated previously, the wind direction has a large impact on the calculated underpressure in the vented crawl space, but wind direction has very little affect on the unvented crawl space or basement houses. Assuming the effective leakage area for the basement and crawl space houses is $250 \mathrm{~cm}^{2}$, adding in the effect of exhaust ventilation calculated in the previous section, gives the following indoor-outdoor floor underpressures

1) for the house with a basement: approximately 4.6 and $5.6 \mathrm{~Pa}$ with 150 and $300 \mathrm{~m}^{3} / \mathrm{hr}$ of exhaust ventilation respectively,

2) Ior the house with a vented crawl space: depending on the wind direction, from 2 to 3 $P a$ for $150 \mathrm{~m}^{3} / \mathrm{hr}$ of exhaust ventilation, and from 3 to $4 P_{a}$ for $300 \mathrm{~m}^{3} / \mathrm{hr}$ of exhaust ventilation, and

3) for the house with an unvented crawl space: approximately 1.7 and $2.67 \mathrm{~Pa}$ with 150 to $300 \mathrm{~m}^{3} / \mathrm{hr}$ of exhaust ventilation respectively.

The affect that these underpressures have on radon entry will be discussed in the chapters that follow. 


\section{CHAPTER III}

\section{ANALYTICAL MODEL OF SOL GAS FLOW INTO BASEMENTS}

Modeling efforts aimed at estimating radon entry rates into basements have primarily focused on modeling the air How rate through the soil. Detailed mathematical models of air flow through soil involve non-linear second order partial differential equations requiring complicated numerical solutions. Although numerical solutions are more flexible than analytical models, they presently require large computer codes for solution. Simpler closed form analytical models allow quick "back of the envelope" calculations which are very helpful in certain situations.

Field studies show mixed success in reducing radon entry rates by sealing basement g ps and cracks. This indicates that in some cases resistance to the flow of soil gas may be substantially affected by the gaps and cracks in the basement. A simple-closed form model must take into account the air flow rate and pressure drop through both the soil and the basement gaps or cracks.

\section{Resiatance to Soil Gas Flow through Soil}

The analytical model developed here is based on an a heat transfer analog which is similar to a model developed by Scott (Sc83b). The object is to show that the flow of soil gas into the house is similar to the flow of heat through a semi-infinite medium of uniform thermal conductivity.

The one-dimensional flow of fluid, such as soil gas, through a porous homogeneous medium is given by Darcy's Law as 


$$
Q=-\left[\frac{k}{\mu}\right] A \frac{\Delta P_{1}}{\Delta X}\left(m^{3} / \mathrm{o}\right)
$$

where $Q=$ soil gas flow rate $\left(\mathrm{m}^{3} / \mathrm{s}\right), k=$ soil permeability $\left(\mathrm{m}^{2}\right), \mu=$ soil gas viscosity $(P a-8), \Delta P_{a}=$ pressure difference across the soil $(P a), \Delta X=$ length of flow path $(m)$, and $A=$ cross-sectional area $\left(m^{2}\right)$. Darcy's Law is an empirical relation based on a classical experiment originally performed by Darcy in 1856 and only holds for laminar flow with Reynolds numbers less than $\sim 75$ (Sch74). The soil permeability, $k$, is a proportionality constant between the applied pressure gradient and the measured soil gas flow rate, per unit cross-sectional area of a given sample, and is measured using a permeameter. The typical units used to express soil permeability are $\left(\mathrm{cm}^{2}\right)$ and it must be converted to units of $\left(\mathrm{m}^{2}\right)$ for use in any of the equations presented here.

The one-dimensional flow of heat through a homogeneous thermally conductive medium is given by Fourier's Law as

$$
Q_{t}=-k_{\mathrm{e}} A \frac{\Delta T}{\Delta X}
$$

where $Q_{t}=$ heat transfer $(W), k_{c}=$ thermal conductivity $(W / m-K), \Delta T=$ temperature difference across the thermally conductive medium (C), $\Delta X=$ length of the heat flow path, and $A=$ crossesectional area $\left(\mathrm{m}^{2}\right)$.

Figure $4 a$ shows a cross-sectional view of a typical house with a basement. Most houses with concrete basements use a method of construction with the foundation walls poured fint and then the foor slab poured inside the walls. This construction method leaves a smali shrinkage gap of from $1 \mathrm{~mm}$ to $7 \mathrm{~mm}$ wide between the basement floor and the walls extending around the circumference of the floor and down to the soil (Sc83b). The shrinkage gap width estimate is based on typical concrete mixes containing 150 to $190 \mathrm{~kg}$ water $/ \mathrm{m}^{3}$, yielding shrinkage strains from end of curing to air-dry of 3 to $6 \times 10^{-4} \mathrm{~m} / \mathrm{m}$. 


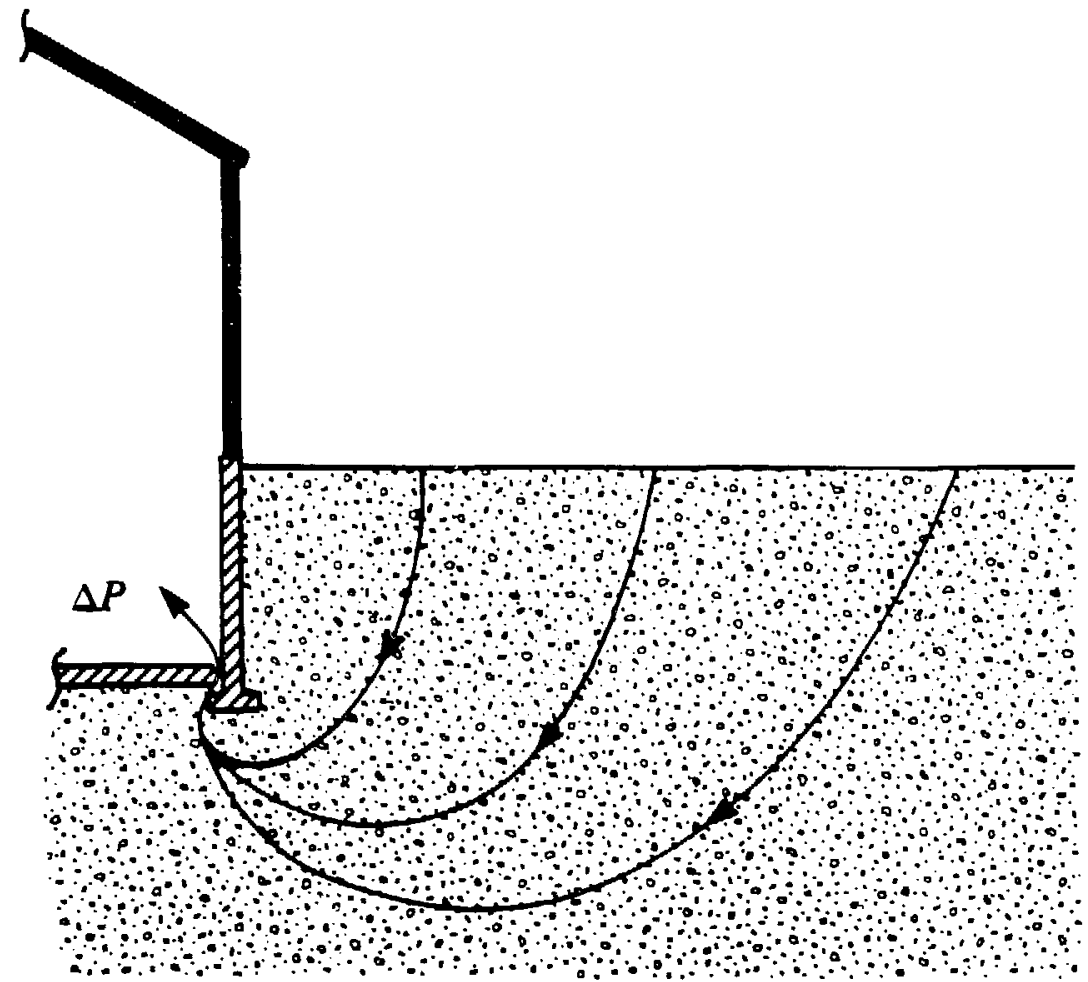

Figure 4a. Crose-sectional view of a house witk a basement, having a poured concrete wall and floor, showing assumed streamlines of soil gas flow into the basement.

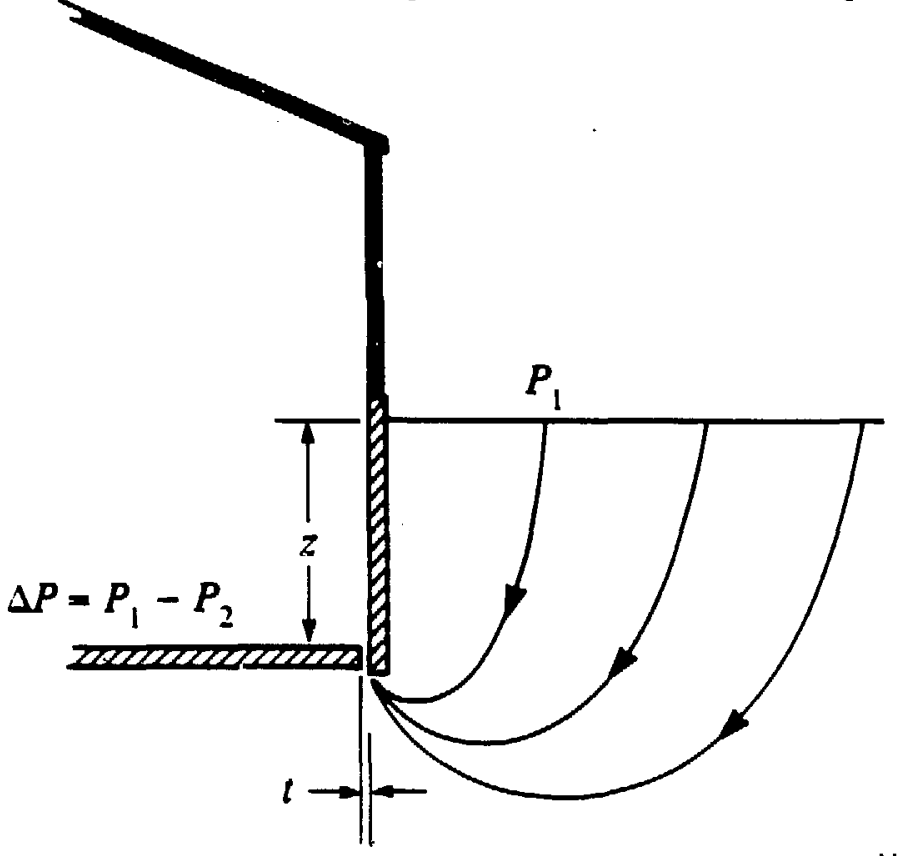

XBL 867.11633

Figure 4b. The simplified geometry assumed for the basement house, showing the streamlines of pressure driven soil gas flow into the perimeter wall-floor basement gap, of width $t$, at a depth, $z$, with homogeneous soil of uniform permeability, $k$. 
Wind and indoor-outdoor temperature differences cause a slight under-pressure at the basement floor, relative to outdoors, inducing air flow through the shrinkage gap from the soil into the hou'se. Soil gas flow may also be induced through cracks (if they exist) and any other penetrations through the basement floor or walls. The soil gas flow into the house is balanced by an equal volume of air flowing from the outdoor air into the soil surface. The soil gas flow rate into the house is determined by the basement under-pressure and the total air flow resistance due to the shrinkage gap, any cracks that may exist, and the soil itself.

Iigures $4 a$ and $4 b$, show the streamlines for the flow of soil gas into the basement gap through homogeneous soil. Figure 5 shows the lines of constant heat-flow between an isothermal surface and a horizontal cylinder imbedded in a homogeneous thermally conductive medium. For the thermally conductive medium, the resistance to heat flow is given by (Kr73)

$$
R=\frac{\cosh ^{-1}\left[\frac{2 z}{a}\right]}{2 \pi k_{e} L},
$$

where $R=$ thermal resistance $(K / W), z=$ depth below the isothermal surface at which the axis of the cylinder is buried $(m), d=$ diameter of cylinder $(m), k_{c}=$ thermal conductivity of the medium $(W / m-K)$, and $L=$ length of cylinder $(m)$.

For the homogeneous soil, the basement cuts of half of the flow field, so by analogy the resistance to soil gas flow is approximated by

$$
R_{\text {eod }}=(2) \mu \frac{\cosh ^{-1}\left[\frac{2 z}{t}\right]}{2 \pi k L}
$$

where $R_{\text {ood }}=$ flow resistance of the soil $\left(P_{a-s} / m^{3}\right), \mu=$ soil gas viscosity $(P a-s), z=$ depth below the soil suriace of the basement gap $(m), t=$ basement gap or crack width 


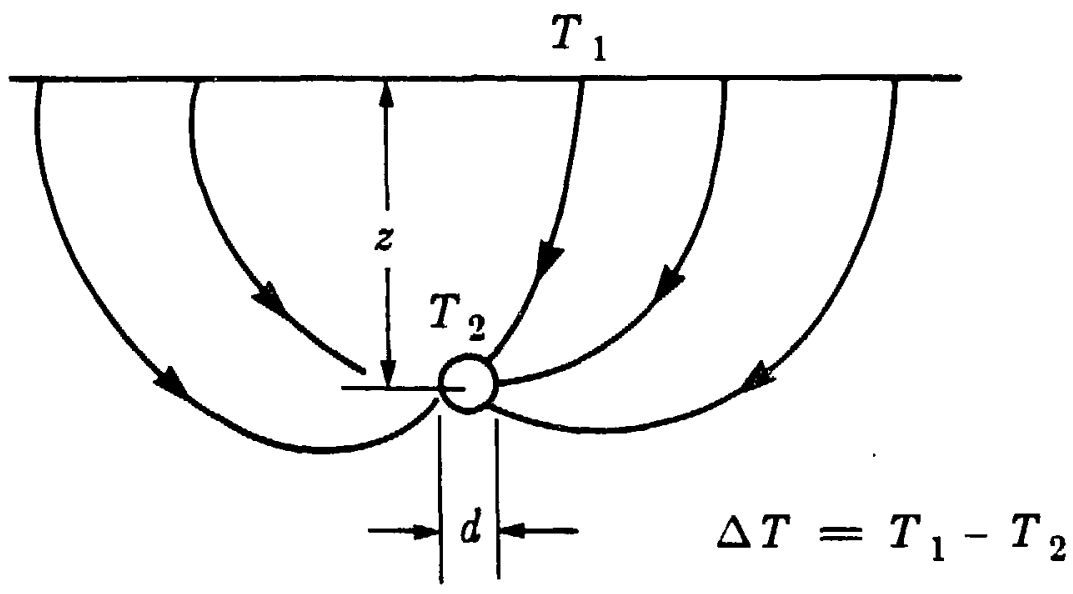

XBL 868-9228

Figure 5. Lines of heat-flow between an isothermal surface at $T_{1}$ and a horizontal cylinder of diameter, $d$, at $T_{2}$, imbedded a distance, $z$, into a homogeneous thermally conductive medium of uniform conductivity, $k_{c}$. 
(m), $k=$ soil permeability $\left(m^{2}\right)$, and $L=$ basement gap or crack length $(m)$.

Using the resistance network concept, Equation (3.1) can be rewritten as

$$
Q=\frac{\Delta P_{0}}{R_{\text {ooil }}}\left(m^{3} / s\right)
$$

If the total pressure drop, $\Delta P_{t}$, from basement floor to soil surface is accounted for, the soil gas flow resistance in the basement gap, $R_{b}$, must also be included in Equation (3.5) as follows:

$$
Q=\frac{\Delta P_{t}}{R_{b}+R_{\text {ooil }}}
$$

Equation (3.6) provides an analytical method for evaluating the relative significance of the two separate soil gas flow resistances. However, the soil gas How in the basement gap must be similarly proportional to $\Delta P$ if we want to simply add the two resistances in series.

\section{Resistance to Soil Gas Flow through Basement Gaps and Cracks}

Some work has been done by Jergling (Je81) to estimate the relationship between pressure drop, $\Delta P$, and air flow rate, $Q$, through cracks ${ }^{1}$ and gaps in concrete slabs. The empirical functional relationships developed by Jergling are presented here along with a simple analytical method. The simple analytical method, though not as accurate, may be easily transformed into a basement resistance, $R_{b}$, and used in Equation (3.6). The simplified model assumes that the soil gas flow rate through the basement gap or crack is proportional to $\Delta P$ according to the standard expression for flow through an opening given by Equation (2.10) and repeated here as

${ }^{1} \mathrm{~A}$ crack is defined here as an une:en break between two concrete slabs that provides a much more tortuous path to the flow of air then does a gap which is assumed to be a smooth walled mechanical separation between two concrete slabs. 


$$
Q=D \Delta P^{n}
$$

where $Q=$ air flow rate $\left(\mathrm{m}^{3} / h r\right), D=$ air permeability of the opening, or in this case the basement gap $\left(m^{3} / h r-P a^{n}\right), \Delta P=$ pressure difference across the basement gap $(P a)$, and $n=$ flow exponent ( $n=1$ for laminar flow, and $n=0.5$ for turbulent flow). In order to determine whether or not the flow is laminar or turbulent it is necessary to calculate the Reynolds number, Re, given by

$$
\operatorname{Re}=\frac{\rho V d_{k}}{\mu}
$$

where $\rho=$ soil gas density $\left(\mathrm{kg} / \mathrm{m}^{3}\right), \quad V=\operatorname{velocity~}(\mathrm{m} / \mathrm{s}), \mu=$ soil gas viscosity $(P a-s)$, and $d_{k}=$ hydraulic diameter, defined as

$$
d_{k}=\frac{4 \times(\text { cross-sectional area })}{\text { perimeter }}=\frac{4(L t)}{2(L+t)} \text {, and }
$$

since $L>>t, d_{k}=2 t$, where $t=$ gap or crack width $(m)$, and $L=$ the gap or crack length $(m)$.

Typical soil gas flow rateg are between 0.1 and $1 \mathrm{~m}^{3} / \mathrm{hr}$ (Sc83a, Na84a), but assuming a maximum flow rate into the house of $10 \mathrm{~m}^{3} / \mathrm{hr}$ will yield a maximum Reynolds number. With a typical basement floor area of $140 \mathrm{~m}^{2}\left(1500 \mathrm{ft}{ }^{2}\right)$, the gap length would be approximately $45 \mathrm{~m}$. With a typical gap of $1 \mathrm{~mm}$, and no cracks, the velocity would be

$$
V=\frac{Q}{A}=\frac{10 \mathrm{~m}^{3} / \mathrm{hr}}{45 \mathrm{~m}(0.001 \mathrm{~m}) 3600 \mathrm{~s} / \mathrm{hr}}=0.0617 \mathrm{~m} / \mathrm{s}, \text { and }
$$

at $T_{.}=20 \mathrm{C}, \rho=1.2041 \mathrm{~kg} / \mathrm{m}^{3}, \mu=18.178 \mathrm{E}-6 \mathrm{Pa-s}$, the maximum Reynolds number would be

$$
\operatorname{Re}=\frac{1.2041(0.0617) 0.002}{18.178 E-6}=8.17
$$


For the previous calculation, and in the remainder of this paper, the density and viscosity of air will be used, since soil gas is primarily air. The soil gas flow is clearly laminar, and therefore the value of the flow exponent $n$ is equal to 1. If more typical values for the soil gas flow rate were selected, the value of $\mathrm{Re}$ would range from 0.08 to 0.8 . Soil gas flow rates and velocities are very low as should be expected for the low driving force of $\Delta P$ which ranges from 2 to $10 \mathrm{~Pa}$ below the ambient outdoor pressure of approximately 100,000 $\mathrm{Pa}$. With the condition of laminar flow, Equation (3.7) may be rearranged into a form like Equation (3.5)

$$
Q=\frac{\Delta P_{b}}{R_{b}}\left(m^{3} / h r\right),
$$

where $\Delta P_{b}=$ the pressure drop across the basement gap or crack $(P a)$. Since $Q$ is directly proportional to $\Delta P$, the resistance of the soil and the basement may be combined in the manner of Equation (3:6). The value of $R_{b}$ may be estimated using a simplified analogy to the flow of air through rectangular ducts.

The standard expression for estimating the pressure drop, $\Delta P$, through rectangular ducts is given as (St82)

$$
\Delta P=f \frac{L_{d}}{d_{k}} \frac{V^{2}}{2} \rho,
$$

where $f=$ friction factor, $L_{d}=$ length of duct $=L_{0}=$ thickness of the basement concrete slab $(m), d_{k}=$ hydraulic diameter $=2 t$ for a gap or crack, where $t=$ gap or crack width $(m), V=$ velocity $(m / \mathrm{o})$, and $\rho=$ soil gas density $\left(\mathrm{kg} / \mathrm{m}^{3}\right)$.

The friction factor for a flat rectangular duct with laminar flow is given by White (Wh74) as

$$
f=\frac{96}{\mathrm{Re}} .
$$


Substituting Equations (3.8) and (3.11) into Equation (3.10) gives

$$
\Delta P=\left[\frac{96}{\mathrm{Re}}\right] \frac{L_{1}}{2 t} \frac{V^{2}}{2} \rho=\left[\frac{96 \mu}{\rho 2 t V}\right] \frac{L_{1}}{2 t} \frac{V^{2}}{2} \rho, \text { and }
$$

simplifying terms gives

$$
\Delta P=\frac{12 \mu L, V}{t^{2}}
$$

For a given velocity, $V$, tha flow rate of soil gas through the basement gap is

$$
Q=3600 V t L\left(\mathrm{~m}^{3} / \mathrm{hr}\right), \text { or } V=\frac{Q}{3600 t L}(\mathrm{~m} / \mathrm{s})
$$

where $L=$ basement gap or crack length $(m)$, and everything else is defined as before. Combining Equation (3.13) and Equation (3.12) gives

$$
Q=\frac{300 L t^{3} \Delta P}{\mu L}\left(m^{3} / h r\right)
$$

Using the resistance network concept yields a simple expression for the basement gap or crack resistance

$$
R_{b}=\frac{\mu L_{t}}{300 L t^{3}}
$$

The accuracy of Equation (3.15) may be evaluated by comparing to empirically derived expressions for air flow through gaps and cracks in concrete slabs. Equation (3.7) gives the general form of the equation for air flow through a gap or crack. The pressure drop, $\Delta P$, in Equation (3.7) generally has two components:
1) frictional losses, and
2) entrance and exit losses. 
When the ratio of gap length to gap width is small and/or the Reynolds number is large, the exit losses dominate. In the case of soil gas flow through a slab, the gap or crack length to width ratio is large and the Reynold's number is very small, so the frictional losses dominate.

Jergling measured the flow rate through gaps and cracks in concrete slabs for pressure differences ranging from 25 to $500 \mathrm{~Pa}$. He found empirical relationships relating pressure drop to flow rate for cracks of from $0.1 \mathrm{~mm}$ to $0.7 \mathrm{~mm}$, and gaps of from $0.3 \mathrm{~mm}$ to $0.7 \mathrm{~mm}$. For a crack of $0.1 \mathrm{~mm}$, the expression for air flow rate per unit length is

$$
q=14\left(10^{\circ}\right) \frac{t^{3}}{L_{0}} \Delta P\left(m^{3} / m-h r\right)
$$

For a crack of from $0.3 \mathrm{~mm}$ to $0.7 \mathrm{~mm}$, the air flow rate per unit length is

$$
q=0.010 \frac{L_{e} C_{e}}{t}\left[\sqrt{1+\Delta P \frac{t^{4}}{L_{a}^{2}} 1.5\left(10^{9}\right)}-1\right]\left(m^{3} / m-h r\right)
$$

where $C_{e}$ is an empirically derived constant, and $C_{e}=1$ for $L_{\mathrm{e}}=0.1 \mathrm{~m}, C_{\mathrm{e}}=0.85$ for $L_{0}=0.15 \mathrm{~m}$, and $C_{\mathrm{s}}=0.7$ for $L_{\mathrm{a}}=0.20 \mathrm{~m}$. All other terms were defined previously.

For a gap of $0.3 \mathrm{~mm}$ to $0.7 \mathrm{~mm}$, and a concrete slab thickness of, $L_{a}=0.15 \mathrm{~m}$, the air flow rate per unit lengith is

$$
q=0.001 \frac{C_{e}}{t}\left[\sqrt{1+220\left(10^{9}\right) t^{4} \Delta P}-1\right]\left(m^{3} / m-h r\right)
$$

where $C_{\mathrm{e}}=1$ for $t=0.3 \mathrm{~mm}$, and $C_{\mathrm{e}}=0.7$ for $(0.5 \mathrm{~mm} \leq t \leq 0.7 \mathrm{~mm})$.

Table 1 shows the calculated pressure drop, $\Delta P$, for air flow rates of from 0.1 to 10 $\mathrm{m}^{3} / \mathrm{hr}$, and gap or crack widths of from 0.1 to $10 \mathrm{~mm}$ using Equations (3.15) through (3.18). 
Table 1. Comparison of calculated pressure drop, $\Delta P$, across gaps and cracks in a concrete slab $0.15 \mathrm{~m}$ thick using Equations (3.15), (3.16), (3.17), and (3.18).

\begin{tabular}{|c|c|c|c|c|c|c|}
\hline \multicolumn{7}{|c|}{$\begin{array}{l}\text { Comparison of the Calculated Pressure Drop } \\
\text { Acrosa Gaps \& Cracks in a Concrete Slab } \\
\text { Uaing a Simple Rectangular Duct Analogy (Eq. 3.15) } \\
\text { and Empirically Derived Relations (Eq. 3.16, 3.17, 3.18) }\end{array}$} \\
\hline \multirow{4}{*}{$\begin{array}{l}\text { Gap or } \\
\text { Crack } \\
\text { Width }\end{array}$} & \multirow{2}{*}{\multicolumn{2}{|c|}{ Flow Rate }} & \multicolumn{4}{|c|}{ Pressure Drop, $\Delta P$} \\
\hline & & & $f=96 / \operatorname{Re}$ & Crack & Crack & Gep \\
\hline & $\mathbf{Q}$ & $q^{1}$ & Eq. $3.15^{2}$ & Eq. 3.16 & Eq. $\mathbf{3 . 1 7}^{\mathbf{3}}$ & Eq. $3.18^{3}$ \\
\hline & $m^{3} j h r$ & $m^{3} / m-h r$ & $\mathrm{~Pa}$ & $P a$ & $P a$ & $P a$ \\
\hline \multirow{3}{*}{$0.1 \mathrm{~mm}$} & 0.1 & 0.0022 & 19.2 & 24 & - & 20 \\
\hline & 1.0 & 0.022 & 192 & 240 & - & 200 \\
\hline & 10.0 & 0.22 & 1920 & 2400 & - & 2040 \\
\hline \multirow{3}{*}{$0.5 \mathrm{~mm}$} & 0.1 & 0.0022 & 0.15 & - & 0.42 & 0.23 \\
\hline & 1.0 & 0.022 & 1.5 & - & 4.2 & 2.3 \\
\hline & 10.0 & 0.22 & 15 & - & 44 & 25 \\
\hline \multirow{3}{*}{$1.0 \mathrm{~mm}$} & 0.1 & 0.0022 & 0.018 & - & 0.052 & 0.029 \\
\hline & 1.0 & 0.022 & 0.18 & - & 0.53 & 0.29 \\
\hline & 10.0 & 0.22 & 1.8 & - & 5.7 & 3.3 \\
\hline \multirow{3}{*}{$10.0 \mathrm{~mm}$} & 0.1 & 0.0022 & $1.95 \times 10^{-6}$ & - & $5.3 \times 10^{-6}$ & $2.0 \times 10^{-6}$ \\
\hline & 1.0 & 0.022 & $1.95 \times 10^{-4}$ & - & $5.7 \times 10^{-4}$ & $2.2 \times 10^{-4}$ \\
\hline & 10.0 & 0.22 & $1.95 \times 10^{-3}$ & - & $9.7 \times 10^{-3}$ & $4.3 \times 10^{-3}$ \\
\hline \multicolumn{7}{|c|}{$\begin{array}{l}{ }^{1} \mathrm{q}\left(\mathrm{m}^{3} / \mathrm{m}-\mathrm{hr}\right) \text { assumes a } 45 \mathrm{~m} \text { gap or crack length. } \\
{ }^{2} \Delta P \text { in Eq. } 3.15 \text { was calculated using } \mu=18.178 \times 10^{-6} \mathrm{Pa-s} \text {. } \\
{ }^{3} \mathrm{Eq} .3 .17 \& 3.18 \text { only apply to } 0.3 \mathrm{~mm} \leq t \leq 0.7 \mathrm{~mm} \text {. }\end{array}$} \\
\hline
\end{tabular}


Note that Equations (3.17) and (3.18) were not meant to be used for $t>0.7 \mathrm{~mm}$ or $t<0.3 \mathrm{~mm}$. Table 1 shows that the simple rectangular duct analogy gives results that are reasonably close to the values of $\Delta P$ calculated from Equations (3.16) through (3.18), especially for small values of $t<0.3 \mathrm{~mm}$. For greater accuracy in the range of $0.3 \mathrm{~mm} \leq t \leq 0.7 \mathrm{~mm}$ a factor, $C_{f}$, may be introduced into the numerator of Equation $(3.15)$

$$
R_{\mathrm{b}}=\frac{C_{f} \mu L_{\mathrm{o}}}{300 L t^{3}}\left(\mathrm{~Pa}-h r / \mathrm{m}^{3}\right)
$$

where:

$$
C_{f}= \begin{cases}3 & \text { if } 0.3 \mathrm{~mm} \leq t_{\text {cruch }} \leq 0.7 \mathrm{~mm} \\ 1.8 & \text { if } 0.3 \mathrm{~mm} \leq t_{\text {gap }} \leq 0.7 \mathrm{~mm} \\ 1 & \text { otherwise }\end{cases}
$$

The resistance of the basement, $R_{b}$, may now be combined with the resistance of the soil, $R_{\text {soi }}$, to arrive at a complete expression relating the under-pressure in a baserrent to the soil gas flow into the basement.

\section{Analytical Model of Soil Gas Flow for a Basement Gap or Crack}

Dividing Equation (3.4) through by $3600 \mathrm{~s} / \mathrm{hr}$, and adding it to Equation (j.19) gives the total series resistance

$$
R_{t}=\frac{\mu}{300 L}\left[\frac{C_{f} L_{t}}{t^{3}}+\frac{1}{12 \pi k} \cosh ^{-1}\left[\frac{2 z}{t}\right]\right]\left(P a-h r / m^{3}\right)
$$

where: 


$$
C_{f}= \begin{cases}3 & \text { if } 0.3 \mathrm{~mm} \leq t_{\text {crack }} \leq 0.7 \mathrm{~mm} \\ 1.6 & \text { if } 0.3 \mathrm{~mm} \leq t_{\text {oap }} \leq 0.7 \mathrm{~mm} \\ 1 & \text { otherwise }\end{cases}
$$

The soil gas flow rate is then given by,

$$
Q=\frac{300 L \Delta P}{\mu}\left[\frac{C_{f} L_{s}}{t^{3}}+\frac{1}{12 \pi k} \cosh ^{-1}\left[\frac{2 z}{t}\right]\right]^{-1}\left(m^{3} / h r\right)
$$

With the total resistance, $R_{t}$ expressed in the form of Equation (3.20) it is possible to examine the effects of varying the parameters:

1) per neability, $k$,

2) basement gap or crack width, $t$,

3) length of gap or crack, $L$ (i.e. around the basement perimeter), and

4) depth of the basement, $z$, and

easily see to what extent the individual resistances, $R_{b}$ and $R_{\text {oil }}$, dominate. The effects of varying the above parameters are seen in Table 2 on the lollowing page. Table 2 clearly shows that for soil permeabilities of from $10^{-6}$ to $10^{-7} \mathrm{~cm}^{2}$ and gap widths of $0.1 \mathrm{~mm}$, the basement resistance, $R_{b}$, dominates. Depending on the soil permeability, the resistances $R_{b}$ and $R_{\text {roil }}$ are approximately the same order of magnitude for gap or crack widths of 0.5 $m m$, and for gap widths greater than $0.5 \mathrm{~mm}$ the soil resistance dominates. The soil resistance approaches an asymptotic limit proportional to permeability above gap widths of 10 $\mathrm{mm}$. The soil gas flow rate is directly proportional to gap or crack length in this 2dimensional model. Varying the depth of the basement from full to half depth $(1 \mathrm{~m})$ decreases the soil resistance approximately 3 to $10 \%$. Chapter 4 compares the analytical model to a 2-dimensional finite difference computer model. 
Table 2. Sensitivity of the basement and soil resistances and the soil gas flow rate with variations in permeability, width and length of the basement gap or crack, and depth of the basement.

\begin{tabular}{|c|c|c|c|c|}
\hline \multicolumn{5}{|c|}{$\begin{array}{c}\text { Sensitivity of Resistances, } R_{b} \text {, and } R_{\text {soil }}, \\
\text { and Soil Gas Flow, } Q \text {, with Variations in } \\
\text { Permeabilty, } k \text {, } \\
\text { Basement Gap or Crack Width, } t \text {, } \\
\text { Depth of Basement, } z, \\
\text { Length of Gap or Crack, } L\end{array}$} \\
\hline \multicolumn{5}{|c|}{$L=45 m, \Delta P=3.5 P a$ for all calculations. } \\
\hline \multicolumn{5}{|c|}{ Permeability $k=10^{-6} \mathrm{~cm}^{2}$} \\
\hline \multirow{2}{*}{$\begin{array}{l}\text { Gap or } \\
\text { Crack, } t\end{array}$} & $R_{\mathrm{b}}$ & $R_{\text {eoil }}$ & $R_{\mathrm{t}}$ & $Q$ \\
\hline & $P a-h r / m^{3}$ & $\mathrm{~Pa}-\mathrm{hr} / \mathrm{m}^{3}$ & $\mathrm{~Pa}-\mathrm{hr} / \mathrm{m}^{3}$ & $m^{3} / h r$ \\
\hline $0.1 \mathrm{~mm}$ gap & 191.1 & 3.86 & 194.96 & 0.018 \\
\hline $0.5 \mathrm{~mm}$ gap & 2.45 & 3.32 & 5.77 & 0.61 \\
\hline $0.5 \mathrm{~mm}$ crack & 4.59 & 3.32 & 7.91 & 0.44 \\
\hline $1.0 \mathrm{~mm} \mathrm{gap}$ & 0.19 & 3.08 & 3.27 & 1.07. \\
\hline $5.0 \mathrm{~mm}$ gap & $1.5 \times 10^{-3}$ & 2.54 & 2.54 & 1.38 \\
\hline $10 \mathrm{~mm} \mathrm{gap}$ & $1.9 \times 10^{-4}$ & 2.31 & 2.31 & 1.52 \\
\hline \multicolumn{5}{|c|}{ Length of Gap or Crack, $L=90 \mathrm{~m}$} \\
\hline $0.1 \mathrm{~mm}$ gap & 95.6 & 1.93 & 97.53 & 0.036 \\
\hline \multicolumn{5}{|c|}{ Permeability, $k=10^{-7} \mathrm{~cm}^{2}$} \\
\hline $0.1 \mathrm{~mm}$ gap & 191.1 & 38.6 & 229.7 & 0.015 \\
\hline $0.5 \mathrm{~mm}$ gap & 2.45 & 33.2 & 35.65 & 0.098 \\
\hline $0.5 \mathrm{~mm}$ crack & 4.59 & 33.2 & 37.8 & 0.093 \\
\hline $1.0 \mathrm{~mm} \mathrm{gap}$ & 0.19 & 30.8 & 30.1 & 0.11 \\
\hline $5.0 \mathrm{~mm} \mathrm{gap}$ & $1.5 \times 10^{-3}$ & 25.4 & 25.4 & 0.14 \\
\hline $10 \mathrm{~mm} \mathrm{sap}$ & $1.9 \times 10^{-4}$ & 23.1 & 23.1 & 0.15 \\
\hline \multicolumn{5}{|c|}{ Half Basement, $z=1 \mathrm{~m}$} \\
\hline $0.1 \mathrm{~mm}$ gap & 191.1 & 10.6 & 201.7 & 0.017 \\
\hline $0.5 \mathrm{~mm} \mathrm{gap}$ & 2.45 & 3.04 & 5.49 & 0.64 \\
\hline $0.5 \mathrm{~mm}$ crack & 4.59 & 3.04 & 7.63 & 0.46 \\
\hline $1.0 \mathrm{~mm}$ gap & 0.19 & 2.8 & 2.99 & 1.17 \\
\hline $5.0 \mathrm{~mm}$ gap & $1.5 \times 10^{-3}$ & 2.26 & 2.26 & 1.55 \\
\hline $10 \mathrm{~mm} \mathrm{gap}$ & $1.9 \times 10^{-4}$ & 2.03 & 2.03 & 1.72 \\
\hline
\end{tabular}




\section{CHAPTER IV}

\section{NUMERICAL MODEL OF SOIl GAS FLOW INTO BASEMENTS}

In order to check the accuracy of the simplified model of soil gas flow into basements given by Equation (3.21), it is necessary to produce a numerical finite difference solution to the partial differential equations which describe the physical process of soil gas flow. This chapter describes the general mathematical model for soil gas flow and the mass transfer of radon into basements. The mathematical equations describing the mass transfer of radon in the soil are only given for completeness. The equations describing the flow of soil gas are used to develope a 2-dimensional numerical finite difference computer program which is used to check the accu.acy of Equation (3.21). The last part of this chapter combines Equation (3.21) and the methods outlined in Chapter 2 for calculating indoor-outdoor pressure differences at the floor level into a simplified model to estimate indoor radon concentrations in houses with bagements of the type shown in Figures $4 a$ and $4 b$.

\section{Mathematical Model of Soil Gas Flow}

A general 3 dimensional mathematical model for soil gas flow is developed for a controi volume of soil. The general model may be used for the specific geometry of a basement with appropriate boundary conditions. A mass balance on the flow of soil gas for a control volume of soil is obtained by writing the continuity equation as follows:

$$
\frac{\partial \rho}{\partial t}+\nabla \cdot[\rho \vec{\imath}]=0
$$


where $\epsilon=$ soil porosity and is defined as the ratio of the volume of void to the total control volume of soil (dimensionlesa), $\rho=$ soil gas density $\left(\mathrm{kg} / \mathrm{m}^{3}\right), t=$ time $(\mathrm{s}), \vec{u}=$ the velocity vector of the soil gas $(\mathrm{m} / \mathrm{s}), \nabla^{\cdot}=$ the divergence operator, and

$$
\nabla \cdot[\rho \vec{u}]=\frac{\partial}{\partial x}(\rho u)+\frac{\partial}{\partial y}(\rho v)+\frac{\partial}{\partial z}(\rho w)
$$

where $u=$ component of velocity in the $x$-direction, $v=$ component of velocity in the $y$ direction, and $w=$ component of velocity in the $z$-direction. The velocity vector, $\vec{u}$, may be obtained from the differential form of the general expression for Darcy's Law which states that the velocity of the soil gas is proportional to the difference between the gradient of the soil gas absolute pressure field and the specific weight of the soil gas as follows (Sch74):

$$
\overrightarrow{\mathrm{u}}=-\left[\frac{k}{\mu}\right][\vec{\nabla} \mathrm{P}-\rho \overrightarrow{\mathrm{g}}]
$$

where $k=$ soil permeability $\left(m^{2}\right), \mu=$ soil gas viscosity $(P a-s), \vec{g}=$ vector accelesation of gravity $\left(m / \mathrm{d}^{2}\right), \mathbf{P}=$ soil gas absolute pressure field $(\mathrm{Pa})$, and

$$
\vec{\nabla}=\vec{i} \frac{\partial}{\partial x}+\vec{j} \frac{\partial}{\partial y}+\vec{k} \frac{\partial}{\partial z}
$$

Equation (4.3) is a strictly empirical relationship and cannot be derived by integrauing the Navier-Stokes equations because the boundary conditions necessary to describe the walls of the soil pores are so complicated (Sch74). The soil gas absolute pressure field, $P$, is made up of two components:

1) the normal hydrostatic pressure field, which is a function of depth, $z$, into the soil, and may be expressed as $P_{h}=P_{0}+\rho \vec{g} z$, where $P_{0}=$ atmospheric pressure $\left(P_{a}\right)$ at a reference level, and 
2) the disturbance pressure field, which may be expressed as $P_{d}=P_{d}(x, y, z)$.

If the above two expressions are substituted into Equation (4.3) we obtain

$$
\vec{u}=-\left[\frac{k}{\mu}\right]\left[\vec{\nabla}\left(P_{0}+\rho \vec{g} z+P_{d}(x, y, z)\right)-\rho \vec{g}\right]
$$

Assuming $P_{0}$ and $\rho$ are spatially invariant, we obtain

$$
\overrightarrow{\mathbb{u}}=-\left[\frac{k}{\mu}\right]\left[\vec{\nabla} P_{d}(x, y, z)+\rho \vec{g}-\rho \vec{g}\right] .
$$

Since we are only interested in the disturbance pressure field, we may drop the subscript and write Darcy's Law as:

$$
\overrightarrow{\boldsymbol{z}}=-\left[\frac{\boldsymbol{k}}{\boldsymbol{\mu}}\right] \vec{\nabla} P
$$

Substituting Equation (4.5) into Equation (4.1), with the assumption of steady-state conditions, yields

$$
\begin{gathered}
\nabla \cdot\left[\frac{k}{\mu} \vec{\nabla} F\right]=0, \text { or } \\
\frac{\partial}{\partial x}\left[\frac{k}{\mu} \frac{\partial P}{\partial x}\right]+\frac{\partial}{\partial y}\left[\frac{k}{\mu} \frac{\partial P}{\partial y}\right]+\frac{\partial}{\partial z}\left[\frac{k}{\mu} \frac{\partial P}{\partial z}\right]=0 .
\end{gathered}
$$

If we assume the soil is homogeneous and isotropic, the permeability, $k$, is constant. If we also assume the soil is isothermal, the viscosity, $\mu$, is constant, and Equation (4.6) reduces to Laplace's equation

$$
\frac{\partial^{2} P}{\partial^{2} x}+\frac{\partial^{2} P}{\partial^{2} y}+\frac{\partial^{2} P}{\partial^{2} z}=0
$$

If the geometry and boundary conditions are known, Equation (4.8) can be solved for the pressure field using the finite difference technique. The velocity field can then be 
determined using Darcy's Law as follows:

$$
\begin{gathered}
\vec{v}=-\left[\frac{k}{\mu}\right] \vec{\nabla} P, \text { or } \\
\text { s }=-\left[\frac{k}{\mu}\right] \frac{\partial P}{\partial x} \\
v=-\left[\frac{k}{\mu}\right] \frac{\partial P}{\partial y} \\
w=-\left[\frac{k}{\mu}\right] \frac{\partial P}{\partial z}
\end{gathered}
$$

Equations (4.9a), (4.9b), and (4.9c) are necessary for determining the mass transfer of radou, $\dot{m}_{R=}$.

\section{Mass Transfer of Radon through Soil}

The mathematical model for the mass transfer of radon given here is based on the definitive textbook, The physics of flow through porous medis, by Scheidegger (Sch57,60,74), original work done by Clements (Cl74), and on preliminary work by C. Loureiro (Lo86). The model is only discussed here for completeness and is not used in this paper.

The mass transfer of radon in the soil may be determined from a mass balance of radon in the soil pore space. The general mass balance continuity equation for radon is (Lo86)

$$
\frac{\partial}{\partial t}(\rho \theta)=-\nabla \cdot \vec{J}+S_{R n}-\lambda_{R n} \rho \theta
$$

where $\theta=$ concentration of radon in the soil gas or the ratio of radon activity to the mass of soil gas $(C i / k g), \vec{J}=$ total radon flux in the soil pore space $\left(C i / m^{2}-s\right), S_{R n}=$ production 
rate of radon in the soil $\left(C i / m^{3}-s\right), \lambda_{R n}=$ decay constant of radon in the soil $=0.0076(h r$ $\left.{ }^{1}\right)$, and $\rho=$ soil gas density $\left(k g / \mathrm{m}^{3}\right)$.

The radon flux terin is made up of a convective component and a diffusive component. The convective component accounts for the flow of radon gas transported through the soil pores along with the bulk flow of soil gas, and is expressed as

$$
\vec{J}_{\mathrm{C}}=\vec{u} \rho \theta
$$

where $\vec{J}_{\mathrm{C}}=$ convective component of the radon flux in the soil pore space $\left(\mathrm{Ci} / \mathrm{m}^{2}-\mathrm{s}\right)$, and all other variables are as previously defined.

The diffusive component accounts for the flow of radon gas through the soil pore space due to differences in radon concentration and is expressed as

$$
J_{D}=-D \rho \vec{\nabla} \Theta
$$

where $\vec{J}_{\mathrm{D}}=$ diffusive component of the radon flux in the soil pore space $\left(C i / m^{2}-a\right), D=$ effective diffusivity coefficient for radon in the soil gas $\left(\mathrm{m}^{2} / \mathrm{s}\right)$, and all other variables are as previously defined.

The production rate of radon into the soil pore space is proportional to the concentration of Radium-226, ${ }^{226} \mathrm{Ra}$, in the soil, the soil density, and the radon emanation fraction and is expressed as

$$
S_{R n}=f \rho, C_{R \bullet} \lambda_{R n}\left[\frac{1-\epsilon}{\epsilon}\right]
$$

where $S_{R_{k}}=$ production rate of radon into the soil pore space $\left(\mathrm{Ci} / \mathrm{m}^{3}-\mathrm{s}\right), \mathrm{f}=$ emanation fraction defined as the percentage of the total radon production rate that ends up in the 
pore space (dimensionless), $\rho_{a}=$ density of soil grains $\left(\mathrm{kg} / \mathrm{m}^{3}\right), \mathrm{C}_{R_{a}}=$ concentration of ${ }^{220} \mathrm{Ra}$ in the soil grains $(C i / \mathrm{kg})$, and all other variables are as previously defined.

Substituting Equations (4.11) and (4.12) into Equation (4.10) yields:

$$
\frac{\partial}{\partial t}(\rho \theta)=-\nabla \cdot[\vec{u} \rho \theta]+\nabla \cdot[D \rho \vec{\nabla} \theta]+S_{R n}-\lambda_{R n} \rho \theta
$$

The velocity field, $\vec{u}$, can be determined from the pressure field by use of Equation (4.9) which satisfies the continuity equation for the soil gas. At steady-state Equation (4.14) becomes:

$$
-\nabla \cdot[\vec{v} \rho \theta]+\nabla \cdot[D \rho \vec{\nabla} \theta]+S_{R_{m}}-\lambda_{R_{n}} \rho \theta=0
$$

At steady-state the continuity or mass balance equation for the soil gas may be written as:

$$
\nabla \cdot[\rho \vec{u}]=0
$$

Writing both of these equations in 3-dimensional form yields:

1) Continuity or Mass-Balance for the Radon Gas

$$
\begin{aligned}
& \frac{\partial}{\partial x}\left[D_{\rho} \frac{\partial \theta}{\partial x}\right]-\frac{\partial}{\partial x}[u \rho \theta]+\frac{\partial}{\partial y}\left[D_{\rho} \frac{\partial \theta}{\partial y}\right]-\frac{\partial}{\partial y}[v \rho \theta] \\
& +\frac{\partial}{\partial z}\left[D_{\rho} \frac{\partial \theta}{\partial z}\right]-\frac{\partial}{\partial z}[w \rho \theta]+S_{R_{n}}-\lambda_{R_{n}} \rho \theta=0, \text { and }
\end{aligned}
$$

2) Continuity or Mass Balance for the Soil Gas

$$
\frac{\partial}{\partial x}(\rho u)+\frac{\partial}{\partial y}(\rho v)+\frac{\partial}{\partial z}(\rho w)=0 .
$$


If the geometry and boundary conditions are known, Equations (4.17) and (4.18) can be solved for the concentration field using the finite difference technique. With the concentration field known the mass transfer or flux of radon at any location can be obtained from the concentration field and the velocity field using Equations (4.11) and (4.12).

\section{Radon Entry Rate into a Basement}

The boundary conditions must be specified if Equations (4.8) and (4.9) are to be solved for the pressure field, and if Equations (4.17) and (4.18) are to be solved for the concentration field. Figure 6 shows a cross-section for a typical basement and soil block. Because of symmetry only half of the cross-section is considered for the problem. Each boundary region is numbered and the boundary descriptions and conditions are given in Table 3 , for the Fressure field, and Table 4, for the concentration field.

A finite difference approach may be used to solve Equation (4.8) using the pressure field boundary conditions shown above. It is necessary to select a large enough area of soil such that the boundary conditions for regions 4 and 5 are met. This is done by a process of iteration using some initial soil area, and then varying the soil area until convergence is obtained. It is also necessary to know the pressure drop across the basement gap or crack, $\Delta P_{b}$, as discussed in Chapter 3. The total pressure drop acress the soil and the basement gap must equal the basement under-pressure. Iteration to achieve convergence on this condition is achieved as follows:

1) assume some initial pressure drop across the basement gap, $\Delta P_{b}$,

2) calculate the pressure boundary condition at region $2, P_{2}$ (from Table 3 ),

3) solve for the pressure field in the soil,

4) calculate a soil gas velocity for region 2 using Equation (4.9), 


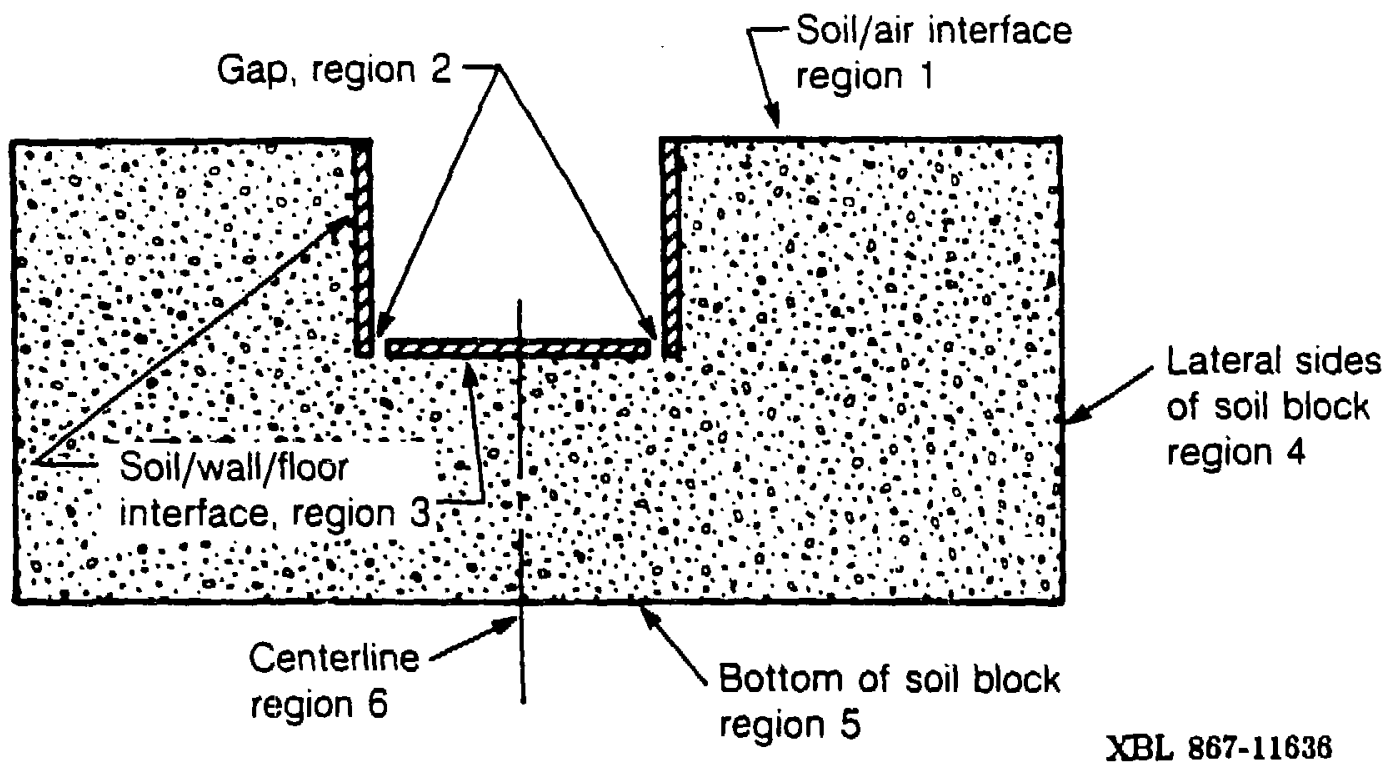

Figure 6. Cross-sectional view of a typical basement and soil block, showing boundary regions for the 2-dimensional finite difference model. 
Table 3. Pressure field boundary conditions used to solve Equation (4.8) for the soil surrounding a basement shown in Figure 6.

\begin{tabular}{|l|l|}
\multicolumn{2}{|c|}{ Preasure Field Boundary Conditions } \\
(necessary to solve Equation 4.8)
\end{tabular}


Table 4. Radon concentration field boundary conditions used to solve Equation (4.17) for the soil surrounding a basement shown in Figure 6.

\begin{tabular}{|c|c|c|}
\hline \multicolumn{3}{|c|}{$\begin{array}{l}\text { Radon Concentration Field Boundary Conditions }{ }^{1} \\
\text { (necesary to solve Equation 4.17) }\end{array}$} \\
\hline \multicolumn{3}{|c|}{${ }^{1}$ Basement geometry is shown in Figure 0.} \\
\hline Region & Description & Boundary Condition \\
\hline 1 & Soil/Air interface & $\theta=0$ \\
\hline 2 & $\begin{array}{l}\text { Bottom of gap or } \\
\text { crack at the soil }\end{array}$ & $\begin{array}{l}\text { Outflow boundary; } \\
\text { No boundary condition is necessary at } \\
\text { an outflow boundary (Lo86). Here the } \\
\text { fow is dominated by the convective } \\
\text { term, }\left(\mathcal{J}_{C}\right) \text {. }\end{array}$ \\
\hline 3 & $\begin{array}{l}\text { Interface of the soil } \\
\text { and the basement walls } \\
\text { and floor, except at } \\
\text { region } 2 \text { (above). }\end{array}$ & $\begin{array}{l}\text { No-Flux Boundary; } \\
\text { Permeability and diffusive components of } \\
\text { concrete (walls and floor) is much lower } \\
\text { than the soil, and the flux perpendicular } \\
\text { to the walls and floor is assumed to be } \\
\text { zero }(J \approx 0) \text {. }\end{array}$ \\
\hline 4 & $\begin{array}{l}\text { Lateral sides of } \\
\text { the soil block }\end{array}$ & $\begin{array}{l}\text { No-Flux Boundary; } \\
\text { At suficiently large distances from the gap } \\
\text { the pressure field and concentration field } \\
\text { will be almost invariable with distance } \\
\text { and the fux perpendicular to the boundaries } \\
\text { is assumed to be zero }(J \approx 0) \text {. }\end{array}$ \\
\hline 5 & Bottom of the soil block & Same as region 4 \\
\hline 6 & $\begin{array}{l}\text { Centerline of soil block } \\
\text { between opposite sides } \\
\text { of the basement walls. }\end{array}$ & $\begin{array}{l}\text { No-Flux Boundary; } \\
\text { Without the infuence of wind the driving } \\
\text { force of the basement under-pressure is } \\
\text { assumed to be equally balanced between } \\
\text { opposing shrinkage gaps in the basement } \\
\text { floor. This produces a symmetric } \\
\text { concentration field about the centerline } \\
\text { and a condition of zero flux perpendicular } \\
\text { to the centerline }(J \approx 0) \text {. }\end{array}$ \\
\hline
\end{tabular}


5) calculate the pressure drop across the basement gap, $\Delta P_{b}^{\prime}$, using Equation (3.12),

6) and check for convergence (i.e $\Delta P_{b}{ }^{\prime} \approx \Delta P_{b}$ ). Once the pressure field has been calculated the velocity field must be calculated using Equation (4.9). Then the radon concentration field can be calculated using the boundary conditions shown in Table 4 to solve Equation (4.17). Once this is done the radon flux or entry rate into the basement may be calculated as follows:

$$
\sigma_{f}=\vec{J}_{\text {oap }} \cdot A_{\text {oep }}
$$

where $\sigma_{f}=$ radon eutry rate into the house $(C i / o), \quad \vec{J}_{\text {app }}=$ radon flux into the gap $\left(C i / m^{2}-s\right)$, and $A_{\text {gap }}=$ area of the basement gap or crack $\left(m^{2}\right)$.

\section{2-Dimensionsl Finite Difference Computer Program Description}

Using the finite difference numerical method to solve Equation (4.8) is computationally expensive for 3-dimensional geometry. Reducing the problem to 2-dimensions is satisfactory if the soil is assumed wo be isotropic and homogeneous and if the basement gap geometry is symmetric. Furthermore, if the radon concentration in the soil is assumed to be constant at a level $C_{\infty}^{1}$, then only the bulk soil gas flow rate is necessary to calculate the radon entry rate into a basement. This method of solving the problem will give an upper bound on the radon entry rate into basements, since depletion of radon in the soil by diffusion and bulk How reduces the radon concentration below $C_{\infty}$. Rewriting Equation (4.8) in 2-dimensions gives:

$$
\frac{\partial^{2} P}{\partial^{2} x}+\frac{\partial^{2} P}{\partial^{2} y}=0
$$

${ }^{1} C_{\infty}$ is defined as the radon concentration in the soil with depletion occuring only from radioactive decay. 
Figure 7 a shows a simple nodal network which may be used to numerically approximate the above second order homogeneous partial differential Equation (In81). The $x$ and $y$ locations in Figure $7 \mathrm{a}$ are designated by $m$ and $n$ indices respectively. Fach node in Figure $7 a$ represents a 2-dimensional region whose pressure is a measure of the average pressure of the region. The pressure at the $(m, n)$ node in Figure $7 \mathrm{a}$ is assumed to represent the average pressure of the shaded region. Figure $7 \mathrm{~b}$ shows a graphical representation of how the first partial derivatives of pressure, with respect to position, may be obtained for any face of the $(m, n)$ shaded region. The faces of the region lie midway between adjacent nodes and the first partial derivatives in the $x$-direction may be obtained as follows:

$$
\begin{aligned}
& \left.\frac{\partial P}{\partial x}\right|_{m-1 / 2, \pi}=\frac{P_{m, n}-P_{m-1, n}}{\Delta x}, \text { and } \\
& \left.\frac{\partial P}{\partial x}\right|_{m+1 / 2, n}=\frac{P_{m+1, n}-P_{m, n}}{\Delta x}
\end{aligned}
$$

where $\Delta x=$ the distance between adjacent nodes in the $x$-direction. In the subscripts the ' + ' denotes nodes neighboring $(m, n)$ to the right (x-direction) or above (y-direction). The second partial derivative may be approximated as follows:

$$
\frac{\partial^{2} P}{\partial x^{2}} \approx \frac{\left.\frac{\partial P}{\partial x}\right|_{m+1 / 2, n}-\left.\frac{\partial P}{\partial x}\right|_{m-1 / 2, n}}{\Delta x}
$$

Substituting from Equations (4.21) and (4.22) we obtain:

$$
\frac{\partial^{2} P}{\partial x^{2}} \approx \frac{P_{m+1, n}+P_{m-1, n}-2 P_{m, n}}{\Delta x^{2}}
$$

The previous Equation may similarly be written for the $y$-direction as:

$$
\frac{\partial^{2} P}{\partial y^{2}} \approx \frac{P_{m, n+1}+P_{m, n-1}-2 P_{m, n}}{\Delta y^{2}} .
$$




\section{Simple Nodal Network}

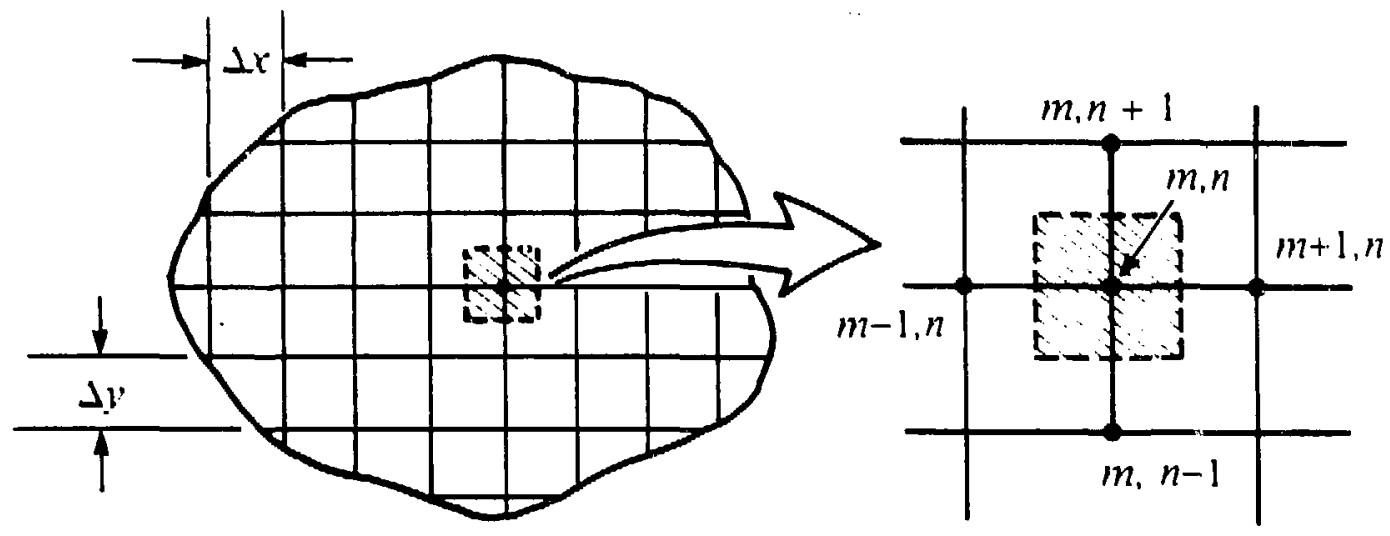

Figure 7a. A 2-dimensional simple nodal network, with $x$, and $y$ locations designated by the $m$ and $n$ indices respectively.

$$
\begin{aligned}
& \left.\frac{\partial P}{\partial x}\right|_{m+1 / 2, n}=\frac{P_{m+1, n}-P_{m, n}}{\Delta x} \\
& \left.\frac{\partial P}{\partial x}\right|_{m-1 / 2, n}=\frac{P_{m_{i n}}-P_{m-1, n}}{\Delta x} \\
& \left.\left.P(x)\right|_{m-1 / 2 \mid} ^{m-1}\right|_{m+1 / 2} ^{1}
\end{aligned}
$$

XBL 867-11632

Figure 7b. 2-dimensional pressure fiebs finite difference approximation. 
To obtain reasonable results without excessive computation time it is necessary to use a variable spaced grid. Figure 8 shows the variable spaced grid and coordinate system used to model the basement geometry. Figure 9 shows the fine grid spacing used near the gap region. For the variable spaced grid Equations (4.24) and (4.25) may be multiplied by a constant and written as follows:

$$
\begin{aligned}
& \frac{\partial^{2} P}{\partial x^{2}} \approx \frac{0.5}{x_{m+1, n}-x_{m-1, n}}\left[\frac{P_{m+1, n}-P_{m, n}}{x_{m+1, n}-x_{m, n}}-\frac{P_{m, n}-P_{m-1, n}}{x_{m, n}-x_{m-1, n}}\right], \text { and } \\
& \frac{\partial^{2} P}{\partial y^{2}} \approx \frac{0.5}{y_{m, n+1-y_{m, n-1}}}\left[\frac{P_{m, n+1}-P_{m, n}}{y_{m, n+1}-y_{m, n}}-\frac{P_{m, n}-P_{m, n-1}}{y_{m, n}-y_{m, n-1}}\right] .
\end{aligned}
$$

Equations (4.26) and (4.27) may be substituted into Equation (4.20), and rewritten into a system of algebraic equations as follows:

$$
\begin{aligned}
& B_{m, n} P_{m, n-1}+C_{m, n} P_{m-1, n}+D_{m, n} P_{m, n} \\
& +E_{m, n} P_{m+1, n}+F_{m, n} F_{m, n+1}=Q_{m, n,}
\end{aligned}
$$

where $Q_{m, n}=$ source term $=0$ in the case of Equation (4.20), and the coefficients $B, C, D, E$, and $F$ are defined as follows:

$$
\begin{aligned}
& B_{m, n}=\frac{0.5}{\left(y_{m, n+1}-y_{m, n-1}\right)\left(y_{m, n}-y_{m, n-1}\right)}, \\
& C_{m, n}=\frac{0.5}{\left(x_{m+1, n}-x_{m}-1, n\right)\left(x_{m, n}-x_{m-1, n}\right)}, \\
& E_{m, n}=\frac{0.5}{\left(x_{m+1, n}-x_{m-1, n}\right)\left(x_{m+1, n}-x_{m, n}\right)}, \\
& F_{m, n}=\frac{0.5}{\left(y_{m, n+1}-y_{m, n-1}\right)\left(y_{m, n+1}-y_{m, n}\right)}, \text { and } \\
& D_{m, n}=-B_{m, n}-C_{m, n}-E_{m, n}-F_{m, n} .
\end{aligned}
$$




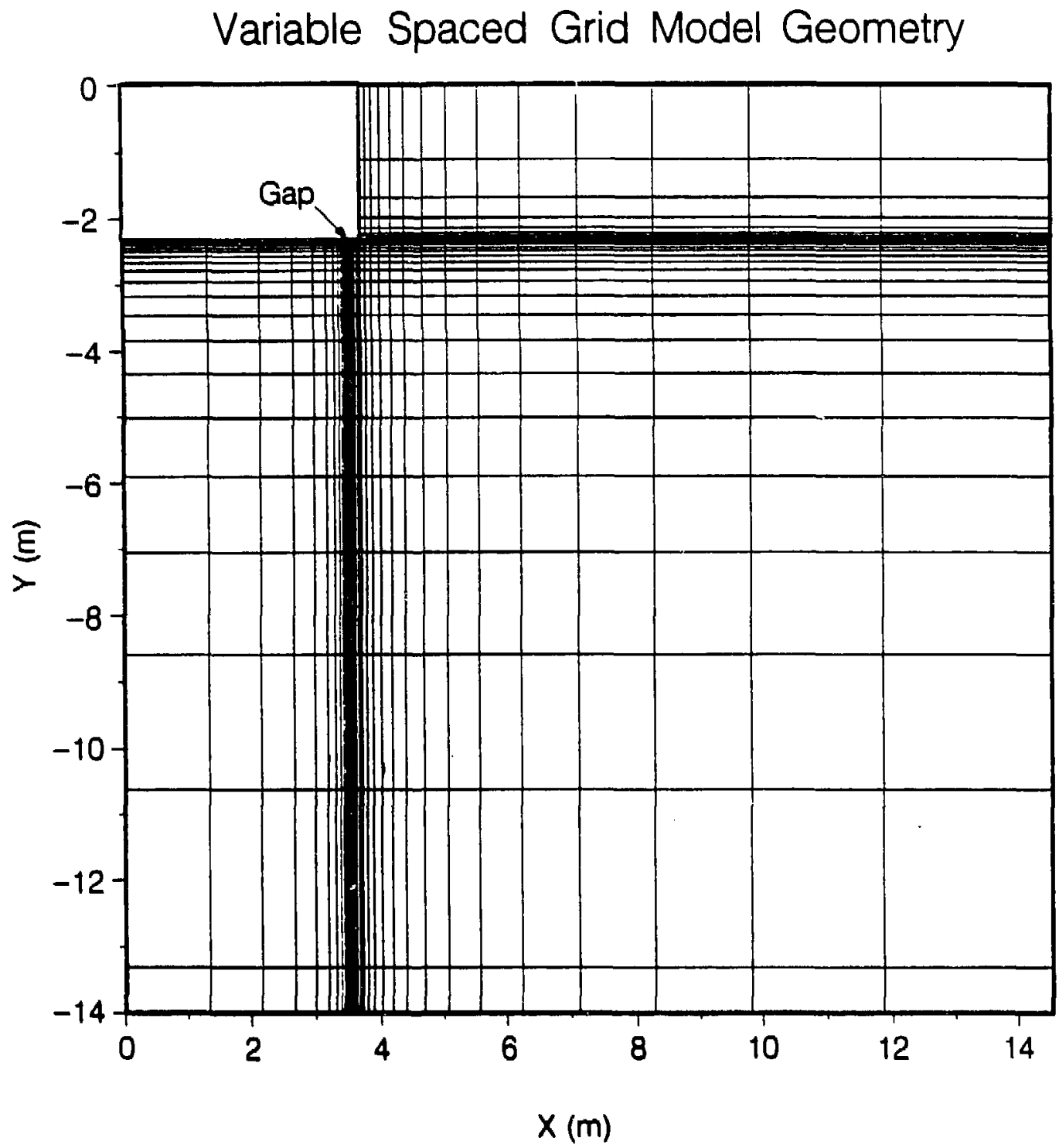

XBL 867.11628

Figure 8. Variable spaced grid and coordinate system used to model the 2-dimensional basement geometry. 


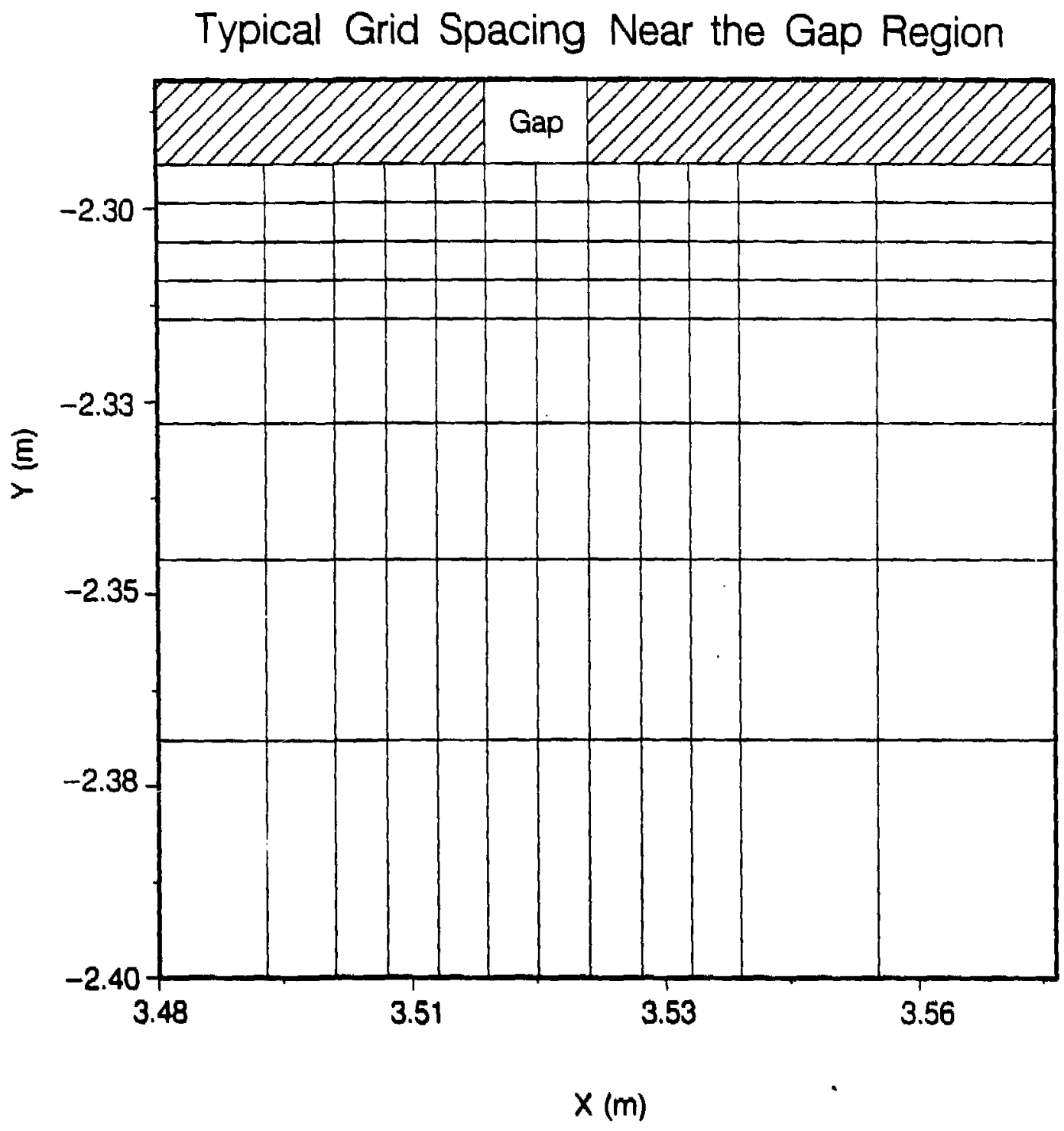

XBL 867-11629

Figure 9. Typical 2-dimensional fine grid spacing used near the gap region. Note that the spacing at the gap is a constant of $1 / 2$ gap width and this constant spacing extends 2 gap widths either side of the gap centerline as well as below the gap. 
The above equations are used for interior nodes with the boundary nodes defined according to Table 3. For Dirichlet boundary conditions (ie. known boundary value; region 1 at the soil/air interface and region 2 at the bottom of the gap or crack) the value of $P_{m, n}$ is set to the known value, $D_{m, n}$ is set to 1 , and all other coefficients are set to zero. For the Neumann boundary conditions (i.e. no-flow boundaries; regions $3,4,5 \& 6$ ) the coefficients just inside the no-flow boundaries are set to their normal values, all other coefficients are set to zero, and $D_{m, n}$ is set to the sum of the non-zero coefficients.

The computer program used to solve the system of algebraic equations represented by Equation (4.28) is contained in the appendix. The program follows the steps outlined in section 4.1.2, and uses a NAG FORTRAN DOSECF subroutine to calculate the pressure field by the method of residuals.

Initial computer runs were made to see how sensitive the model was to the selection of

1) the variable spaced grid size, and

2) the soil depth and extent.

The variable spaced gridding must be fine near the gap, wnere the local partial derivatives are large, and gradually increase to coarser spacing near the "no-flow" boundaries where the partial derivatives are approximately zero. Selecting the proper variable spaced grid size must be done to avoid inaccurate numerical results, and excessive computation time. The final variable grid selected had approximately 6000 nodes. The soil depth and extent must be great enough to satisfy the "no-flow" boundary conditions, while not being so great as to require excessive computation time. The final soil depth selected was $11 \mathrm{~m}$ below the depth of the basement and $11 \mathrm{~m}$ outside the basement wall. The variable grid spacing used for the modeling was determined using an exponential exnression as follows:

$$
\Delta_{i}=M e^{B i} \text {, }
$$


where $\Delta_{i}=$ incremental variable spacing in either the $x$ or $y$ direction, $i=$ the $i$ th increment number of from 1 to $N$ increments, and $\delta=$ constant of proportionality depending on the max and min grid sizes selected as follows:

$$
\delta=\frac{-\ln (\max / \min )}{N-1}
$$

The value of the multiplier, $M$, is calculated as:

$$
M=\frac{D I S\left(1-e^{\delta}\right)}{e^{\delta}-e^{\delta(N+1)}}
$$

where DIS = the overall distance of interest, and

$$
D I S=\sum_{i=1}^{N} \Delta_{i}
$$

The above exponential expression for $\Delta_{i}$ insures smooth variable spacing, and allows for easily changing the overall model area and max and min grid spacing parameters. This was important initially for selecting the "optimal" geometry for each run.

Figure 9 shows that the fine grid spacing at the wall-floor gap itself is a constant size of $1 / 2$ gap width and extends 2 gap widths to either side of the gap centerline and 2 gap widths down to provide accuracy in calculating the pressure field at the gap region. Figures 10 and 11 show the pressure field for soil depths of $14 \mathrm{~m}$ and $30 \mathrm{~m}$ respectively, with a gap w: Ath of $1 \mathrm{~mm}$ and a basement underpressure of $\Delta P=-3.5 P a$. Figure 12 shows the pressure field for a $10 \mathrm{~mm}$ gap and is similar to Figure 10, except that with a larger gap width the isobars are spread further out into the soil. Figure 13 shows a close-up view of the pressure field within $30 \mathrm{~cm}$ of the gap region. Figure 13 clearly shows that the pressure field is attenuated very close to the gap, and the other isobaric plots show that the basement under-pressure is reduced by almost $70 \%$ in the first $0.5 \mathrm{~m}$ of soil. This indicates that the soil characteristics in the region very close to une basement gap have a large influence on the flow of soil gas into the basement. If very low permeability clay is placed in this region 
Soil Gas Pressure Field for a Basement Section Gap Size, $t=1 \mathrm{~mm}, \Delta P=-3.5 \mathrm{~Pa}$

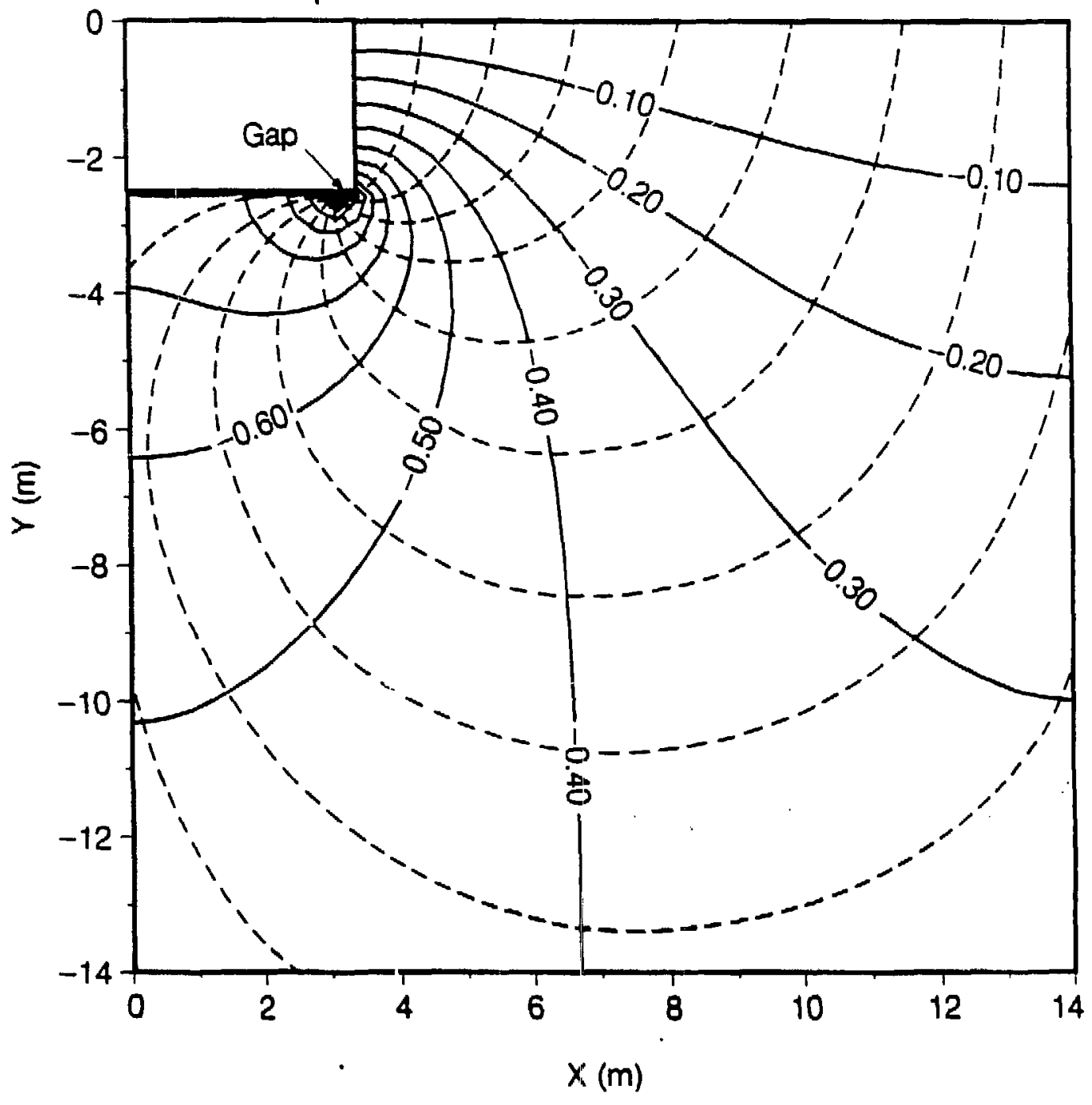

XBL $867 \cdot 11634$

Figure 10. Sol gas pressure field for a basement section, with homogeneous permeability, a gap size of $1 \mathrm{~mm}, \Delta P=-3.5 P a$, and model geometry extending $14 \mathrm{~m}$. The streamlines of soil gas flow are drawn in dashed lines, and the calculated soil gas flow rate at the gap is $97.3 \mathrm{l} / \mathrm{hr}$. 
Soil Gas Pressure Field for a Basement Section Gap Size, $t=1 \mathrm{~mm}, \Delta \mathrm{P}=-3.5 \mathrm{~Pa}$

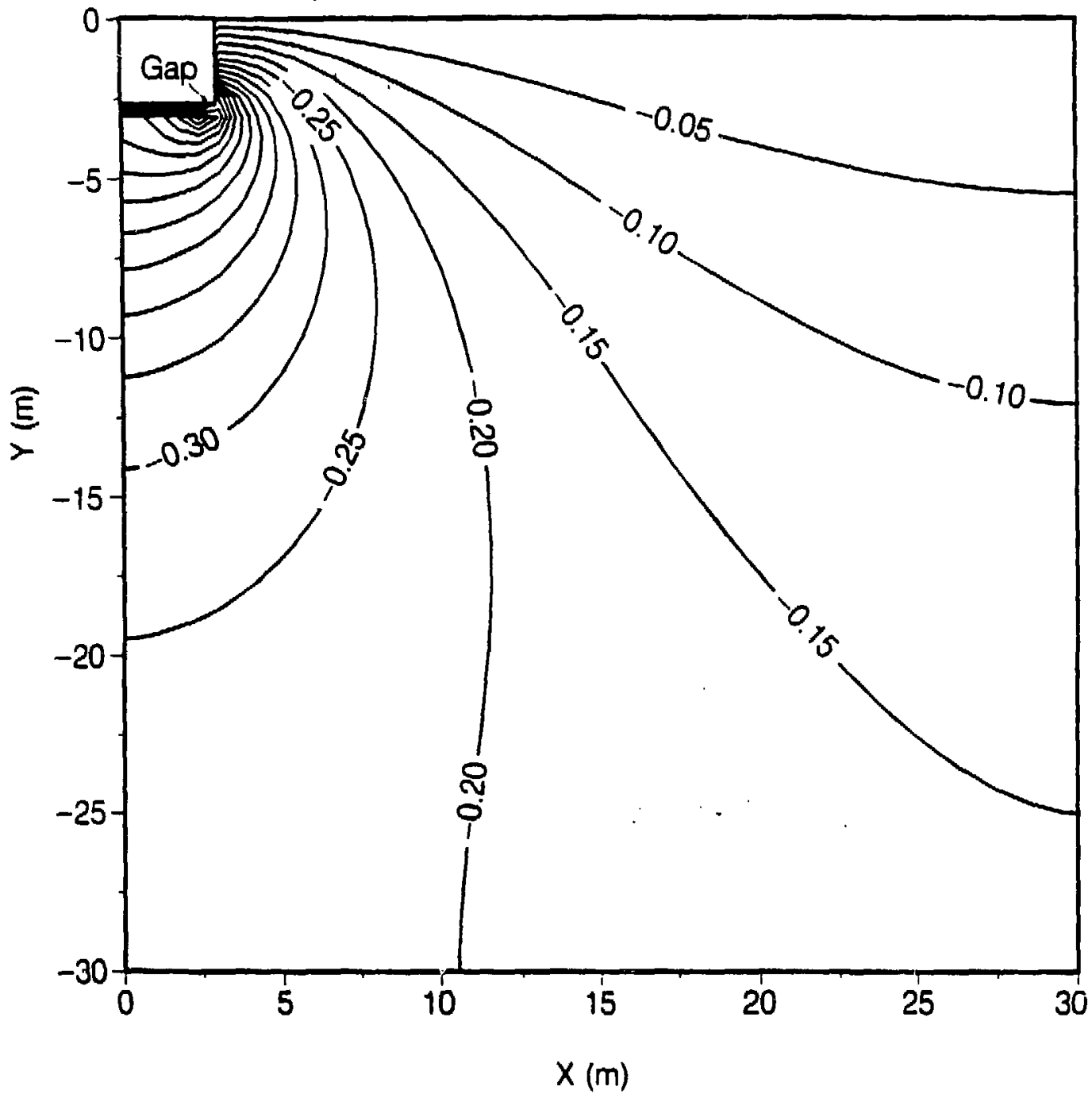

XBL 867-11631

Figure 11. Soil gas premure field for a basement section, with homogeneous permeability, a gap aize of $1 \mathrm{~mm}, \Delta P=-3.5 P_{a}$, and model geometry extending $30 \mathrm{~m}$. The calculated soil gas flow rate at the gap is $96.7 \mathrm{l} / \mathrm{hr}$. 
Soil Gas Pressure Field for a Basement Section Gap Size, $t=10 \mathrm{~mm}, \Delta \mathrm{P}=-3.5 \mathrm{~Pa}$

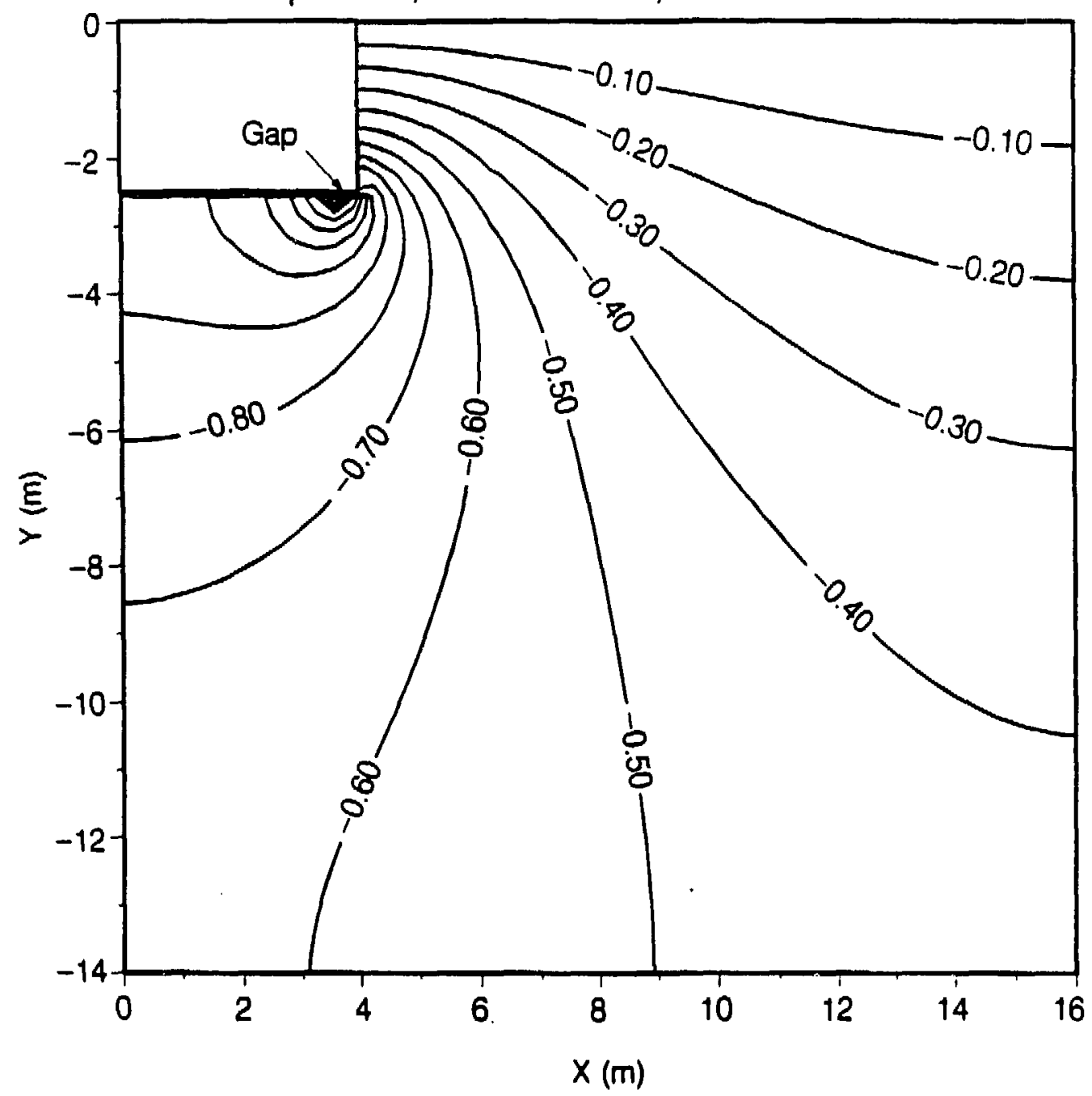

XBL $867 \cdot 11637$

Figure 12. Soil gas pressure field for a basement section, with homogeneous permeability, a gap size of $10 \mathrm{~mm}, \triangle P=-3.5 \mathrm{~Pa}$, and model geometry extending $14 \mathrm{~m}$. The calculated soil gas flow rate at the gap is $123.6 \mathrm{l} / \mathrm{hr}$. 
Soil Gas Pressure Field for the Fine Grid Region $\Delta P=3.5 \mathrm{~Pa}$, Gap Size $=1 \mathrm{~mm}$

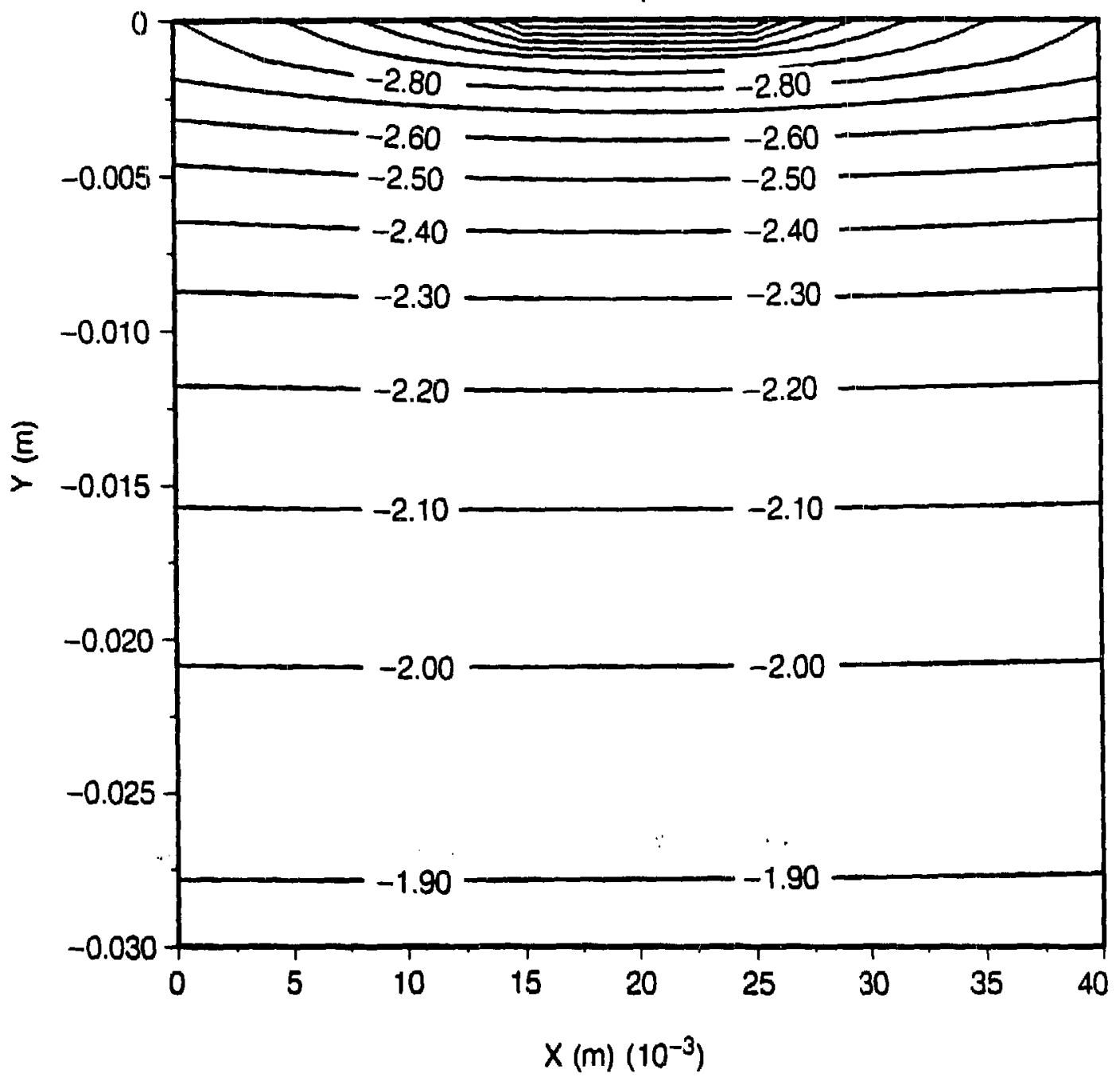

XBL $867 \cdot 11630$

Figure 13. Close-up view of the soil gas pressure field for a basement section, with gap gize of $1 \mathrm{~mm}, \Delta P=-3.5 P a$, homogeneous permeability, and model geometry extending $14 \mathrm{~m}$. 
at the time of construction, the flow of soil gas and hence radon entry into basements might be reduced or eliminated entirely. It is necessary to conduct experiments to see if a subbasement layer of clay would eliminate the radon entry problem and also to determine how such a mitigation effort would successfully withstand the test of time.

\section{Analytical vs. Numerical Model of Soil Gas Flow}

Figure 14 shows a comparison of the soil gas flow rate calculated using the analytical and numerical models. The calculations were performed using a basement under-pressure of 3.5 $\mathrm{Pa}$, basement wall-floor gap widths ranging from $0.05 \mathrm{~mm}$ to $10 \mathrm{~mm}$, and soil permeabilities ranging from $1 \times 10^{-4} \mathrm{~cm}^{2}$ to $1 \times 10^{-10} \mathrm{~cm}^{2}$. The curves were fitted to the data using a parametric cubic spline interpolation procedure. The plots show good agreement for the two models particularly at gap widths less than $1 \mathrm{~mm}$. At gap widths larger than $1 \mathrm{~mm}$ the differences between the two models increase with increasing gap width to a maximum difference of $13 \%$ at $10 \mathrm{~mm}$. The arithmetic mean difference between the two models varied from $4 \%$ at a soil permeability of $1 \times 10^{-4} \mathrm{~cm}^{2}$ to almost $9 \%$ at a soil permeability of $1 \times 10^{-10} \mathrm{~cm}^{2}$. Figures 15 and 16 show plots of soil gas flow rate for pressures of $0.3 P a$ and 10.0 $\mathrm{Pa}$ respectively, with the numerical model calculation only performed for the $1 \mathrm{~mm}$ gap width. Figures 14, 15, and 16 show the following relationships between the soil gas flow rate and the soil and gap resistances:

1) for gap widths larger than approximately $1 \mathrm{~mm}$ the resistance to flow through the gap is small compared to the resistance to flow through the soil,

2) for gap widths between $0.3 \mathrm{~mm}$ and $1.0 \mathrm{~mm}$ (transition region) the soil gas flow rate depends on the combined resistances of the gap and the soil, and

3) Ior gap widths less than $0.3 \mathrm{~mm}$ the soil gas flow rate is dominated by the gap resistance. 


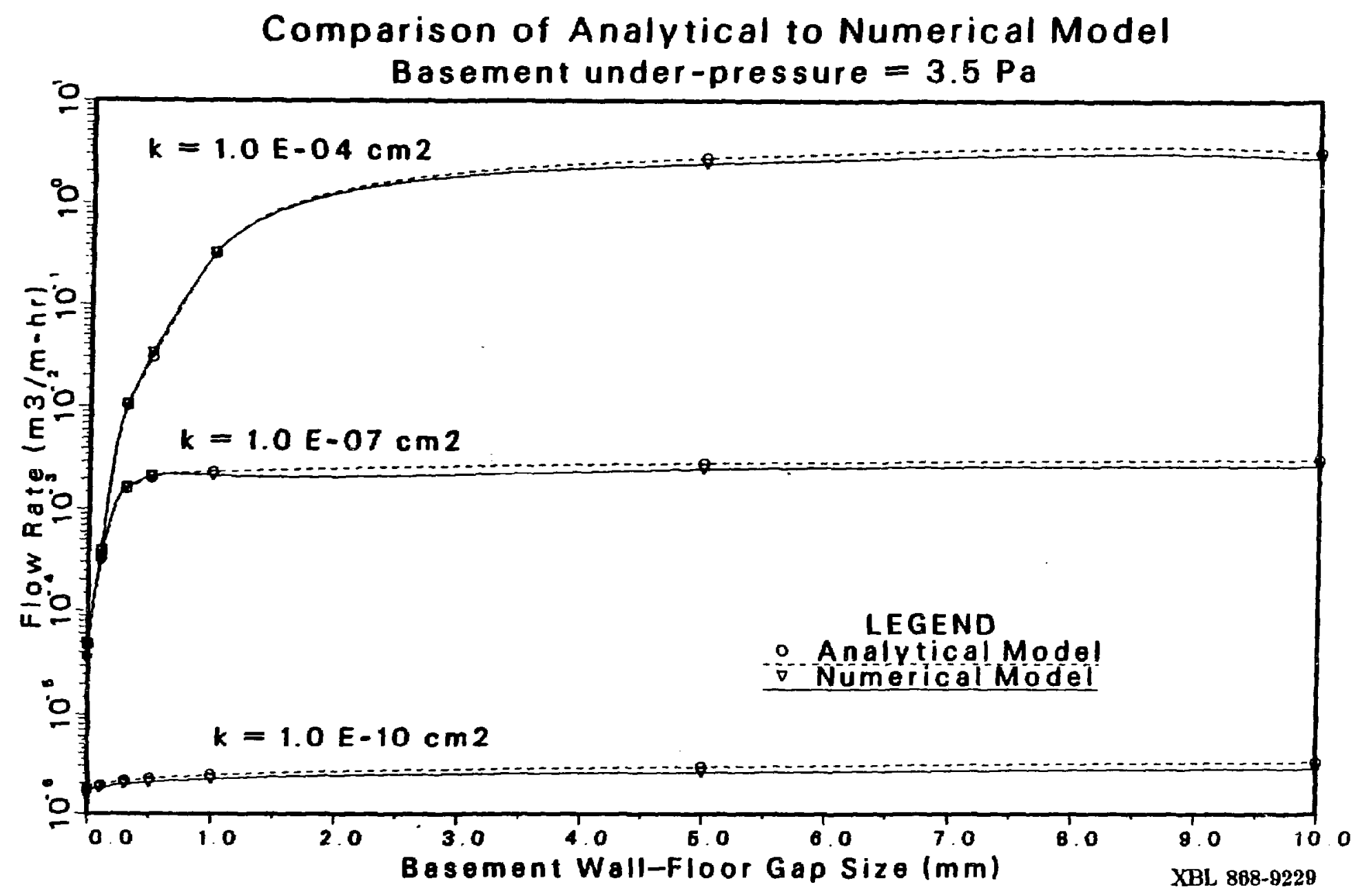

Figure 14. A comparison of the simple analytical model to the numerical model of soil gas flow rate vs. basement wall-floor gap size, for a basement underpressure of $\Delta P=-3.5 \mathrm{~Pa}$, and soil permeabilities of $10^{-4}, 10^{-7}$, and $10^{-10} \mathrm{~cm}^{2}$. 


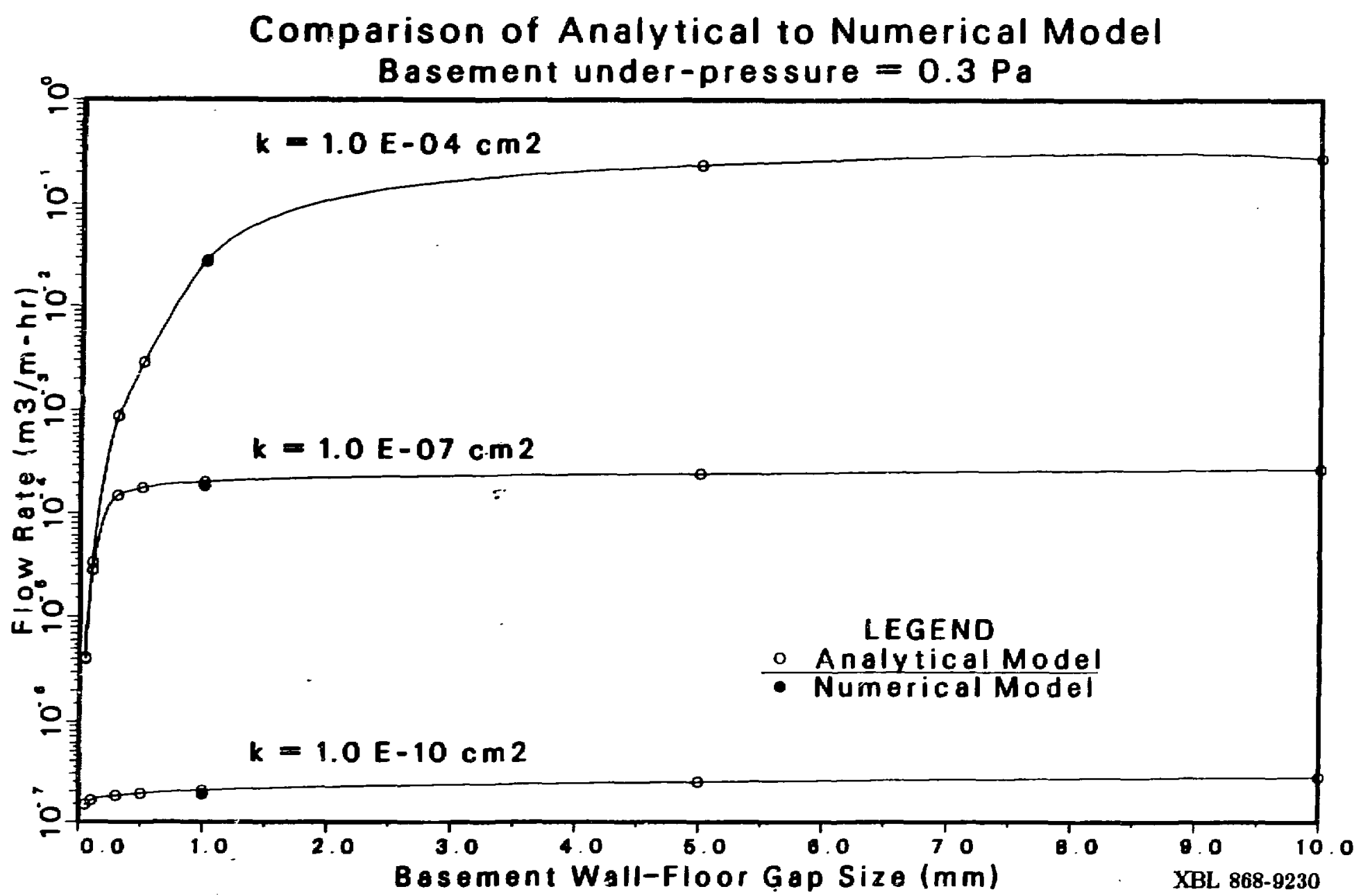

Figure 15. A comparison of the simple analytical model to the numerical model of soil gas flow rate vs. basement wall-floor gap size, for a basement underpressure of $\Delta P=-0.3 \mathrm{~Pa}$, and soil permeabilities of $10^{-1}, 10^{-7}$, and $10^{-10} \mathrm{~cm}^{2}$. 


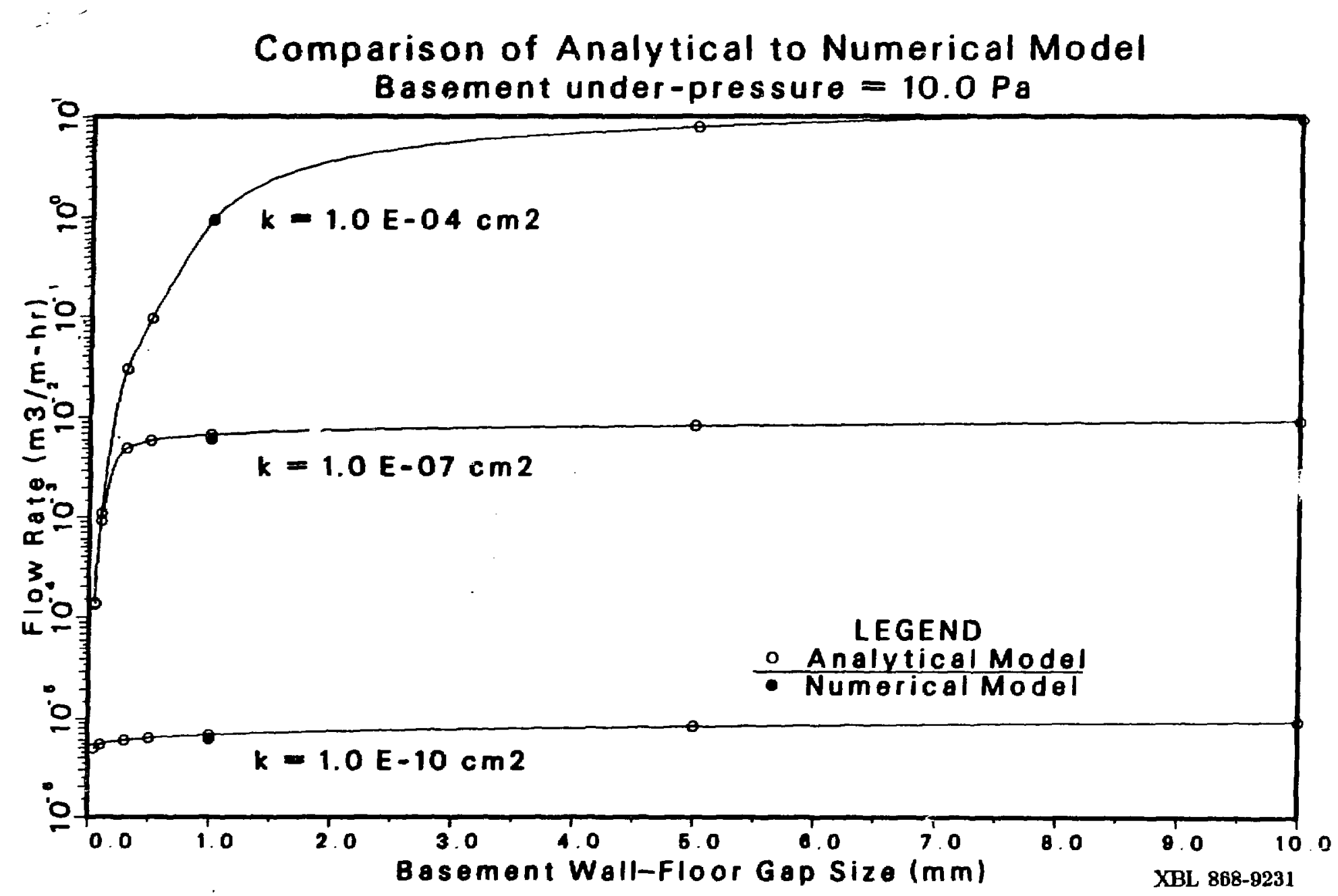

Figure 16. A comparison of the simple analytical model to the numerical model of soil gas flow rate vs. basement wall-floor gap size, for a basement underpressure of $\Delta P=-10 \mathrm{~Pa}$, and soil permeabilities of $10^{-4}, 10^{-7}$, and $10^{-10} \mathrm{~cm}^{2}$. 
The extent of the transition region where the magnitude of gap and soil resistances balance is dependent on the magnitude of the soil permeability. This may be seen by comparing curves of different permeability.

The numerical model has definite advantages over the simple analytical model such as:

1) the ability to describe various basement geometries,

2) describing layered non-homogeneous soil permeability,

3) using the calculated pressure field to calculate the velocity field and solve for the mass transfer of radon in the soil, and

4) if the numerical method is implemented on a very high speed computer it would be possible to deal with 3-dimensional geometry and non-steady-state problems.

For a poured basement geometry with a shrinkage gap, the analytical model is almost as accurate as the numerical model, and has the advantage of being easy to implement on a hand held calculator.

The major disadvantages of both of these models are in the simplifying assumptions. The motivation for doing a simplified analysis is to gain insight into the important parameters involved in the physical process of soil gas flow. Continuing the effort to solve for the mass transfer of radon in the soil, and then moving into 3-dimensional modeling will be easier with the knowledge gained from the simplified 2-dimensional steady-state analysis.

\section{Measured vo. Calculated Radon Entry Rates into Basements}

The simplified analytical model of soil gas flow, discussed in Chapter 3, is based on a number of simplifing assumptions. The most important of these are: 
1) the basement substructure is a poured concrete wall and floor construction with a wall-floor shrinkage gap, and

2) the soil around the substructure has homogeneous permeability.

Both of these assumptions are met by house ESP108C, which was monitored for indoor radon concentration from the end of October 1985 through the end of March 1986 in a study by Turk et al. (Tu86). A plan view of the house is shown in Figure 17. The basement substructure of ESP108C is of the type assumed in the model, except that the floor was poured in two sections. The basement was also paneled and carpeted so it wasn't possible to measure the width of the shrinkage gaps. Since the simplified model assumes the basement floor is a monolithic slab the centerline gap is neglected, and the net concrete shrinkage is lumped into an assumed perimeter shrinkage gap. Assuming typical portland concrete was used, the width of the gap should be between 2 and $5 \mathrm{~mm}$ wids: This is based on the $8 \times 22 \mathrm{~m}^{2}$ size of the basement floor and a shrinkage strain of 3 to $6 \times 10^{-1} \mathrm{~m} / \mathrm{m}$. The gravelly soil around the house is very homogeneous with a nessured permeability of $\mathrm{k}=$ $2.2 \times 10^{-6} \mathrm{~cm}^{2}$ (Mo86). The homogeneity of the soil in the Spoitane area, where ESP108C is located, results from the outwash of glacially-dammed Lake Missoula following melting of the Corilleran ice sheet 18,000 to 30,000 years ago. Deposits are reported to be over $25 \mathrm{~m}$ in depth. Measured radon concentrations at a depth of $1 m$ into the soil around house ESP108C were about $500 \mathrm{pCi} / \mathrm{l}$. Ine radon concentration at the basement Hoor depth of 2 $m$ into the soil is estimated to be $C_{\infty}=700 \mathrm{pCi} / /$ (Tu86).

The house has a finished basement with a total floor area of $340 \mathrm{~m}^{2}$, basement and first floor ceiling heights of $\mathbf{2 . 3} \mathrm{m}$, and an interior occupied volume of $787 \mathrm{~m}^{3}$. Blower door measurements on three different occasions gave an average effective leakage area of $981 \mathrm{~cm}^{2}$. The infiltration rate is calculated using the $L B L$ Model (Sh80), and the important physical characteristics of the house are shown in. Table 5. A $10 \mathrm{~m}$ weather tower was installed at the 


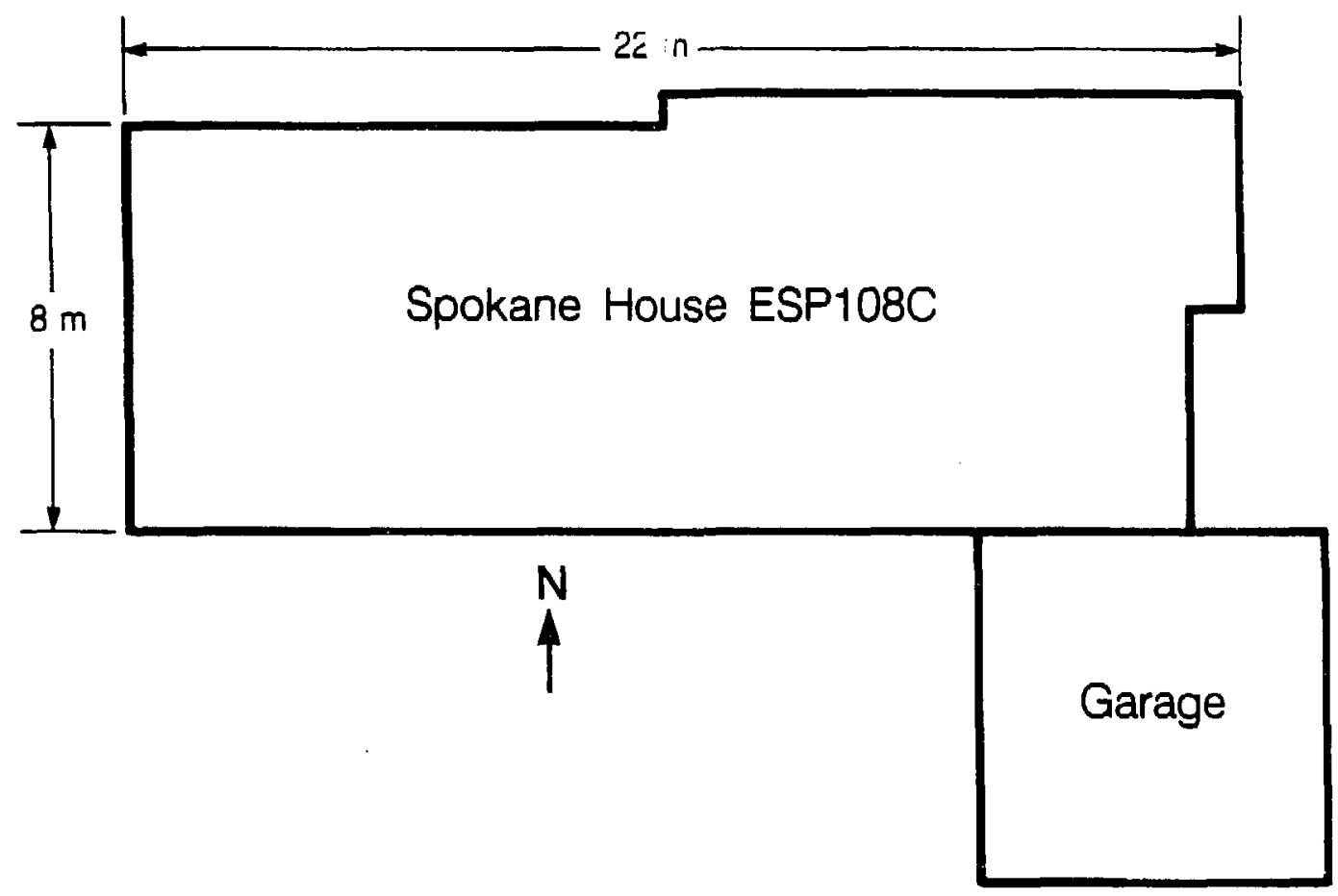

XBL 868-9232

Figure 17. Plan view of the Spokane, WA bouse which has a basement substructure. 
Table 5 Physical characteristics of the Spokane, WA, and the Portland, OR house used in the sample calculations.

\begin{tabular}{|c|c|c|c|}
\hline \multicolumn{4}{|c|}{$\begin{array}{l}\text { Physical Characteristics of Houses } \\
\text { used in the Sample Calculations }\end{array}$} \\
\hline Parameter & Units & Spokane House & Portland House \\
\hline Substructure Type & - & Basement & Crawl Space \\
\hline House Identifler & - & ESP108C & $\mathrm{P}-\mathrm{C}$ \\
\hline Floor Area & $m^{2}$ & 340 & 107 \\
\hline Ceiling Height & $m$ & 2.3 & 2.5 \\
\hline Basement Height & $m$ & 2.3 & - \\
\hline Volume & $m^{s}$ & 787 & 262 \\
\hline Leaknge Ares, ELA & $\mathrm{cm}^{2}$ & 981 & 455 \\
\hline After House Doetor $E L A_{D S}$ & $\mathrm{~cm}^{8}$ & 735 & 340 \\
\hline Floor Leakage Area, $E L A$, & $\mathrm{cm}^{2}$ & - & 153 \\
\hline After House Doctor $E L A, D_{n}$ & $\mathrm{~cm}^{2}$ & - & 115 \\
\hline Exhaust Air Flow Rate & $m^{s} / h r$ & 300 & 150 \\
\hline Terrain Claas & - & 3 & 3.5 \\
\hline Terrain Factor, $L_{1}$ & - & 0.87 & 0.86 \\
\hline Shielding Class & - & 3 & 2.75 \\
\hline Shielding Coefficient & - & 0.24 & 0.25 \\
\hline Reduced Wind Parameter & - & 0.145 & 0.149 \\
\hline Crawl Space Height & $m$ & - & 0.7 \\
\hline \# House Sides Vented & $=$ & - & 3 \\
\hline Vents/Side & - & 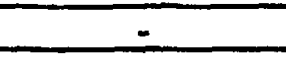 & 2 \\
\hline Typical Vent Area & $\mathrm{cm}^{*}$ & - & 900 \\
\hline Total Vent Area & $m^{2}$ & $=$ & .0 .54 \\
\hline
\end{tabular}


house site for accurate measurement of the local wind speed. The typical prevailing wind direction is westerly, so the average pressure coefficients for the windward and leeward sides of the building are assumed to be 1.0 and -0.3 respectively. Using these pressure coefficients, and an enveiope permeability ratio of $E P R=0.93$, gives an interior pressure coefficient from Figure 3 of $\Psi=-0.23$ and a reduced interior pressure coefficient, from Equation (2.14), of

$$
c_{i}=\Psi f_{t}^{2}=-c .23(0.87)^{2}=-0.19
$$

The comparison between measured and calculated values is made for two periods covering 6 days in the Fall and Winter of 1985 . Measured weather data is used to calculate the pressure driven flow of soil gas into the house. The stack and wind components of the floor pressure in the basement, $\Delta P_{f}$, are calculated using Equations (2.5) and (2.15) given in Chapter 2. Equation (3.21) is used to calculate the soil gas flow rate into the basement and is repeated here

$$
Q=\frac{300 L \Delta P_{f}}{\mu}\left[\frac{C_{f} L_{1}}{t^{3}}+\frac{1}{12 \pi k} \cosh ^{-1}\left[\frac{2 z}{t}\right]\right]^{-1}\left(m^{3} / h r\right)
$$

The indoor radon concentration is calculated using

$$
R n_{i}=\frac{\sigma_{f}}{\lambda_{1}}+R n_{0}
$$

where $R_{n}:=$ indoor radon concentration $(p C i / \eta), \lambda_{v}=$ ventilation rate, air changes per hour $\left(h r^{-1}\right), R_{n_{0}}=$ outdoor radon concentration $\approx 0.25(p C i / D$, and the flow of radon from the soil into the house, $\sigma_{f}$, is given by

$$
\sigma_{f}=1000\left[Q C_{\infty}\right](p C i / h r)
$$

where $Q=$ soil gas flow rate $(/ / h r)$. Table 6 shows the weather data, calculated soil gas entry rate, and measured vs. calculated values of indoor radon concentration for two 
Table 6. Basement House, Spoikane, WA. Measured vs. Calculated Values of Indoor Radon Concentration, Rn $\mathrm{n}_{\mathrm{i}}$. All values in the above table are calculated except wind speed, indoor-outdoor temperature differences, $\Delta T$, and indoor radnn concentration, $R n_{i, \text { meap }}$. The value $\Delta \mathbf{R n}_{\mathrm{i}}$ is the percentage difference between measured and calculated indoor radon concentrations, $\Delta \mathbf{P}_{t}$ is the toor underpressure, and $\sigma_{t, c a l c}$ is the calculated radon entry rate.

\begin{tabular}{|c|c|c|c|c|c|c|c|c|c|}
\hline \multicolumn{10}{|c|}{$\begin{array}{l}\text { Basement House, Spokane, WA } \\
\text { Calculated Indoor Radon Concentration, } R n_{1}\end{array}$} \\
\hline \multicolumn{10}{|c|}{ Calculated for a $5 \mathrm{~mm}$ Wall-Floor Gap } \\
\hline \multirow{2}{*}{ Dete } & Wind & $\Delta T$ & ACH & $\Delta P_{r}$ & Soil Gas & $\sigma_{\text {r,eale }}$ & $\mathrm{Rn}_{\mathrm{i}, \mathrm{eale}}$ & $\mathbf{R n}_{\mathrm{i}, \mathrm{mex}}$ & $\Delta R n_{i}$ \\
\hline & $m / s$ & $C$ & $h_{r}^{-1}$ & $P_{a}$ & $m^{s} / h r$ & $p C_{i} / 1-h r$ & $p C \mathrm{i} / \mathrm{l}$ & $p C i / l$ & $\%$ \\
\hline $10 / 28 / 8 E$ & 2.79 & 16.5 & 0.38 & -3.27 & 3.99 & $3.5 \mathrm{~A}$ & 10.0 & 8.25 & +21 \\
\hline $10 / 20 / 85$ & 0.41 & 20.2 & 0.35 & -2.88 & $3.5:$ & 3.12 & 9.2 & 15.63 & -41 \\
\hline $10 / 30 / 85$ & 1.89 & 19.3 & 0.37 & -3.16 & 3.85 & $\$ .42$ & 9.7 & $\$ 3.35$ & -27 \\
\hline $10 / 31 / 85$ & 1.33 & 21.1 & 0.37 & -3.20 & 3.90 & $\mathbf{3 . 4 7}$ & 9.7 & 10.68 & -9 \\
\hline $11 / 01 / 85$ & 2.79 & 16.6 & 0.38 & -3.28 & 4.01 & 3.57 & 10.0 & 11.04 & -9 \\
\hline $11 / 02 / 86$ & 1.52 & 13.8 & 0.31 & -2.23 & 2.72 & 2.42 & 8.2 & 6.75 & +21 \\
\hline Average & 1.79 & 17.9 & 0.39 & -3.00 & 3.66 & 3.26 & 0.5 & 10.95 & -13 \\
\hline $12 / 13 / 85$ & 0.13 & 35.8 & B.47 & -5.08 & 6.20 & 5.51 & 12.1 & 14.97 & -19 \\
\hline $12 / 14 / 85$ & 0.05 & 36.7 & 0.47 & -5.21 & 6.35 & 5.65 & 12.2 & 15.69 & -22 \\
\hline $12 / 15 / 85$ & 0.10 & 32.5 & 0.44 & -4.61 & 5.63 & 5.01 & 11.5 & 1580 & -27 \\
\hline $12 / 10 / 85$ & 0.02 & 32.0 & 0.44 & -4.54 & 5.54 & 4.93 & 11.4 & 14.74 & -23 \\
\hline $12 / 17 / 85$ & 0.04 & 32.2 & 0.44 & -4.56 & 5.57 & 4.95 & 11.5 & 15.60 & -26 \\
\hline $12 / 18 / 85$ & 0.04 & 32.0 & 0.44 & -4.54 & 5.54 & 4.93 & 11.4 & 14.60 & -22 \\
\hline Average & 0.06 & 33.5 & 0.45 & -4.76 & 5.81 & 5.16 & 11.7 & 15.23 & -23 \\
\hline
\end{tabular}


separate weeks in November and December 1985 respectively. Figures 18 and 19 show the data from Table 6 in graphical iorm. Both Figures show a clear relationship between soil gas entry and infiltration (air changes per hour, ACH). This is expected since both are calculated from the measured weather data of wind speed and indoor-outdoor temperature differences $(\Delta T)$. There is almost zero wind speed for the December period, as shown in Figure 19, so only the stack effect acts to drive $A C H$ and soil gas entry. The measured indoor radon concentrations for November show substantial variability. The wind appears to have the effect of depleting the soil of radon on windy days and reducing the radon entry and indoor radon concentration. This effect of the wind causing low indoor radon concentrations, and vice versa, is also seen in Figure 20 during a week of continuous data for house ESP111 from the same study and almost the same period.

As discussed in Chapter 2, Nazarof has suggested that wind pressure disturbances in highly permeable soil take about a minute to propagate, resulting in depletion of radon in the soil. This eflect is seen in Figure 20 where a rapid increase in wind speed produces a rapid decrease in indoor radon concentration for house ESP111 which is similar soil characteristics as house ESP108C. The model assumes constant radon concentration in the soil and does not account for variable wind pressures on the soil surface that would deplete the soil of radon. The measured and calculated indoor radon concentrations for December aren't influenced at all by wind, and here there is generally good agreement between the model and the measured data, since both follow the general trend of $\triangle T$ and $A C H$.

It was expected that the model would overestimate the indoor radon conceniration since a value of $C_{\infty}=700 \mathrm{pCi} / \mathrm{l}$ was used in the calculations instead of the measured soil gas radon concentration at $1 \mathrm{~m}$ of $C_{1 \mathrm{~m}}=500 \mathrm{pCi} / \mathrm{l}$. However, the 25\% underestimate of calculated vs. measured indoor radon concentration is quite good given the uncertainties in handling the wall-floor shrinkage gap and the simplifications inherent in the 2-d model. 


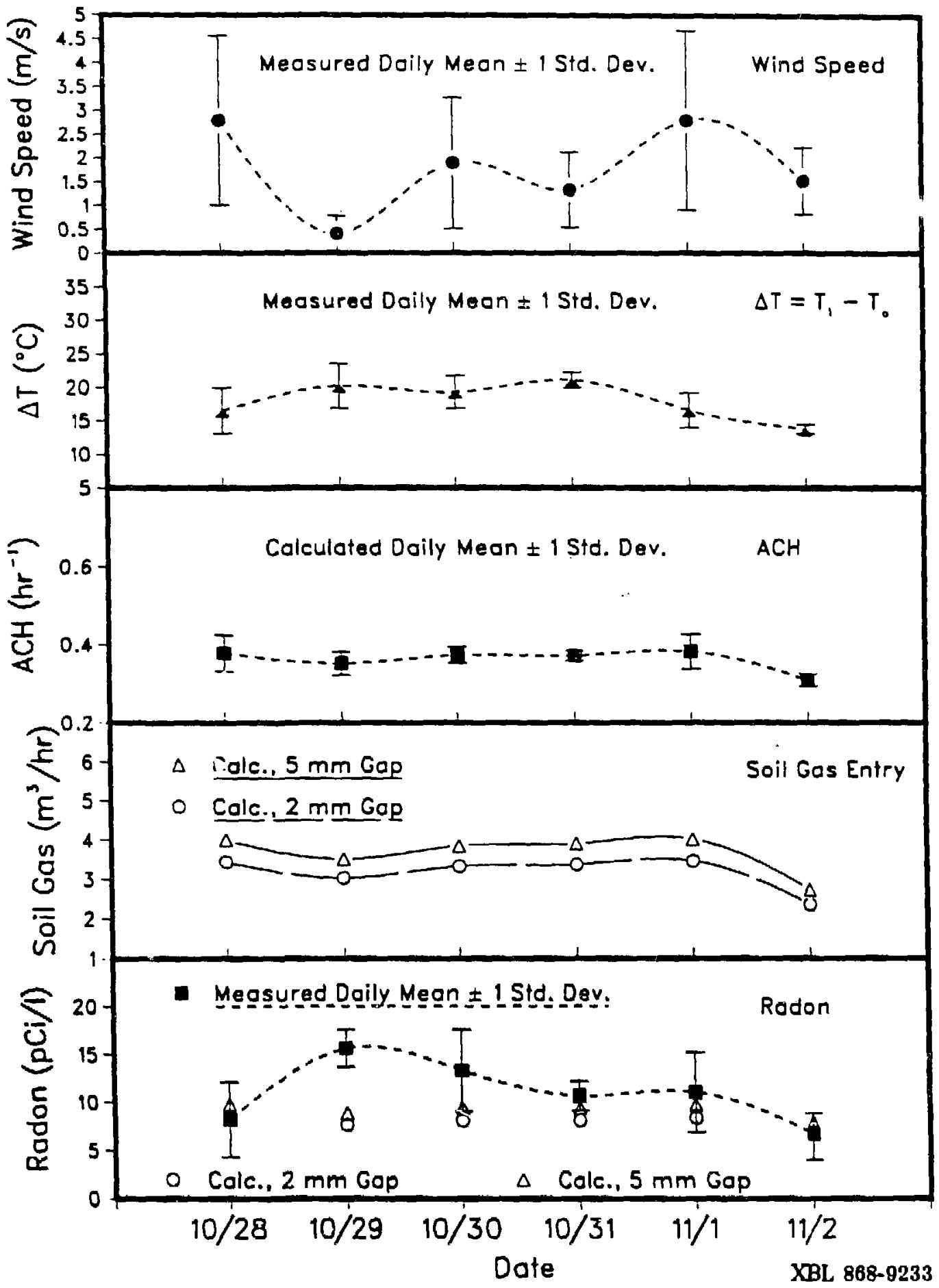

Figure 18. Spokane, WA house with basement (ESP108C), measured vs. calculated indoor radon concentrations, and calculated soil gas entry rates for the period of October 28 through Novemeber 2, 1985. 


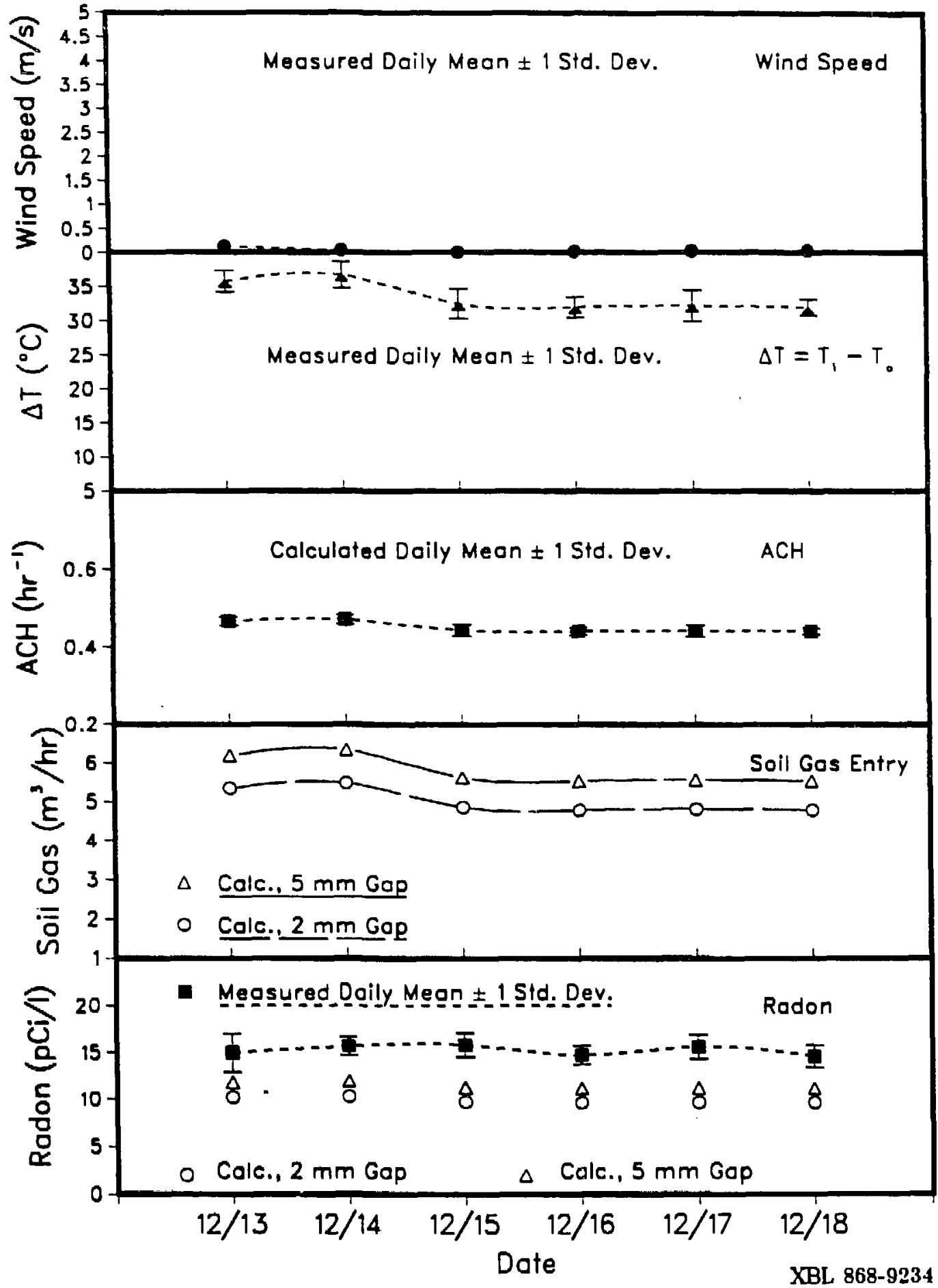

Figure 19. Spokane, WA house with basement (ESP108C), measured vs. calculated indoor radon concentrations, and calculated soil gas entry rates for the period of December 13 through December 18, 1985. 


\section{RADON - WIND SPEED - TEMPERATURE DIFFERENCE}

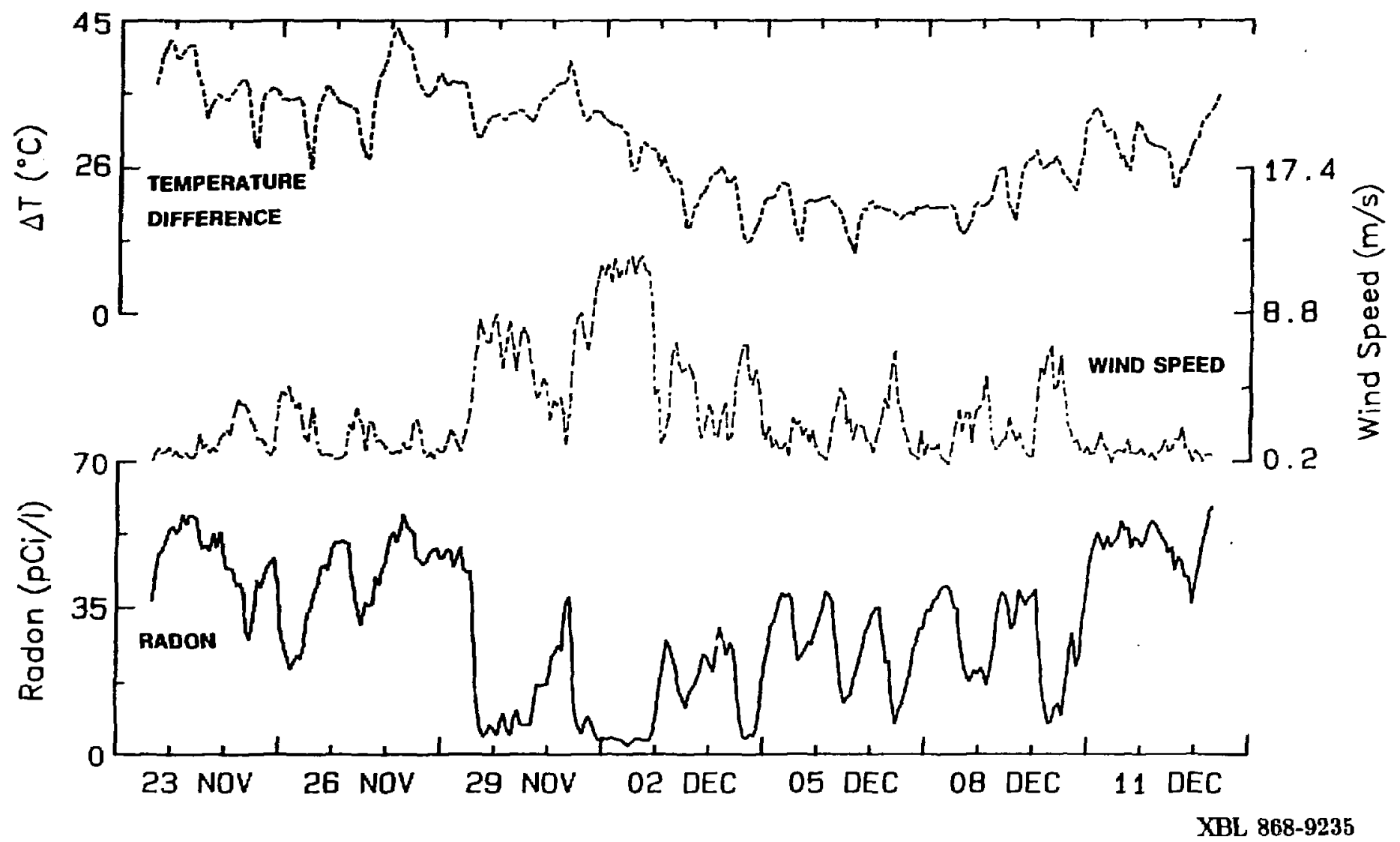

Figure 20. Spokane, WA house (ESP111), Measured data from a period from November 23 through December $14,1985$. 
Better methods of handling various gap or crack geometries would definitely improve the model. These might include a method of calculating an equivalent resistance to the flow of soil gas through networks of gaps or cracks in a basement substructure similar to mathematical techniques used for finding an equivalent resistance for the flow of electrical current through parallel resistors. Validation studies on houses having a wider range of soil types around the basement substructure are necessary in order to assess the general applicability of the model. The limited data base that currently exists on radon entry into houses with basements is incomplete with respect to all of the parameters that are needed to validate a simplified model. 


\section{CHAPTER V}

\section{SIMPLE MODEL OF RADON ENTRY INTO HOUSES FROM CRAWL SPACES}

Estimating radon entry rates and indoor radon concentrations in houses with crawl spaces may be simplified by breaking the problem into two parts. The first part involves looking only at the flow of air, and hence radon gas, from the crawl space into the house. The second part involves estimating the radon concentration in the crawl space. The radon concentration in the crawl space at any time depends on both the radon flux entering the crawl space from the soil and the crawl space ventilation rate.

There has been very little, if any, work done on estimating crawl space ventilation rates. Crawl spaces are unheated so the natural ventilation rate is dependent mainly on wind speed and the amount of air that passes from the crawl space into the house. The flux of radon from the soil into the crawl space is also dependent on the wind speed and direction, but more important is the soil permeability. Like the basement problem, the pressure difference between the crawl space and the soil/air interface outside the house determines the flow of soil gas and radon into the crawl space according to Darcy's Law. For the purpose of this paper only the first part of the problem, namely that of estimating the flow of radon from the crawl space into the house, is examined.

The flow of air trom the crawl space into the house depends on the difference between the house floor level pressure and the pressure in the crawl space just below the floor. It also depends on the permeability or leakage area of the floor. The house floor level pressure may be estimated using the methods outlined in Chapter 2 and repeated here as: 


$$
\begin{gathered}
\Delta P_{l}=\Delta P_{\text {A }}+\Delta P_{\bullet}+\Delta P_{\text {smv }} \text {, or } \\
\Delta P_{f}=-\rho g \frac{\Delta T}{T}(z-N P L)-c_{i} \rho \frac{v^{2}}{2}-\frac{\rho}{2}\left[\frac{Q_{\text {nm }}}{E L A}\right]^{2}
\end{gathered}
$$

where all variables are as described earlier in Chapter 2.

The crawl space pressure may be estimated using the methods outlined in Chapter 2, and the expression for the wind induced pressure is:

$$
\Delta P_{\mathrm{ce}}=c_{\mathrm{i}, \mathrm{e \bullet}}\left[\rho \frac{v^{2}}{2}\right](P \mathrm{a})
$$

Note that the sign of the crawl space reduced interior pressure coefficient, $c_{i, c}$, depends on the magnitude of the envelope permeabilty ratio, EPR, discussed in Chapter 2. As was showr in Chapter 2, the wind direction is only important for calculating the wind induced interior pressure for a vented crawl space. For houses with unvented crawl spaces the wind acts amost equally on both the house and the unvented crawl space, effectively canceling out any wind induced pressure at the floor, and only the stack effect and unbalanced mechanical ventilation ( $u m v$ ) induced pressure differences act to drive crawl space air and hence radon gas into the house.

Once the floor pressure difference, $\Delta P_{f}$, and the crawl space pressure difference, $\Delta P_{c o}$, are estimated for the given weather conditions, the radon entry rate may be predieted from:

$$
\sigma_{l}=\frac{3600}{V o l} R n_{c l} E L A_{f}\left[\frac{2\left|\Delta P_{/}-c l\right|}{\rho}\right]^{1 / 2}\left(p C_{i} / /-h r\right)
$$

where $\sigma_{l}=$ convective radon entry rate from the crawl space $(p C i / l-h r), \quad V o l=$ house occupied volume $\left(m^{3}\right), R n_{e \varepsilon}=$ radon concentration in the crawl space $(p C i / \eta, E L A f=$ effective leakage area of the floor $\left(\mathrm{m}^{2}\right), \Delta P_{t-c e}=$ pressure difference across the floor of the 
house $(P a)$, and all other variables are as previously described. Note that if $\Delta P_{f-c a}$ is negative the flow of air will be into the house, and if it is positive the flow of air is into the crawl space. The effective leakage area of the floor can be estimated by area weighting the total effective leakage area of the house measured using a blower door. The indoor concentration of radon in the house can be calculated using Equation (2.2) in Chapter 2.

\section{Measured va. Calculated Radon Entry into Houses from Crawl Spaces}

The simple analytical model of radon entry into houses from crawl spaces is based on the assumptions that

1) the house floor is well insulated, such that the crawl space and outdoor temperatures are equal, and

2) the crawl space radon concentration is known or can be estimated from measured data.

Nazarof and Doyle did a study of radon entry into houses with crawl spaces and monitored a house in Portland, Oregon that meets the above assumptions (Na83). A plan view of the Portland house is shown in Figure 21. The house was monitored during the months of March and April of 1983 . The house has an attached garage and so the crawl space is vented on only 3 sides. Each side has 2 vents approximately $900 \mathrm{~cm}^{2}$ placed midway up the $0.7 \mathrm{~m}$ crawl space walls. Other important house characteristics are shown in Table 5.

The dirt floor of the crawl space was covered with two $0.015 \mathrm{~cm}$ polyethylene groundsheets. There were small gaps between the groundsheet and the foundation walls, and posts around which the groundsheet was loosely gathered. As was noted by Nazaroff, the presence of the groundsheet should have reduced the diffusive radon flux by almost $80 \%$, compared to exposed soil. However, the radon concentrations in the crawl space were greater than levels expected from difiusinn from exposed soil alone indicating that the radon 


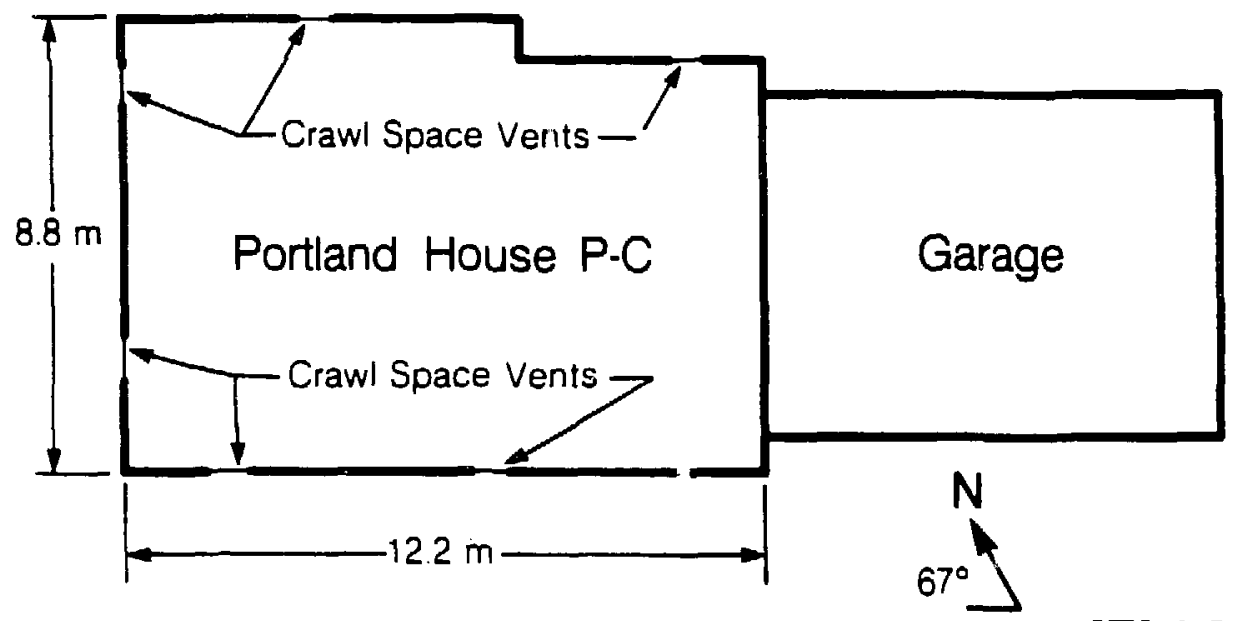

XBL 867-11635

Figure 21. Plan view of the Portland, OR house which has a vented crawl space substructure. 
flux from the soil was pressure driven and the presence of the groundsheet made little difference.

Sample calculations for the Portland house are done using measured weather data and crawl space radon concentrations for 3 periods when the crawl space vents were open and 2 periods when the vents were sealed. The prevailing wind direction in Portland for this time of year is northwest, and from Figure 21, the orientation of the floor plan is such that a $90^{\circ}$ wind direction should be used for calculating the wind induced interior pressure. The methods outlined in Chapter 2 are used for calculating the stack and wind induced pressures. The envelope permeability ratios are $E P R_{i}=0.87$ and $E P R_{c,}=0.66$, giving values of $\Psi=-0.21$ and $\Psi=0.04$ for the house interior and crawl space respectively. The results of the calculations are shown in Table $\overline{7}$.

Table 7 shows that the calculated radon entry rates are from $26 \%$ to $83 \%$ higher than the values estimated by Nazaroff $\left(\sigma_{t, \mathrm{~N} 2 \mathrm{sg}}\right)$. However, the calculated house radon concentration, $\mathrm{Rn}_{\mathrm{i}, \text { eale }}$, is only $10 \%$ to $68 \%$ higher than than the values measured by Nazaroff $\left(R n_{i, m e s}\right)$. Nazarofis estimate of the radon entry rate was obtained using a mass balance based on measured radon concentrations in the house and crawl space and the calculated infiltration rate using the $L B L$ Model. The outdoor concentration was below the detectable limit of $0.2 \mathrm{pCi} / /$ so a value of $R n_{0}=0.1 \mathrm{p} C i / /$ was assumed. Since measured crawl space radon concentrations, $\mathrm{Rn}_{\mathrm{a} \text {, }}$ were used in the calculations, either the foor underpressure, $\Delta P_{f}$, or the floor effective leakage area, $E L A_{f}$, must have been overestimated. As was stated above, an area weighted value of $E L A$, was used in the calculations, and Nazaroff also used an area weighted value for $E L A_{f}$, so the overestimate in the calculations could be due to overestimates of $\Delta P$, , or in errors by Nazaroff in measuring the radon concentrations, or in calculating infiltration rates. The calculated wind induced pressures could easily be high since the pressure : oefficients used in the model do not take into account the effect 
Table 7. Crawl Space House, Portland, OR. Measured vs. Calculated Values of Indoor Radon Concentration, Rn in the table are calculated except wind speed, indoor-outdoor temperature differences, $\Delta T$, and crawl space radon concentration, $R_{n_{a}}$. The value $\sigma_{f, N_{2} 83}$ is the calculated radon entry rate by Nazaroff (Na83). The value $\Delta \mathrm{Rn}_{\mathrm{i}}$ is the percentage difference between measured and calculated house radon concentrations and $\Delta \mathrm{P}_{\mathrm{f}-\mathrm{cs}}$ is the pressure difference across the floor of the house.

\begin{tabular}{|c|c|c|c|c|c|c|c|c|c|c|}
\hline \multicolumn{11}{|c|}{$\begin{array}{l}\text { Crawl Space House, Portland, OR } \\
\text { d va. Caleulated Indoor Radon Concentration, Rn, }\end{array}$} \\
\hline \multicolumn{11}{|c|}{ Vents Open } \\
\hline \multirow{2}{*}{ Date } & Wind & $\Delta \mathbf{T}$ & ACH & $\mathbf{R} \mathbf{n}_{a}$ & $\Delta P_{\text {I-a }}$ & $\sigma_{t, c a l c}$ & $\sigma_{t, \mathrm{~N} \perp 83}$ & $\mathbf{R n}_{\mathbf{i}_{,}, \mathbf{c} \mathbf{u l t}}$ & $\mathbf{R n}_{\mathbf{i}, \text { mea }}$ & $\Delta \mathrm{Rn}_{\mathrm{i}}$ \\
\hline & $m / s$ & $C$ & $h r^{-1}$ & $p C i / I$ & $\mathrm{~Pa}$ & $p C i / 1-h r$ & $p C_{i} / l-h r$ & $p C i / l$ & $p C i / 1$ & $\%$ \\
\hline $3 / 27$ to $4 / 01 / 83$ & 1.8 & 9.4 & 0.35 & 3.0 & -0.87 & 0.76 & 0.6 & 2.2 & 2.0 & +10 \\
\hline $4 / 02$ to $4 / 07 / 83$ & 1.4 & 9.1 & 0.30 & 1.6 & -0.68 & 0,36 & 0.2 & 1.2 & 0.8 & +50 \\
\hline $4 / 08$ to $4 / 14 / 83$ & 1.3 & 12.4 & 0.34 & 1.5 & -0.81 & 0.37 & 0.3 & 1.0 & 0.8 & +11 \\
\hline Average & 1.5 & 10.3 & 0.33 & 2.0 & -0.79 & 0.50 & 0.4 & 1.47 & 1.2 & +22 \\
\hline \multicolumn{11}{|c|}{ Vents Sesled } \\
\hline \multirow{2}{*}{ Date } & Wind & $\Delta \mathrm{T}$ & $\mathrm{ACH}$ & $\mathbf{R n}_{\mathrm{es}}$ & $\Delta \mathbf{P}_{\mathrm{I}-\mathrm{es}}$ & $\sigma_{f, c a d e}$ & $\sigma_{1, \mathrm{~N}_{283}}$ & $\mathbf{R n}_{\mathbf{i}, \text { calte }}$ & $\mathrm{Rn}_{\mathrm{i}, \text { mess }}$ & $\Delta \mathbf{R n}_{\mathbf{i}}$ \\
\hline & $\mathrm{m} / \mathrm{s}$ & $C$ & $h r^{-1}$ & $p C i / l$ & $P a$ & $p C i / 1-h r$ & $p C i / l-h r$ & $p C_{i} / l$ & ${ }_{p} C_{i} / l$ & $\%$ \\
\hline $3 / 10$ to $3 / 17 / 83$ & 2.4 & 6.2 & 0.33 & 6.2 & -0.31 & 0.93 & 0.6 & 2.8 & 2.1 & +33 \\
\hline $3 / 18$ to $3 / 25 / 83$ & 1.3 & 8.9 & 0.30 & 6.1 & -0.44 & 1.1 & 0.6 & 3.7 & 2.2 & +68 \\
\hline Average & 1.8 & 7.5 & 0.31 & 6.1 & -0.38 & 1.0 & 0.6 & 3.25 & 2.2 & +48 \\
\hline
\end{tabular}


of local shielding. A nearby house and fence were located just a few feet away from two of the walls of the house, which would have dramatically affected the average pressure coefficients on these walls. More extensive wind tunnel studies on the wake effects of nearby buildings are necessary to estimate what affect such local shielding has on wind induced interior pressures.

The calculations for the case where the vents were sealed assumed the wind effect acted equally on both the crawl space and house interiors, and only the stack effect was used to calculate $\Delta P_{f}$. With only the stack effect acting, $\Delta P_{f}$ is about half that of the case with vents open. However, sealing the vents reduces the ventilation rate of the crawl space and almost triples the crawl space radon concentrations resulting in higher calculated values of radon entry and indoor radon concentrations. The measured data shows only 1.5 times higher radon concentrations in the house even though the indoor-outdoor temperature differences, $\Delta T$, and wind speed remain about the same as when the vents were open. I am not sure why this occurs and no specific reason is given by Nazaroff.

The model is quite good at sbowing how the effects of wind speed and $\Delta T$ produce a pressure difference across the floor, $\Delta P_{f}$, which drives the flow of air, and hence radon, from the crawl space into the house. It is encouraging to note that in this example the model overpredicted, on average, by no more than 50\%. Applying it to other houses and making comparisons to more measured data is necessary in order to determine the general applicability of the model. The model does not examine the relationship between floor pressure, $\Delta P_{f}$, and pressure driven flow of soil gas, and hence radon, into the crawl space. This interrelated phenomena is very important, and must be examined in more detail. Chapter 6 examines to what extent $\Delta P_{f}$, and radon entry, $\sigma_{f}$, are affected by the presence of an unbalanced exhaust mechanical ventilation system. 


\section{CHAPTER VI}

\section{THE EFFECT OF EXHAUST VENTILATION ON SOIL GAS ENTRY, RADON ENTRY, AND INDOOR RADON CONCENTRATIONS}

Mechanical exhaust ventilation or unbalanced mechanical ventilation (umv) systems draw air out of the house and produce a slight underpressure which may lead to increased radon entry. Understanding the amount of underpressurization that occurs and how it interacts with stack and wind induced pressure was discussed in Chapter 2. This chapter will discuss how the indoor radon concentration, in houses with basements or crawl spaces, . is affected by the presence of unbalanced mechanical ventilation. Example calculations are performed on the houses previously examined and also on bouses with a "tighter" building envelope. All calculations performed in this thapter use the following weather conditions:

1) indoor temperature, $T_{i}=20 \mathrm{C}$,

2) indoor-outdoor temperature difference, $\Delta T=20 \mathrm{~K}$, and

3) wind speed, $v=3 \mathrm{~m} / \mathrm{s}$.

These values represent typical winter conditinns for most northern climates in the United States.

The expression given for estimating floor underpressurization due to an unbalanced mechanical ventilaxion system was given in Chapter 2 and is repeated here

$$
\Delta P_{\mathrm{smv}}=\frac{\rho}{2}\left[\frac{Q_{\mathrm{umv}}}{E L A}\right]^{2}\left(P_{a}\right)
$$


This may be added to the stack and wind induced pressures as shown in Chafters 2 and 5 and repeated here

$$
\begin{gathered}
\Delta P_{J}=\Delta P_{\mathrm{J}}+\Delta P_{\mathrm{v}}+\Delta P_{\mathrm{umv}} \text {, or } \\
\Delta P_{J}=-\rho g \frac{\Delta T}{T}(z-N P L)-c_{i} \rho \frac{v^{2}}{2}-\frac{\rho}{2}\left[\frac{Q_{\mathrm{umv}}}{E L A}\right]^{2}(P a),
\end{gathered}
$$

where all variables se as described earlier.

Equation (2.17) shows that $\Delta P_{\mathrm{sm}}$ is inversely proportional to the square of the effective leakage area, ELA. In new "tighter" energy efincient houses the value of ELA may be quite small, ranging from $100 \mathrm{cs}^{2}$ to $250 \mathrm{~cm}^{2}$, for a typical house with a floor area of 140 $m^{2}\left(1500 f^{2}\right)$ (Gr83). With values of $E L A$ in this range, an exhaust veatilation system can produce significant underpressures depending on the magnitude of the exhaust air flow rate.

The underpressure caused by an exhaust syitem makes the ventilation rate almost independent of outside weather conditions. For this reason exhaust systems are designed to provide a minimum ventilation rate depending on the volume of the house. The Nordic Committee on Building Regulations (NKB81) recommends a minimum ventilation rate oi 0.50 air changes per hour (ACH) for residences, and the recently revised version of the ASHRAE 62 standard (Gr86) recommends a minimum ventilation rate of $15 \mathrm{c} / \mathrm{m} / \mathrm{person}$ or $0.35 \mathrm{ACH}$, whichever is larger. The exhaust air flow rates used in the example calculations for the basement and crawl space houses were selecte : _tve minimum ventilation rates close to these recommended lev...3. 


\section{Effect of Exhaust Ventilation in Houses with Basements}

The basement house, located in Spokane, WA, that was used in the previous example calculations, is used in this chapter to show what effect an exhaust ventilation system has on soil gas entry and indoor radon concentration. The floor plan of the house is shown in Figure 17, and the important characteristics of the house, that were discussed previously, are shown in Table 5 . Since the house plus basement has an interior volume of $787 \mathrm{~m}^{3}$, a value of $300 \mathrm{~m}^{3} / \mathrm{hr}$ is selected for the exhaust air flow rate.

Exhaust systems are mainly used in new construction, but it is conceivable that an exhaust system could be installed as a retrofit measure. If used in a retrofit, the effective leakage area, ELA, of the house would be reduced by approximately $25 \%$ using "housedoctoring" techniques (Di82). The original leakage area of this house was $981 \mathrm{~cm}^{2}$ so the retrofit $E L A$ would be $735 \mathrm{~cm}^{2}$. For new construction a value of $E L A=600 \mathrm{~cm}^{2}$ is assumed, and for "super-tight" congtruction a value of $E L A=240 \mathrm{~cm}^{2}$ is assumed. Thes values are used for all of the basement house example calculations.

\section{Effect of Exhaust Ventilation in the Spokane House with a Basement}

The wall-floor gap size might vary depending on construction techniques and type of concrete used, and efforts might be made to seal any wall-floor gaps or other cracks. For this reason calculations are performed using gap sizes of 5,1 , and $0.5 \mathrm{~mm}$. The $5 \mathrm{~mm}$ gap size is an upper limit for shrinkage with portland cement for an $8 \times 22 \mathrm{~m}^{2}$ floor area.

The results of the calculations for variable gap sizes are shown in Table 8 and Figure 22. The Bonneville Power Administration (BPA) action level of $5 p C i / l$ is also shown in Figure 22. This action level is slightly lower than the National Council on Radiation Protection 
Table 8. The Effect of Exhaust Ventilation, $\mathbf{Q}_{\text {umv }}$, gap size, $t_{\text {gap }}$, and effective leakage area, ELA, on soil gas entry and indoor radon concentration, $\mathbf{R n}_{\mathrm{i}}$, in a house with a basement. The value $\Delta R_{n_{1}}$ is the percentage difference between indoor radon concentrations for the base case and the specified conditions. The value $\Delta \mathbf{R}_{\mathbf{n}_{\mathrm{i}, N E}}$ indicates the impact of adding exhaust ventilation with no change in any other parameters. The values for the air change rate with no exhaust ventilation are $0.398,0.298,0.162$, and $0.097 \mathrm{hr}^{-1}$ for ELA's of $981,735,600$, and $240 \mathrm{~cm}^{2}$ respectively. All calculations use $T_{i}=20 \mathrm{C}, \Delta T=20 \mathrm{~K}$, and wind speed, $v=3 \mathrm{ni} / \mathrm{s}$. The soil parameters are $C_{\infty}=700 \mathrm{p} C \mathrm{i} / \mathrm{l}$, and $k=2.22 \times 10^{-6} \mathrm{~cm}^{2}$.

\begin{tabular}{|c|c|c|c|c|c|c|c|}
\hline \multicolumn{8}{|c|}{$\begin{array}{c}\text { Basement House, } \\
\text { Variable ELA and Wall-Floor Gap }\end{array}$} \\
\hline \multicolumn{6}{|c|}{ Bave Case, No Exhaust Ventilation, $t_{\text {oop }}=5 \mathrm{~mm}$} & \multicolumn{2}{|c|}{ No Exhaust (NE) } \\
\hline $\mathbf{E L A}$ & ACH & $\Delta \mathbf{P}_{\mathbf{P}}$ & Soil Gar Entry & $\mathbf{R n}_{\mathbf{1}}$ & $\Delta \mathbf{R}_{\mathbf{n}}$ & $\mathbf{R n}_{\mathbf{l , N E}}$ & $\Delta \mathbf{R n}_{\mathbf{1}, \mathbf{N E}}$ \\
\hline $\mathrm{cm}^{2}$ & $h r^{-1}$ & $P a$ & $m^{3} / h r$ & $p C i / l$ & $\%$ & $p C i / l$ & $\%$ \\
\hline 981 & 0.398 & -3.91 & 4.70 & 10.7 & 0 & - & - \\
\hline \multicolumn{6}{|c|}{ Effect of Exhaust Ventilation, $Q_{u m v}=300 \mathrm{~m}^{3} / \mathrm{hr}$} & \multirow{2}{*}{\multicolumn{2}{|c|}{$\frac{\text { No Exhaust (NE) }}{t_{\text {gap }}=5 \mathrm{~mm}}$}} \\
\hline \multicolumn{6}{|c|}{$t_{\text {ocp }}=5 \mathrm{~mm}$} & & \\
\hline 881 & 0.551 & -4.35 & 5.30 & 8.8 & -18 & 10.7 & -18 \\
\hline 735 & 0.484 & -4.68 & 5.71 & 10.7 & 0 & 14.2 & -25 \\
\hline 600 & 0.452 & -5.07 & 6.18 & 12.4 & +16 & 17.4 & -29 \\
\hline 240 & 0.393 & -11.17 & 13.62 & 31.0 & +190 & 43.1 & -28 \\
\hline & & & $=1 \mathrm{~mm}$ & & & \multicolumn{2}{|c|}{$t_{\text {pap }}=1 \mathrm{~mm}$} \\
\hline 981 & 0.551 & -4.35 & 3.78 & 6.4 & -40 & 7.8 & -18 \\
\hline 735 & 0.484 & -4.68 & 4.08 & 7.7 & -28 & 10.4 & -28 \\
\hline 600 & 0.452 & -5.07 & 5.07 & 8.9 & -17 & 12.8 & -29 \\
\hline 240 & 0.383 & -11.17 & 11.17 & 22.2 & +107 & 31.2 & -29 \\
\hline \multicolumn{6}{|c|}{$t_{\text {osp }}=0.5 \mathrm{~mm}$} & \multicolumn{2}{|c|}{$t_{\text {gap }}=5 \mathrm{~mm}$} \\
\hline 981 & 0.551 & -4.35 & 1.51 & 2.7 & -75 & 3.3 & -18 \\
\hline 735 & 0.484 & -4.68 & 1.63 & 3.2 & -70 & 4.3 & -26 \\
\hline 600 & 0.452 & -5.07 & 1.76 & 3.7 & -65 & 5.2 & -29 \\
\hline 240 & 0.393 & -11.17 & 3.88 & 9.0 & -18 & 12.6 & -29 \\
\hline
\end{tabular}




\section{Basement House, Spokane, WA.}

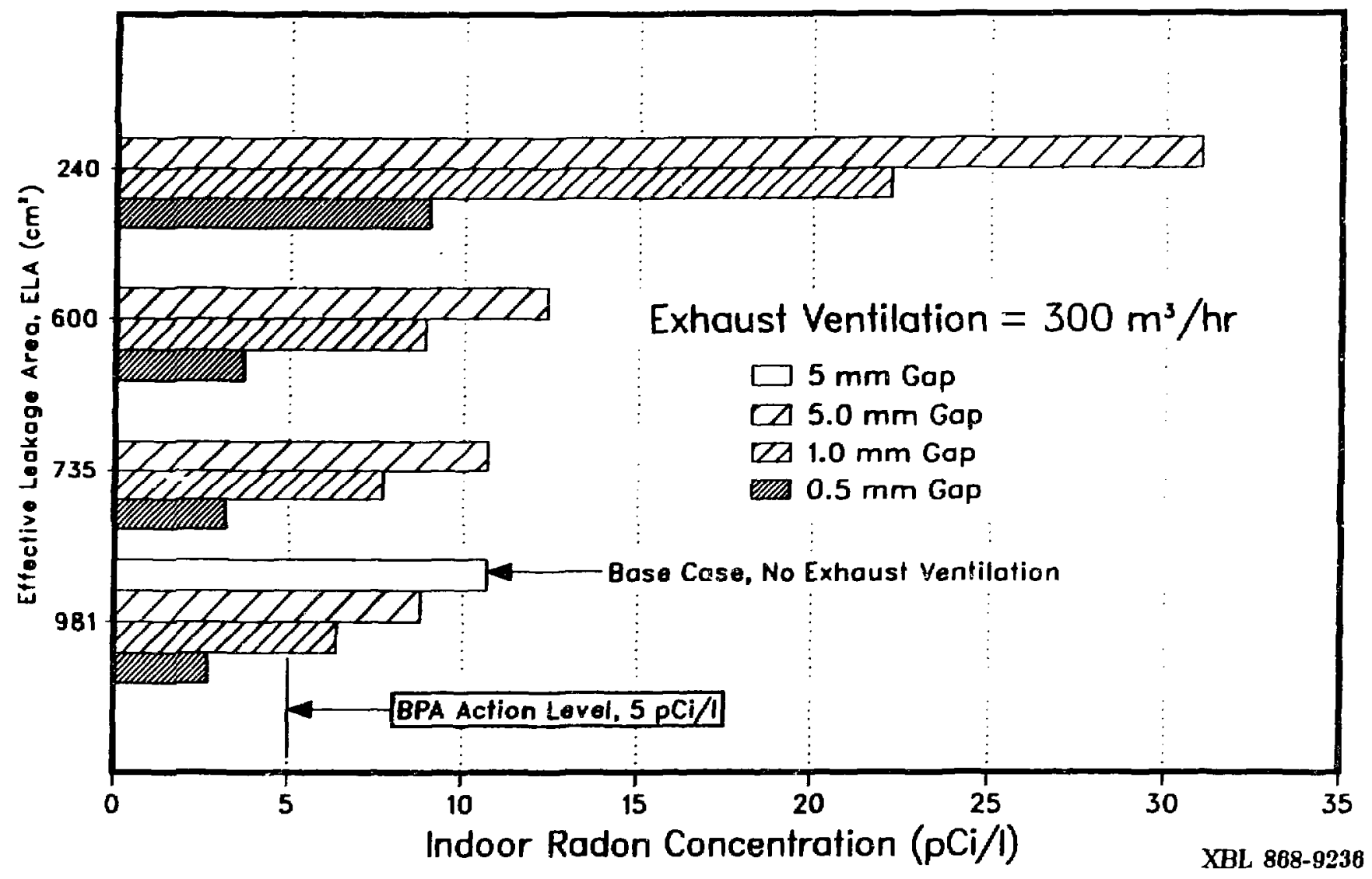

Figure 22. The effect of exhaust ventilation, effective leakage area, and wall-floor gap width on indoor radon concentration in a house with a basement. All calculations were performed using soil permeability of $k=2.22 \times 10^{-6} \mathrm{~cm}^{2}$ and soil gas radon concentration of $C_{\infty}=700 \mathrm{pCi} / \mathrm{l}$. 
guideline of $8 p C i / l$ and higher than the ASHRAE recommendation of $2 \mathrm{pCi} / \mathrm{l}$. The results clearly show the effect of increasing floor underpressure, $\Delta P_{f}$, with decreasing $E L A$. The floor underpressure increases to a maximum value of -11 Pa for the "tightest" ELA value of $240 \mathrm{~cm}^{2}$ which is almost three times greater than the floor underpressure with no exhaust ventilation. This increase in floor underprassure which causes an increase in radon entry is offset by the increased ventilation rate produced by the exhaust system. This is shown in Table 8 where simply adding $300 \mathrm{~m}^{3} / \mathrm{hr}_{\mathrm{r}}$ of exhaust ventilation, without changing any of the other parameters, increasea the ventilation rate from $38 \%$ to $300 \%$ and reduces the indoor radon concentration from $18 \%$ to $29 \%$ below the levels expected for the same house without the system. Tightening the house by $25 \%$, to an $E L A$ of $735 \mathrm{~cm}^{2}$, and adding $300 \mathrm{~m}^{3} / \mathrm{hr}$ of exhaust ventilation produces the same indsor radon concentration as the base case. of 10.7 pCi/l. Further "tightening" of the building envelope increases the indoor radon concentration unless an effort is made to seal the wall-floor gap. The exhaust system is only effective at reducing indoor radon concentrations below the BPA action level when the wall-floor gap is reduced to $0.5 \mathrm{~mm}$ and the effective leakage area is $600 \mathrm{~cm}^{2}$ or greater. If no effort is made to reduce the wall-floor gap the indoor radon levels equal or exceed the base case when the building envelope is "tightened" and an exhaust ventilation system is installed.

\section{Exhaust Ventilation in Basement Houses with Other Soil Conditions}

In order to examine how exhaust systems affect radon entry in locations other than Spokane, WA, calculations are performed using different soil permeabilities, $k$, and soil gas radon concentrations, $C_{\infty}$. Soil permeability can vary by several orders of magnitude as shown in Figure 23. Silty and clay-like soils have very low permeability $\left(<10^{-10} \mathrm{~cm}^{2}\right)$, and for these soils the dominant transport mechanism for radon is molecular diffusion. For houses built in regions with silty or clay-like soils, an exhaust ventilation system is unlikely to lead to unarceptable radon entry rates unless soil gas radon concentrations are very high. 


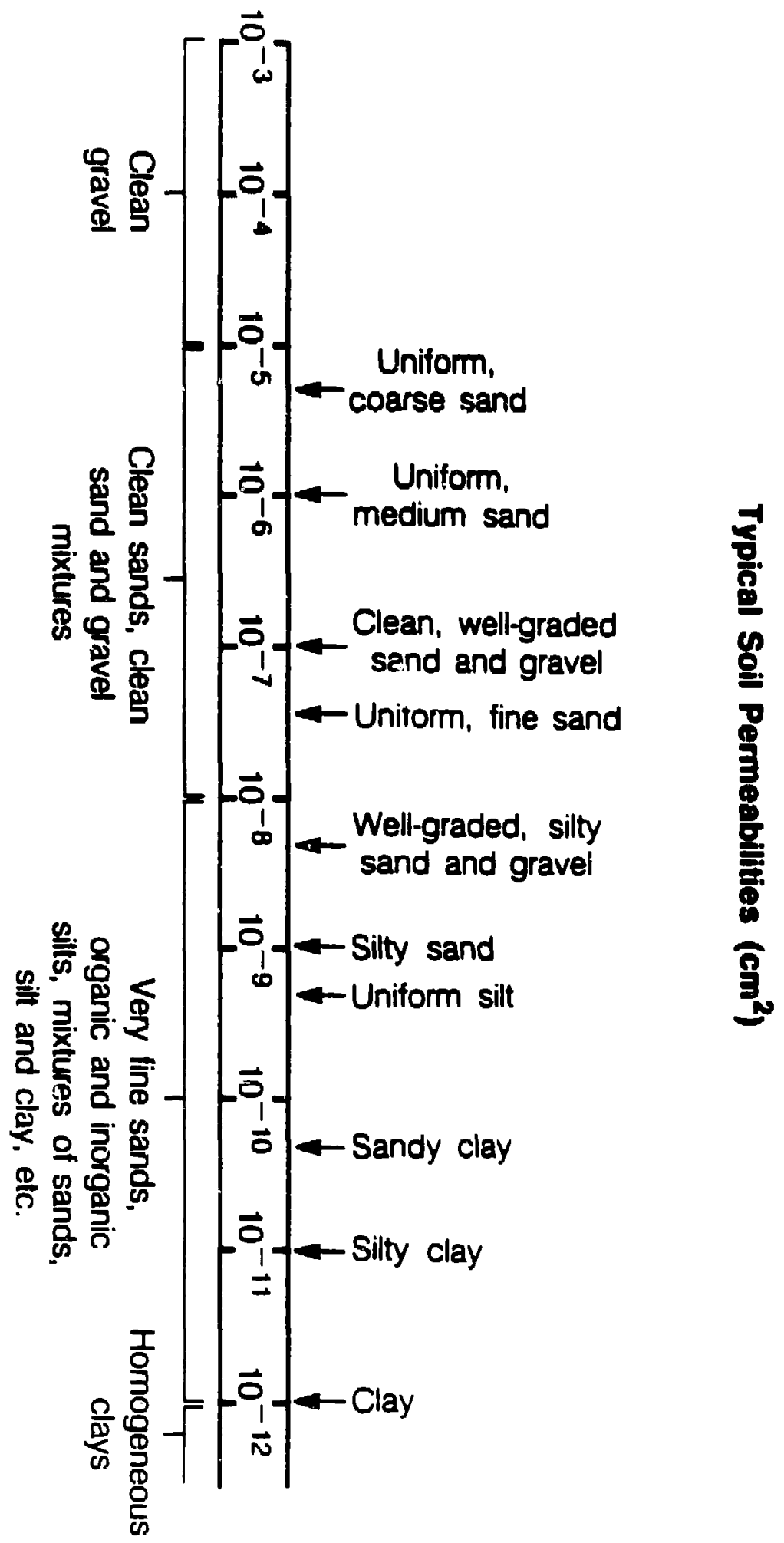


The range of soil permeabilities used for the calculations is from $10^{-5}$ to $10^{-8} \mathrm{~cm}^{2}$. Soil gas radon concentrations range from 200 to $6,000 \mathrm{pCi} / /(\mathrm{Ns} 84 \mathrm{~b})$, and the calculations use these values for an upper and lower limit. The base case soil gas radon concentration of $700 \mathrm{pCi} / \mathrm{l}$ is close to the average value of $540 \mathrm{pCi} / \mathrm{l}(\mathrm{Na} 4 \mathrm{~b})$. The calculations were performed using a wall-floor gap size of $5 \mathrm{~mm}$.

Table 9 shows the results of the calculations. It is evident from the table that the soil gas flow rate and indoor radon concentration are dramatically affected by variations in the soil permeability. Increasing or decreasing the soil permeability by an order of magnitude raises or lowers the indoor radon concentration by a proportional amount. As was discussed in Chapter 4, for gap sizes greater than a few millimeters, the model indicates that soil gas flow rates and radon entry rates are directly proportional to soil permeability. Actually, an increase in soil permeability will permit greater dilution of the soil gas radon concentration by wind pressures propagating through the soil. The effect of exhaust ventilation will be much greater for highly permeable soil since greater underpressures will cause greater soil gas flow rates. Reducing the soil permeability by an order of magnitude, to $10^{-7} \mathrm{~cm}^{2}$, produces soil gas flow rates of a few $100 \mathrm{l} / \mathrm{hr}$. The only way such flow rates can produce higher-than-average indoor radon concentrations is if the soil gas radon concentration is high. Raising the soil gas radon concentration to $C_{\infty}=6,000 \mathrm{pCi} / \mathrm{l}$ produces indoor radon concentrations of between 1 and $10 \mathrm{pCi} / /$ for soil permeabilities ranging from $10^{-7}$ to $10^{-8}$ $c \mathrm{~m}^{2}$. Table 9 shows that simply adding $300 \mathrm{~m}^{3} / \mathrm{hr}$, sust ventilation, without changing any of the other parameters, produces a reduction in indoor radon concentration of from $12 \%$ to $30 \%$ below the levels expected for the same house and soil conditions and no mechanical ventilation system. However, the exhaust system appears to be generally ineffective at reducing indoor radon concentrations below the BPA action level for cases with already high indoor radon concentrations. 
Table 9. The Effect of Exhaust Ventilation, $\mathbf{Q}_{\mathrm{umv}}$, soil permeability, $k$, soil gas radon concentration, $C_{\infty}$, and effective leakage area, ELA, on soil gas entry and indoor radon concentration, $\mathbf{R n}_{\mathbf{i}}$, in \& house with a basement. The value $\Delta \mathbf{R}_{\mathbf{i}}$ is the percentage difference between indoor radon concentrations for the base case and the specified conditions. The value $\Delta \mathbf{R n}_{\mathrm{i}, \mathrm{NE}}$ indicates the impact of adding exhaust ventilation with no change in any other parameters. The values for the air change rate with no exhaust ventilation are $0.398,0.298,0.162$, and $0.097 \mathrm{hr}^{-1}$ for ELA's of $981,735,600$, and $240 \mathrm{~cm}^{2}$ respectively. All calculations use $t_{\text {oep }}=5 \mathrm{~mm}, T_{i}=20 C, \Delta T=20 \mathrm{~K}$, and $v=3 \mathrm{~m} / \mathrm{s}$.

\begin{tabular}{|c|c|c|c|c|c|c|c|}
\hline \multicolumn{8}{|c|}{ Basement House, Other Soil Conditions } \\
\hline \multicolumn{6}{|c|}{ Base Care, No Exhaust Ventilation, $t_{\text {oup }}=5 \mathrm{~mm}$} & \multicolumn{2}{|c|}{ No Exhaust (NE) } \\
\hline \multicolumn{6}{|c|}{$k=2.22 \times 10^{-\infty} \mathrm{cm}^{2}, C_{\infty}=700 \mathrm{pCi} / \mathrm{l}$} & \multicolumn{2}{|c|}{ — same soil } \\
\hline ELA & ACH & $\Delta \mathbf{P}_{\mathbf{l}}$ & Soil Gas Entry & $\mathbf{R n}_{\mathbf{i}}$ & $\Delta \mathbf{R n}_{\mathbf{i}}$ & $\mathbf{R n}_{\mathbf{i}, N E}$ & $\Delta \mathbf{R n}_{\mathrm{i}, \mathrm{NE}}$ \\
\hline $\mathrm{cm}^{8}$ & $h r^{-1}$ & $P_{a}$ & $m^{3} / h r$ & $p C i / l$ & $\%$ & $p C i / l$ & $\%$ \\
\hline 981 & 0.398 & -3.91 & 4.70 & 10.7 & 0 & + & - \\
\hline \multicolumn{6}{|c|}{ Efrect of Exheunt Ventilation, $Q_{u m r}=300 \mathrm{~m}^{3} / \mathrm{hr}$} & \multicolumn{2}{|c|}{ No Exhaust (NE) } \\
\hline \multicolumn{6}{|c|}{$k=2.22 \times 10^{-a} \mathrm{~cm}^{2}, C_{\infty}=700 \mathrm{pCi} / 1$} & \multicolumn{2}{|c|}{ - seme soil } \\
\hline 981 & 0.551 & .4 .35 & 5.30 & 8.8 & -18 & 10.7 & -18 \\
\hline \multicolumn{6}{|c|}{$k=10^{-6} \mathrm{~cm}^{2}, C_{\infty}=700 p C i / l$} & \multicolumn{2}{|c|}{ - same soil } \\
\hline 881 & 0.551 & .4 .35 & 23.39 & 38.0 & +255 & 47.3 & -20 \\
\hline 735 & 0.484 & -1.68 & 25.22 & 46.6 & +335 & 63.0 & -26 \\
\hline 800 & 0.452 & -5.07 & 27.30 & 53.9 & +400 & 77.1 & -30 \\
\hline 240 & 0.383 & -11.17 & 60.12 & 136.2 & +1170 & 192.4 & -30 \\
\hline \multicolumn{6}{|c|}{$k=10^{-6} \mathrm{~cm}^{2}, C_{\infty}=200 p C i / 1$} & \multicolumn{2}{|c|}{ — same soil } \\
\hline 981 & 0.551 & -4.35 & 23.39 & 11.0 & +3 & 13.7 & -20 \\
\hline 735 & 0.484 & -4.68 & 25.22 & 13.5 & +26 & 18.2 & -26 \\
\hline 600 & $0.45 \%$ & -5.07 & 27.30 & 15.6 & +45 & 22.2 & -30 \\
\hline 240 & 0.393 & -11.17 & 60.12 & 39.1 & +265 & 55.2 & -29 \\
\hline \multicolumn{6}{|c|}{$k=10^{-7} \mathrm{~cm}^{2}, C_{\infty}=700, \mathrm{Ci} / \mathrm{l}$} & \multicolumn{2}{|c|}{ — same soil } \\
\hline 881. & 0.551 & -4.35 & 0.24 & 0.63 & -94 & 0.72 & -13 \\
\hline 735 & 0.484 & -4.68 & 0.25 & 0.72 & .93 & 0.88 & -18 \\
\hline 600 & 0.452 & -5.07 & 0.27 & 0.79 & -93 & 1.02 & -23 \\
\hline 240 & 0.393 & -11.17 & 0.60 & 1.62 & -85 & 2.18 & -28 \\
\hline \multicolumn{6}{|c|}{$k=10^{8} \mathrm{~cm}^{2}, C_{\infty}=8,000 \mathrm{pCi} / \mathrm{l}$} & \multicolumn{2}{|c|}{ - same soil } \\
\hline 981 & 0.551 & -4.35 & 0.02 & 0.58 & -95 & 0.66 & -12 \\
\hline 735 & 0.484 & -4.68 & 0.03 & 0.65 & -94 & 0.79 & -17 \\
\hline 600 & 0.452 & -5.07 & 0.03 & 0.71 & -93 & 0.91 & -22 \\
\hline 240 & 0.393 & -11.17 & 0.06 & 1.42 & .87 & 1.91 & $-2 B$ \\
\hline
\end{tabular}




\section{Effect of Exhaust Ventilation in Houses with Crawl Spaces}

The crawl space house, located in Portland, OR, that was referred to previously, is used in this chapter to show how indoor radon concentrations are affected by the presence of an exhaust ventilation system. The foor plan of the house is shown in Figure 21, and the important characteristics of the house, discussed in Chapter 5, are shown in Table 5. An exhaust air flow rate of $150 \mathrm{~m}^{3} / \mathrm{hr}$ was selected for this house based on its interior volume of $262 \mathrm{~m}^{3}$.

The original effective leakage area of this house was $455 \mathrm{~cm}^{2}$ with an assumed floor leakage area, $E L A_{f}$, of $153 \mathrm{~cm}^{2}$. If "bouse-doctoring", discussed previously, were used on this house the envelope leakage area would be reduced to $340 \mathrm{~cm}^{2}$ and the floor leakage area would be reduced to $115 \mathrm{~cm}^{2}$. For new construction values of $E L A=190 \mathrm{~cm}^{2}$ and $E L A$, $=64 \mathrm{~cm}^{2}$ are assumed, and for "super-tight" construction values of $E L A=75 \mathrm{~cm}^{2}$ and $E L A_{f}=25 \mathrm{~cm}^{2}$, are assumed. An additional case is examined where "house-doctcring" is done on the house, without any floor "tightening", and for this case the values are $E L A=$ $340 \mathrm{~cm}^{2}$ and $E L A_{f}=153 \mathrm{~cm}^{2}$.

The calculations for the crawl space can be generalized to other locations rather easily by varying the crawl space radon concentrations. The measured crawl space radon concentrations in the Portland, OR house averaged $2.2 \mathrm{pCi} / \mathrm{l}$ with the vents open. Values as high as $10 \mathrm{pCi} / \mathrm{l}$ were messured at the site over a five week period $(\mathrm{Na83})$. Values of 3,10 , and $30 \mathrm{pCi} / \mathrm{l}$ are used in the calculations as a representative sample of expected crawl space radon concentrations.

The results of the calculations are shown in Table 10 and Figure 24. The BPA action level, of $5 \mathrm{pCi} / \mathrm{l}$, is also shown in Figure 24 as a reference. The results show a direct 
Table 10. The Effect of Exhaust Ventilation, $\mathbf{Q}_{u m v}$, crawl space radon concentration, $\mathbf{R n}_{\text {ea' }}$ and effective leakage areas, ELA and ELA $\mathbf{A}_{r}$, on radou entry rates, $\sigma_{r}$ and indoor radon concentrations, $\mathbf{R}_{\mathbf{n}}$, in a house with a crawl space. The value $\Delta \mathbf{R}_{n_{1}}$ is the percentage difference between indoor radon concentrations for the base case and the specified conditions. The value of $\Delta \mathbf{R n}_{1, N E}$ indicates the impset of adding exhaust ventilation with no change in any other parameters. The values for the air change rate with no exhaust ventilation are $0.450,0.338$, 0.189 , and $0.075 \mathrm{hr}^{-1}$ for ELA's of $455,340,190$, and $75 \mathrm{~cm}^{2}$ respectively. All calculations use $T_{i}=20 C, \Delta T=20 \mathrm{~K}$, and $v=3 \mathrm{~m} / \mathrm{s}$.

\begin{tabular}{|c|c|c|c|c|c|c|c|c|}
\hline \multicolumn{9}{|c|}{ Crawl Space House } \\
\hline \multicolumn{7}{|c|}{ Base Case, No Exhauet Ventilation, $\mathbf{R n}_{\mathrm{cs}}=3 \mathrm{pCi} / \mathrm{l}$} & \multicolumn{2}{|c|}{ No Exhsust (NE) } \\
\hline ELA & $\mathbf{E L A}$ & $\mathbf{A C H}$ & $\Delta \mathbf{P}_{\mathbf{r}}$ & $\sigma_{\mathrm{i}}$ & $\mathbf{R n}_{1}$ & $\Delta \mathbf{R n}_{1}$ & $\mathbf{R n}_{1, \mathrm{NE}}$ & $\Delta \mathbf{R}_{\mathbf{i}, \mathbf{N E}}$ \\
\hline $\mathrm{cm}^{2}$ & $c m^{2}$ & $h r^{-1}$ & $P a$ & $p C i / l-h r$ & $p C i / l$ & 96 & $p C i / l$ & 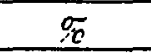 \\
\hline 455 & 153 & 0.450 & -1.92 & 1.13 & 2.59 & 0 & - & - \\
\hline \multicolumn{7}{|c|}{ Efrect of Exhaust Ventilation, $Q_{\text {umv }}=150 \mathrm{~m}^{3} / \mathrm{hr}$} & \multicolumn{2}{|c|}{ No Exhaust (NE) } \\
\hline \multicolumn{7}{|c|}{$\operatorname{Rn}_{\mathrm{es}}=3 \mathrm{pCi/l}$} & \multicolumn{2}{|c|}{$\mathbf{R n}_{\mathrm{es}}=3 \mathrm{pCi} / \mathrm{i}$} \\
\hline 155 & 153 & 0.730 & -2.43 & 1.27 & 1.84 & -29 & 2.59 & -29 \\
\hline 340 & 115 & 0.665 & -2.83 & 1.03 & 1.84 & -36 & 2.60 & -37 \\
\hline 190 & 64 & 0.603 & -4.82 & 0.75 & 1.34 & -48 & 2.59 & -48 \\
\hline 75 & 25 & 0.577 & -20.51 & 0.60 & 1.14 & -56 & 2.57 & -56 \\
\hline \multicolumn{7}{|c|}{$\mathrm{Rn}_{\mathrm{ce}}=10 \mathrm{pCi} / \mathrm{l}$} & \multicolumn{2}{|c|}{$\operatorname{Rn}_{\mathrm{ct}}=10 \mathrm{pCi} / l$} \\
\hline 455 & 153 & 0.730 & -2.43 & 4.22 & 5.88 & +127 & 8.40 & -30 \\
\hline 340 & 115 & 0.685 & -2.83 & 3.42 & 5.25 & +103 & 8.44 & -38 \\
\hline 190 & 64 & 0.603 & -4.82 & 2.49 & 4.23 & +63 & 8.41 & -50 \\
\hline 75 & 25 & 0.577 & -20.51 & 2.00 & 3.57 & +38 & 8.32 & -57 \\
\hline \multicolumn{7}{|c|}{$\mathrm{Rn}_{\mathrm{es}}=30 \mathrm{pCi} / \mathrm{l}$} & \multicolumn{2}{|c|}{$\mathbf{R} \mathbf{n}_{\mathrm{el}}=\mathbf{3 0} \mathbf{p C i} / l$} \\
\hline 455 & 153 & 0.730 & .2 .43 & 12.7 & 17.5 & +574 & 25.0 & -30 \\
\hline 340 & 115 & 0.685 & -2.83 & 10.3 & 15.5 & +500 & 25.1 & -38 \\
\hline 190 & 64 & 0.603 & -4.82 & 7.46 & 12.5 & +382 & 25.0 & -50 \\
\hline 75 & 25 & 0.577 & -20.51 & B.01 & 10.5 & +306 & 24.8 & -58 \\
\hline \multicolumn{7}{|c|}{ Awuming No "Tightoning" in Floor } & \multicolumn{2}{|c|}{ No Exhaust (NE) } \\
\hline \multicolumn{7}{|c|}{$\mathbf{R n}_{\mathrm{es}}=3 \mathrm{pCi} / 1$} & \multicolumn{2}{|c|}{$\mathbf{R n}_{\mathrm{ca}}=3 \mathrm{pCi} / \mathrm{l}$} \\
\hline 340 & 153 & 0.730 & -2.83 & 1.37 & 2.16 & -17 & 3.40 & -36 \\
\hline \multicolumn{7}{|c|}{$\mathbf{R n}_{\mathrm{es}}=10 \mathrm{pCi} / \mathrm{l}$} & \multicolumn{2}{|c|}{$\mathbf{R n}_{\mathrm{cs}}=10 \mathrm{pCi} / \mathbf{l}$} \\
\hline 340 & 153 & 0.730 & .2 .83 & 4.55 & 8.95 & +168 & 11.2 & -38 \\
\hline \multicolumn{7}{|c|}{$\mathbf{R n}_{\mathrm{eq}}=\mathbf{3 0} \mathrm{pCi} / \mathrm{l}$} & \multicolumn{2}{|c|}{$\mathbf{R}_{\mathrm{ce}}=\mathbf{3 0} \mathrm{pCi} / 1$} \\
\hline 340 & 153 & 0.730 & -2.83 & 13.66 & 20.65 & +698 & 33.4 & -38 \\
\hline
\end{tabular}




\section{Crawl Space House, Portland, OR.}

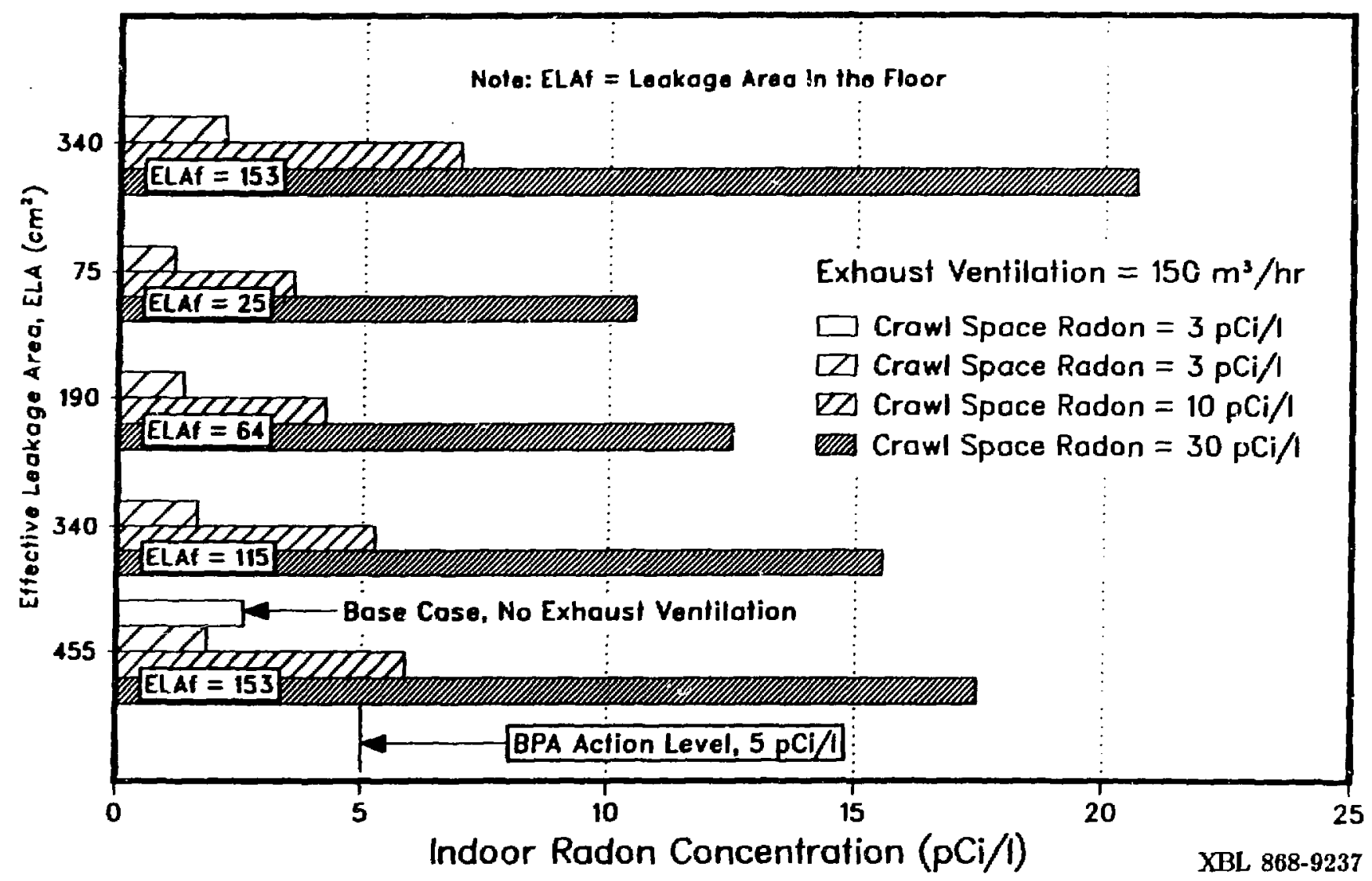

Figure 24. The effect of exhaust ventilation, erawl space radon concentration, and effective leakage area on indoor radon concentration in a house with a vented crawl space. 
dependence on crawl space radon concentration, as expected. The floor underpressure, due to the exhaust system, is inversely proportional to the square of the effective leakage area, $E L A$, and goes down to $-20 \mathrm{~Pa}$ for the "super-tight" house $\left(E L A=75 \mathrm{~cm}^{2}\right)$ which is more than ten times greater than the floor underpressure with no exhaust ventilation. Even with this large increase in floor underpressure, the indoor radon concentration is shown to decrease for the the following reasons:

1) the assumption of "tightening" the floor above the crawl space causes a decrease in the radon entry rate despite the increase in floor underpressure, and

2) the total air change rate increases.

Table 10 shows that simply adding $150 \mathrm{~m}^{3} / \mathrm{hr}$ of exhaust ventilation, without changing any of the other parameters, increases the ventilation rate from $62 \%$ to $670 \%$ and reduces indoor radon concentrations from $29 \%$ to $58 \%$ below the level expected for the same house without a mechanical ventilation system. If the floor is not "tightened" with the rest of the envelope, then indoor radon concentrations increase by about $32 \%$ over the values obtained assuming uniform "tightening". The combination of exhaust ventilation with house "tightening" measures, which include "tightening" the floor above the crawl space, is shown to reduce indocr radon concentrations from $29 \%$ to $56 \%$ below levels expected for a house with the same crawl space radon concentration. The exhaust system is not very effective at reducing indoor radon levels primarily because of the large floor underpressures which it produces. However, unlike the results from the house with a basement, indoor radon concentrations do not increase due to the combination of house "tightening" measures and exhaust ventilation. 


\section{Conclusions Regarding the Use of Exhaust Ventilation Systems in Houses with Basements or Crawl Spaces}

The pressure driven flow of soil gas and radon into houses is dependent on both the soil permeability and soil gas radon concentration. The soil gas flow rate is dependent on the combination of three parameters:

1) underpi'essures at the floor level,

2) openings, such as gaps or cracks, in the substructure, and

3) soil permeability.

As houses are "tightened" to reduce infiltration rates indoor radon concentrations will increase if care is not taken to reduce radon entry rates. Combining "tightening" measures with exhaust ventilation can compound this problem unless openings in the substructure are sealed or unless operable vents are installed to reduce the associated underpressure caused by the exhaust system. Most house "doctoring" appronches include procedures to "tighten" craw! space floor opening but efforte to seal basement. gapg or cracks have not always been taken. Sealing basement gaps or cracks should be included in any house "doctoring" strategy if radon is a potential problem. The soil permeability will limit the magnitude of soil gas flow rates according to the simple models presented here since, if the gap or crack width is greater than approximately $1 \mathrm{~mm}$ the soil gas flow rate is almost directly proportional to soil permeability. For every order of magnitude decrease in soil permeability a corresponding decrease in soil gas flow rate will occur for the same floor underpressure. However, if the radon concentration in the soil is very high, even relatively low soil permeability and low soil gas flow rates can lead to high radon entry rates.

Based on the analysis here the following conclusions may be made regarding a house with a basement: 
1) exhaust ventilation will reduce indoor radon concentrations by $12 \%$ to $30 \%$ below the levels expected for the same house, soil conditions, and no ventilation system,

2) the combined effects of "tightening" the building envelope and installing an exhaust ventilation system will generally increase indoor radon concentrations by as much as a factor of 2, and

3) the increased radon entry rate due to these effects may be countered by sealing penetrations in the basement substructure so that the resistance to flow through the substructure is increased.

The following conclusions may be made regarding a house having evenly distributed leakage area and a vented crawl space:

1) the exhaust system will reduce indoor radon levels from $29 \%$ to $58 \%$ below the levels expected for the same house without the system,

2) the combination of exhaust ventilation with house "tightening" measures, which include "tightening" the floor above the crawı space, will reduce indoor radon concentrations from $29 \%$ to $56 \%$ below levels expected for a house with the same crawl space radon concentration.

In summary, for houses with either basement or crawl spar? substructures, the exhaust ventilation system can be expected to reduce indoor radon concentrations by up to roughly $50 \%$ for a house with a crawl space and up to $30 \%$ for a house with a basement. Installing an exhaust ventilation system will not increase indoor radon levels unless the building envelope is also "tightened". Any "tightening" measures should include sealing penetrations in the substructure of the house to avoid increasing the radon entry rate. In regions where particularly high indoor radon concentrations are anticipated, it may be wise to avoid the use of exhaust ventilation in houses with basements. However, it is recommended that field studies be performed to verify the theoretical predictions of this report. 


\section{BIBLIOGRAPHY}

Ak79 Akins, R.E., Peterka, J.A., Cermak, J.E., Average Pressure Coefficients for Rectangular Buildings, in Proceedings of the Fifth International Conference of Wind Engineering, Boulder, CO, July 1979.

Ar84 Arens, E.A., Pollock, R.I., Boundary Layer Wind Tunnels: A Unique Tool for Planning and Design, Association of Environment Professionals Journal, Volume 10, Issue 1, Fall 1984.

AS81 ASHRAE, ASHRAE Standard 62-81, "Ventilation for Acceptable Indoor Air Quality", American Society of Heating, Refrigerating, and Air-Conditioning Engineers, Atlanta, GA, 1981.

Ay85 Aynsley, R.M., Modeling Parametero for Boundary Layer Wind Tunnel Studies of Natural Ventilation, ASHRAE Transactions, Vol. 91-2A, 1985.

Bas1 Baies, R.C., Edwards, J.C., The Efectiveness of Overpresaure Ventilation: A Mathematical Study, In Radiation Hazards in Mining: Control, Measurement, and Medical Aspects, Gomez, M. (ed.), Society of Mining Engineers, New York, NY, pp. 149-154, 1981.

Cl74 Clements, W.E., The Effect of Atmospheric Pressure Variation on the Transport of ${ }^{222} R n$ from the Soil to the Atmosphere, PhD Thesis, New Mexi :o Institute of Mining and Technology, Socorro, NM, 1974.

Co82 Colle, R., Rubiu, R.J., Knab, L.I., Hutchinson, J.M.R., Radon Transport through and Exhalation from Building Materials: A Review and Assessment, NBS Technical Note 1139, Washington, D.C., U.S. Govt. Printing Ofiee, 1981.

Di82 Diamond, R.C., Dickinson, J.B., Lipschutz, R.D., O'Regan, B., Shohl, B., The House Doctor's Manual, LBL-3017, Lawrence Berkeley Laboratory, Berkeley, CA, 1982.

Ev69 Evans, R.D., Guide to the Elementary Behavior of Radon Daughters, Health Physics, Vol. 17, pp. 229-252, 1969.

Fe85 Feustel, H.E., Development of a Simplified Multizone Infiltration Model, LBL-19095, Lawrence Berkeley Laboratory, Berkeley, CA, 1985.

Fe86 Private conversation with $\mathrm{H}$. Feustel at Lawrence Berkeley Laboratory, 6/86.

Fo78 Fox, R.W., McDonald, A.T., Introduction to Fluid Mechanics, 2nd. edition, John Wiley \& Sons, New York, 1978.

Gr83 Grimsrud, D.T., Sherman, M.H., Sonderegger, R.C., Calculating Infiltration: Implications for a Construction Quality Standard, LBL-9416, Lawrence Berkeley 
Laboratory, Berkeley, CA, April 1983.

Gr86 Grimsrud, D.T., Private conversation concerning the draft version of the revised ASHRAE 62-81R standard, Lawrence Berkeley Laboratory, Berkeley, CA, July 9, 1986.

He83 Hess, C.T., Weiffenbach, C.V., Norton, SA., Environmental Radon and Cancer Correlations in Maine, Health Physics, Vol. 45, No. 2, pp 339-348, 1983.

In81 Incropera, F.P., DeWitt, D.P., Fundamentala of Feat Transfer, ISBN 0-471-42711-X, John Wiley \& Sons, New York, 1981.

Ja81 James, A.C., Jacobi, W., Steinhausler, F., Respiratory Tract Dosimetry of Radon and Thoron Daughters: The State-of-the-art and Implicationo for Epidemiology and Radiobiology, In Radiation Hazards in Mining: Control, Measurement, and Medical Aepects, Gomez, M. (ed.), Society of Mining Engineers, New York, NY, pp. 42-54, 1981.

Je81 Jergling, A., Air Leakage Through Cracks in Concrete Elements, 2nd AIC Conference Procedings, Air Infiltration Centre, Old Brackneil Lane West, Bracknell, Berkshire, Great Britain, RG12 4AH, 1981.

Kr57 Krischer, O., Beck, H., Die Durchlueftung von Raeumen durch Windangriff und der Waermebedarf fuer die Lueftung, [The Airflow in Buildings due to Wind and the Heat Loss due to Ventilation], VDI-Berichte, Vol. 18, pp. 29-59, 1957.

.Kr73 Kreith, F., Principles of Heat Transfer, 3rd Ed., Harper \& Row, Publishers, 1973.

La82 Landman, K.A., Diffusion of Radon through Cracks in a Concrete Slab, Heaith Physica, Vol. 43, pp. 65-71, 1982.

Lo86 Loureiro, C., Calculation of the Steady-State Indoor Radon Concentration in a House with a Basement Under a Constant Negative Pressure, University of Michigan, Ann Arbor, MI, February 1986.

Mo85 Modera, M., Peterson, F., Simplified Methodo for Combining Mechanical Ventilation and Natural Infiltration, LBL-18955, Lawrence Berkeley Laboratory, Berkeley, CA, January 1985.

Mo86 Moed, B., Private conversation at Lawrence Berkeley Laboratory, Berkeley, CA, June, 1986.

Mo88 Mowris, R.J., An Energy and Economic Analysis of Mechanical Ventilation Systems for New Reaidential Buildings, Building Systems Engineering, Department of Civil and Architectural Engineering, University of Colorado, Boulder, CO, 1986.

Na83 Nazarofi, W.W., Doyle, S.M., Radon Entry Into Houses Having a Crawl Space, LBL-16837, Lawrence Berkeley Laboratory, Berkeley, CA, December 1983. 
Na84a Nazaroff, W.W., Feustel, H., Nero, A.V., Revzan, K.L., Grimsrud, D.T., Essling, M.A., Toohey, R.E., Radon Transport Into A Single-Family House with a Basement, LBL-16572, Lawrence Berkeley Laboratory, Berkeley, CA, January 1984.

Na84b Nazaroff, W.W., Nero, A.V., Tranoport of Radon From Soil Into Residences, LBL16823, Lawrence Berkeley Laboratory, Berkeley, CA, February 1984.

Na85 Nazaroff, W.W., Moed, B.A., Sextro, R.G., Revzan, K.L., Nero, A.V., Factors Influencing Soil á a Source of Indoor Radon: A Framework for Geographically Assessing Radon Source Potentials, LBL-20645, Lawrence Berkeley Laboratory, Berkeley, CA, 1985.

NC84 NCRP, Exposurea from Uranium Series with Emphasis on Radon and Its Daughtors, National Council on Radiation Protection, NCRP Report 77, Bethesda, MD, 1984.

NC84b NCRP, Evaluation of Occupational and Environmental Exposures to Radon and Radon Daughters in the United States, National Council on Radiation Protection, NCRP Report 78, pp. 21-33, Bethesda, MD, 1984.

Ne83 Nero, A.V., Indoor Radiation Exposures From ${ }^{222} R$ n and Its Daughters: $A$ View of the Ioare, Health Phyoies, Vol. 45, No. 2, pp. 277-288, August 1983.

Ne84 Nero, A.V., Schwehr, M.B., Nazarof, W.W., Revzan, K.L., Distribution of Airborne Radon-222 Concentrations in U.S. Homes, LBL-18274, Lawrence Berkeley Laboratory, Berkeley, CA, 1984.

Ne86 Nero, A.V., Private conversation at Lawrence Berkeley Laboratory, Berkeley, CA, 6/24/86.

NKB81 Nordic Committee on Building Regulations, Indoor Climate, NKB Report No. 41, ISSN 0359-9981, May 1981.

Ra84 Radford, E.P., Clair, K.G., Application of Studies of Miners to Radon Problem in Homes, Indoor Air, Radon, Passive Smoking, Particulates and Housing Epidemiology 2, Swedish Council for Building Research, Stockholm, Sweden, pp. 93-96, 1984.

Ru79 Rundo, J., Markun, F, Plondke, N.J., Observation of High Concentrations of Radan in Certain Houses, Health Physice, Vol 36, pp. 729-730, 1979.

Sc838 Scott, A., Review of Existing Instrumentation and Evaluation of Possibilities for Researeh and Development of Instrumentation to Determine Future Levels of Radon at a Proposed Building Site, DSMA Atcon Ltd., Toronto, Ontario, Canada, January 1983.

Sc83b Scott, A.G., Findlay, W.O., Demonstration of Remedial Techniques Against Radon in Houses on Florida Phosphate Lands, EPA 520/5-83-009, United States Environmental Protection Agency Office of Radiation Programs, Eastern Environmental Radiation Facility, Montgomery, AL, 1983. 
Sc85 Scott, A., A Computer Study of Soil Gas Movement into Basements, DSMA Atcon Ltd., Toronto, Ontario, Canada, March 1985.

Sch74 Scheidegger, A.D., The physics of flow through porous media, ISBN 0-8020-1849-1, 3rd. edition, University of Toronto Press, 1974.

Se84 Sextro, R.G., Offermann, F.J., Nazaroff, W.W., Nero, A.V., Revzan, K.L., Yater, J., Evaluation of Indoor Aerosol Control Devices and Their Effects on Radon Progeny Concentrations, LBL-17598, Lawrence Berkeley Laboratory, Berkeley, CA, 1984. 4

Se85 Sextro, R.G., Control of Indoor Radon and Radon Progeny Coneentrations, LBL18726, Lawrence Berkeley Laboratory, Berkeley, CA, May 1985.

Sh80 Sherman, M.H., Air Infiltration in Buildings, PhD Thesis, LBL-10712, University of California, Lawrence Berkeley Laboratory, Berkeley, CA, 1980.

Sh84 Shermax, M.H., Wilson, D.J., Kiel, D.E., Variability in Residential Air Leakage, Proceedings of the Symposium on Measured Air Leakage Performance of Buildings, ASTM, Philadelphia, PA, 1984.

Th84 Thor, P.W., BPA Radon Field Monitoring Study, in Doing Better: Setting an Agenda for the Second Deeade, , ACEEE 1984 Summer Study on Energy Efficiency in Buildings, Santa Cruz, CA, Vol. B, pp. 283-298, American Council for an Energy Eficient Economy, Washington, D.C. 1884.

Te67 Tersaghi, K., Peck, R.B., Soil Mechanics in Engineering Practice, 2nd edition, Wiley, New York, 1967.

Tu73 Tuma, J.J., Abdel-Hady, M., Engineering Soil Mechanics, Prentice-Hall, Englewood Cliffs, New Jersey, 1973.

Tu86 Turk, B.H., Prill, R.J., Fisk, W.J., Grimsrud, D.T., Moed, B.A., Sextro, R.G., Fiadon and Remedial Action in Spokane River Valley Residences, LBL-21399, Lawrence Berkeley Laboratory, 1986.

UN77 UNSCEAR, Ionizing Radiation: Sources and Biological Effects, United Nations Seientific Committee on the Effects of Atomic Radiation,. United Nations, New York, NY, 1977.

US79 U.S. Department of Energy, Progress Report on the Grand Junction Uranium Mine Tailings Remedial Action Program, DOE/EV-0033, 1979.

Wh84 White, F.M., Viscous Fluid Flow, McGraw-Hill, Inc., 1974.

Wi72 Wilkening, M.H., Clements, W.E., Stanley, D., Radon-222 Flux Measurements in Widely Separated Regions, in Natural Radiation Environment II, Adams, J.A.S., Lowder, W.W, Gesell, T.F. (eds.), pp. 717-730, Springfield: NTIS Report CONF720805, 1972. 


\section{APPENDLX A}

\section{TABLE OF SYMBOLS}

\begin{tabular}{|c|c|}
\hline$A$ & $\operatorname{area}\left(m^{2}\right)$ or $\left(\mathrm{cm}^{2}\right)$ \\
\hline$c_{i}$ & reduced indoor pressure coefficient $(-)$ \\
\hline$\overline{c_{k}}$ & pressure coefficient $(-)$ \\
\hline $\bar{c}_{\text {lee }}$ & average pressure coeficient on leeward side $(-)$ \\
\hline $\bar{c}_{\mathbf{l u v}}$ & average pressure coefficient on windward side $(-)$ \\
\hline$C_{l}$ & empirical constant (-) \\
\hline$C_{\infty}$ & soil gas radon concentration ( $p C i / h)$ \\
\hline$C^{\prime}$ & shielding coeficient $(-)$ \\
\hline$C_{R}$ & ${ }^{220} \mathrm{Ra}$ concentration in soil grains $\left(C_{i} / k_{g}\right)$ \\
\hline$d$ & diameter $(m)$ \\
\hline$d_{h}$ & hydraulic diameter $(m)$ \\
\hline D & diffusivity coefficient for radon in the soil gas $\left(\mathrm{m}^{2} / \mathrm{s}\right)$ \\
\hline$D$ & air permeability $\left(\mathrm{m}^{3} / \mathrm{h}-\mathrm{Pa}_{\mathrm{a}}\right)$ \\
\hline$D_{\text {let }}$ & leeward air permeability $\left(m^{3} / h-P_{a}\right)$ \\
\hline$D_{l w}$ & windward air permeability $\left(\mathrm{m}^{3} / h-\mathrm{Pa}^{n}\right)$ \\
\hline D. & air permeability of the total building envelope $\left(\mathrm{m}^{3} / \mathrm{h} \cdot \mathrm{Pa}^{\mathrm{n}}\right)$ \\
\hline$E L A$ & effective leakage area of the building $\left(\mathrm{cm}^{2}\right)$ \\
\hline$E L A_{\gamma}$ & effective leakage area of tloor $\left(\mathrm{cm}^{2}\right)$ \\
\hline$E P R$ & envelope permeability ratio (-) \\
\hline$f$ & friction factor (-) \\
\hline
\end{tabular}




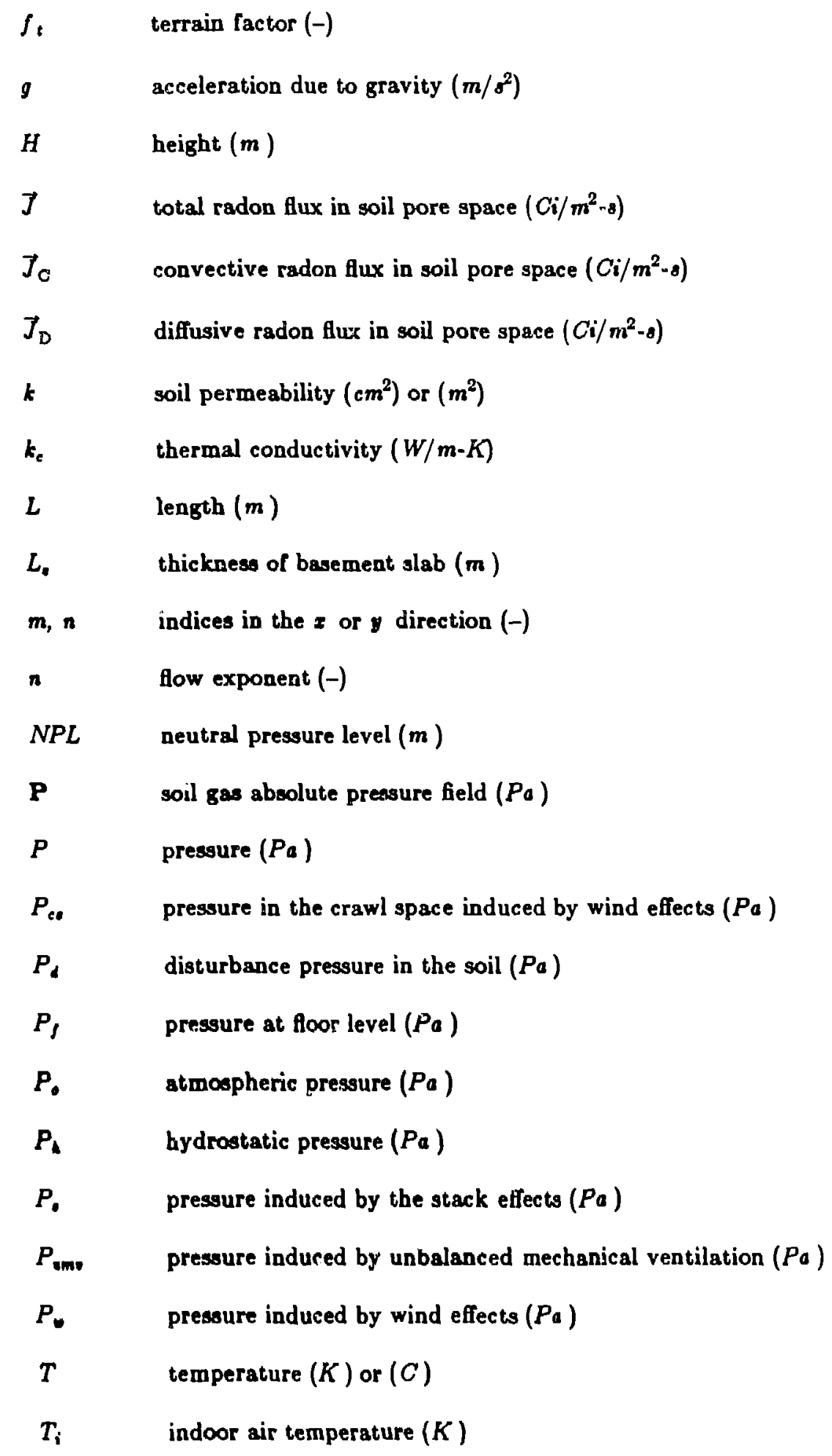




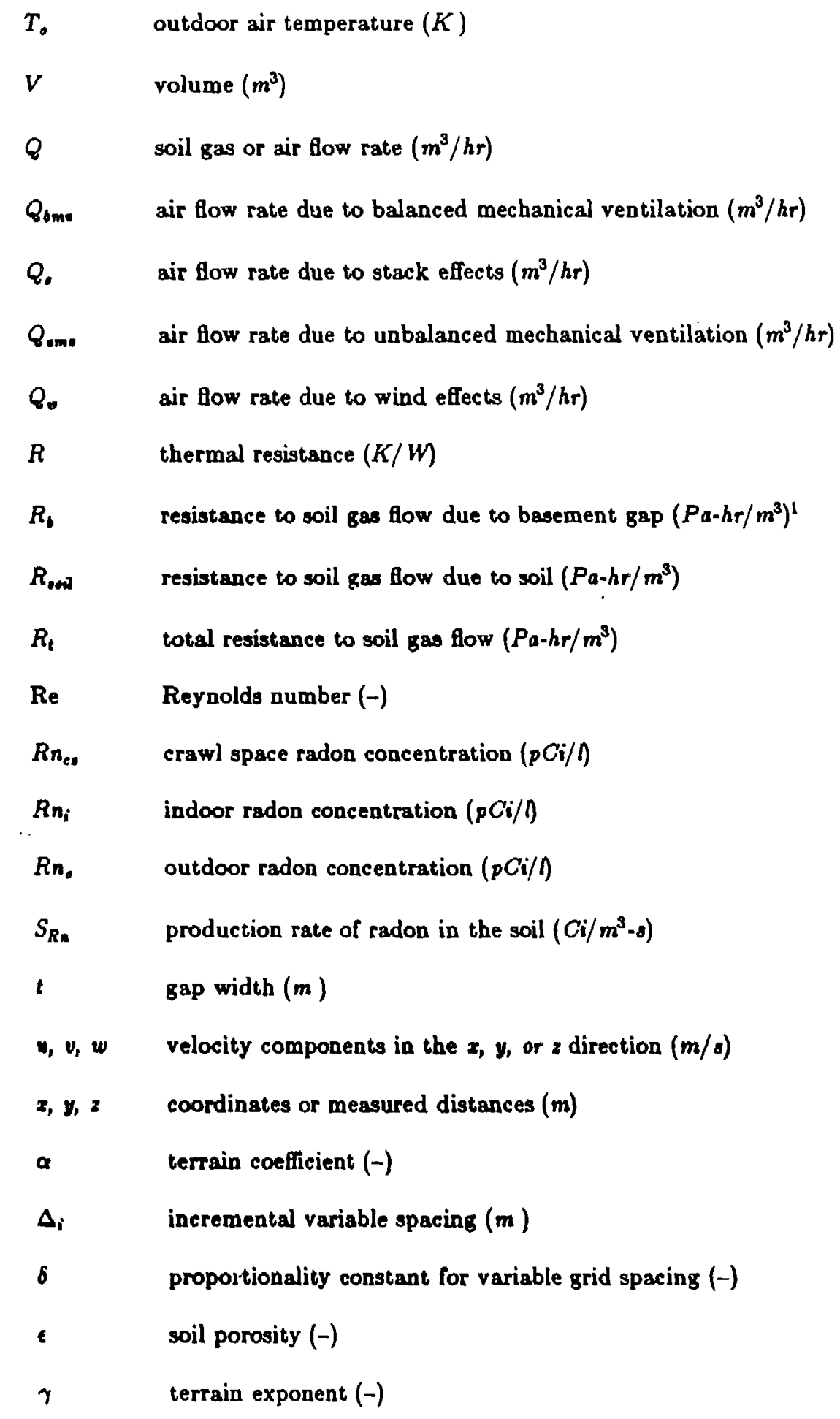

'The first mention of flow resistance in Equation (3.4) gives units of $\left(\mathrm{Pa-s} / \mathrm{m}^{3}\right)$. 
$\lambda$, house ventilation rate $\left(h r^{-1}\right)$

$\lambda_{R}$. decay constant of radon in the soil $\left(s^{-1}\right)$

$\mu \quad$ absolute air or soil gas viscosity (Pa-s)

$\rho \quad$ soil gas or air density $\left(\mathrm{kg} / \mathrm{m}^{3}\right)$

$\rho_{i} \quad$ indoor air density $\left(\mathrm{kg} / \mathrm{m}^{3}\right)$

p. outdoor air density $\left(\mathrm{kg} / \mathrm{m}^{3}\right)$

$\sigma_{d} \quad$ radon entry rate from diffusion $(p C i / l-h r)$

$\sigma_{f} \quad$ radon entry rate from convection ( $\left.p C i / l-h r\right)$

$\Psi \quad$ indoor pressure coefficient $(-)$

$\Theta \quad$ ratio of radon activity to the mass of soil gas $(\mathrm{Ci} / \mathrm{kg})$ 


\section{APPENDIX B}

\section{LBL MODEL TERRAIN AND SHIELDING COEFFICIENTS}

Table 1. Terrain parameters and generalized shielding coefficients used in the $L B L$ Model of infiltration for residential buildings (Sh80).

Table 1a. Terrain parameters for atandard terrain conditions

\begin{tabular}{|c|c|c|l|}
\hline \hline Class & $\gamma$ & $\alpha$ & \multicolumn{1}{c|}{ Description } \\
\hline I & 0.10 & 1.30 & $\begin{array}{l}\text { Ocean or other body of water with at } \\
\text { least 5 } \mathrm{km} \text { of unrestricted expanse. }\end{array}$ \\
\hline II & 0.15 & 1.00 & $\begin{array}{l}\text { Flat terrain with some isolated } \\
\text { ostacles (e.g. buildings or trees } \\
\text { well separated from each other). }\end{array}$ \\
\hline III & 0.20 & 0.85 & Rural areas with low buildings or trees. \\
\hline IV & 0.25 & 0.67 & Urban industrial or forest areas. \\
\hline V & 0.35 & 0.47 & Center of large city (e.g. Manhattan) \\
\hline
\end{tabular}

Table 1b. Generalised shielding coefficients for local shielding.

\begin{tabular}{|c|c|l|}
\hline \hline Clasa & $C^{\prime}$ & \multicolumn{1}{|c|}{ Description } \\
\hline I & 0.324 & No obstructions or local shielding whatsoever. \\
\hline II & 0.285 & Light local shielding, with few obstructions. \\
\hline III & 0.240 & $\begin{array}{l}\text { Moderate local shielding, some obstructions } \\
\text { within two house heights. }\end{array}$ \\
\hline IV & 0.185 & $\begin{array}{l}\text { Heavy shielding, obstructions around most } \\
\text { of perimeter. }\end{array}$ \\
\hline V & 0.102 & $\begin{array}{l}\text { Very heavy shielding, large obstructions } \\
\text { surrounding perimeter within two house } \\
\text { heights. }\end{array}$ \\
\hline
\end{tabular}




\section{2-DRMENSIONAL FINITE DIFFERENCE COMPUTER PROGRAM}

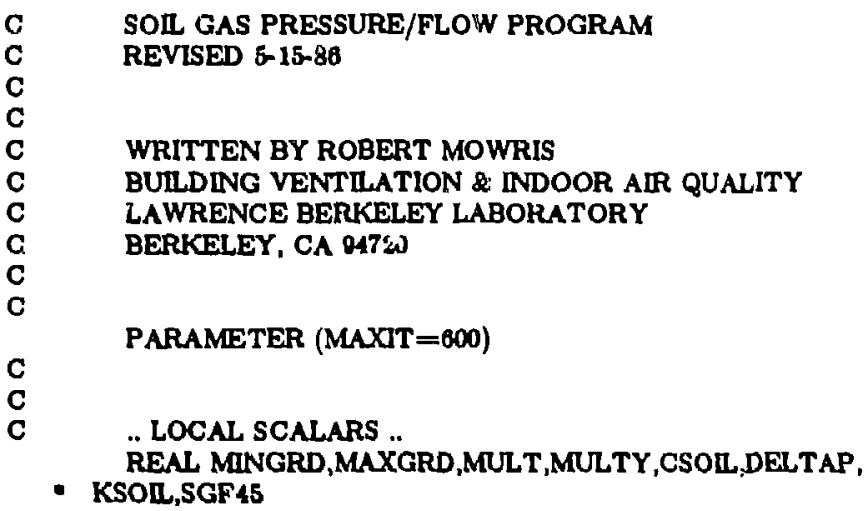

C

REAL“8 APARAM,CONCHN,CONRES,ROOT2,XWALL,DXWALL,CSIZE, C

- AIRDEN,PBAR,PERIM,DX,_DXR,DYL,DYU,DELP,DPSOL,PGAP

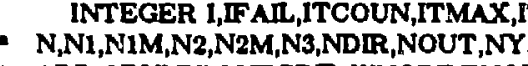

- ADD,CRKNUM,NFGRID,WNODE,FNODE,XCENTER,XCL, C

- XCR,DONE

C . LOCAL ARRAYS . REAL $\otimes$ A $(200,150,2), B(200,150,2), C(200,150,2)$, CHNGS(MAXIT),

- $E(200,150,2), F(200,150,2), G(200,150,2), Q(200,150,2)$,

- $P(200,150,2), W R K S P 1(200,150,2), W R K S P 2(200,150,2)$,

- WRKSP4(200,150,2),X(300),Y(150),Z(2),DY(150),DX(150),DB(100),

- $\mathrm{D}(200,150,2), \mathrm{RESIDS}(\mathrm{MAXIT}), \mathrm{WRKSP3}(200,150,2), \mathrm{DC}(100)$,

- FX(50),FY(50),FP(50,50)

C

REAL SUM(15),SFLOW/(15)

C
C
C COMMON VARLABLES USED WTTH SUBROUTINES

COMMON /BLK1/ ADD,NX,NFGRD,NXL, WNODE,XWALL,X,FINEX COMMON /BLKI/ MAXGRD,MINGRD,DXL,DXR,DYL,DYU COMMON /BLKS/ AIRUEN

$\mathrm{C}$
$\mathrm{C}$
$\mathrm{C}$ OPEN DATA FLES FOR OUTPUT

OPEN (UNT $=7, F I L E=$ 'P2DAT',STATUS='NEW',FORM='UNFORMATTED') OPEN (UNIT=9,FILE='PF.DAT',STATUS='NEW',

C
C
C
C
C
C
C
C
C - FORM - 'UNFORMATTED')

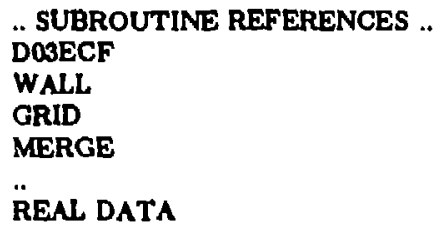


C

DATA KSOL,PERIM,AIRDEN

/1.0E-04,45.0,18.178E-08/

DATA CSIZE,MAXGRD /0.001,0.25/

DATA DELP,DPSOL,DXWALL /-10.0,-1.3882,0.15/

C

DATA DXL,DXR,DYU,DYL /3.5,11.0,2.3,11.0/

c

C

C

INTEGER DATA

CRKNUM $=$ NUMBER OF NODES AT THE CRACK

NXI,NXR,NYL,NYU $=$ NUMBER OF VARIABLE SPACED NODES AWAY

FROM THE FINE SPACED NODES AT THE CRACK REGION

DATA NXI,NXR,NYU,NYL $/ 12,20,0,20 /$

C

DATA CRKNUM /2/

DATA NOUT /6/

c

WRITE(NOUT,00009)

MINGRD - CSIZE/CRKNUM

c

C

SET UP VARLABLE NODAL, GRID SPACNG

NFGRD $=4^{*}$ CRKNUM

C

C

SET UP X-GRID

$\mathrm{CDIS}=\mathrm{DXI}$

$\mathrm{NB}=0$

$\mathrm{NC}=\mathrm{NXZ}$

CALL GRID (CDIS,DC,NG)

CALL MERGE (DB,NB,DC,NC,DX,NXL)

$\mathrm{NXI}=\mathbf{N X I}+\mathbf{I}$

DO I $=2, N X]$

$X(I)=X(I-1)+D X(I-1)$

END DO

DO I = 1,NFGRID

$L=N X \mathbb{L}+\mathbf{I}$

$X(L)=X(L-1)+M I N G R D$

END DO

$\mathbf{N X}=\mathbf{N X C}+\mathbf{N F G R D}$

C

C

SET UP THE X-VALUES FOR PLOTTING THE FINE GRID AREA

$F X(1)=0.0$

$K=1$

DO J $=\mathrm{NX} L+1, N X$

$K=\mathbf{K}+1$

$F X(K)=F X(K-1)+(X(J)-X(J-1))$

ENDDO

$\mathrm{NFX}=\mathrm{K}$

C

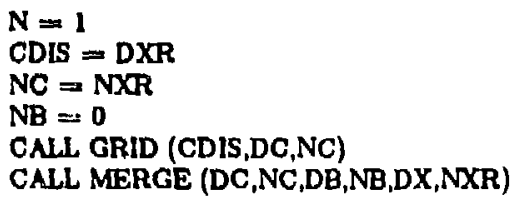




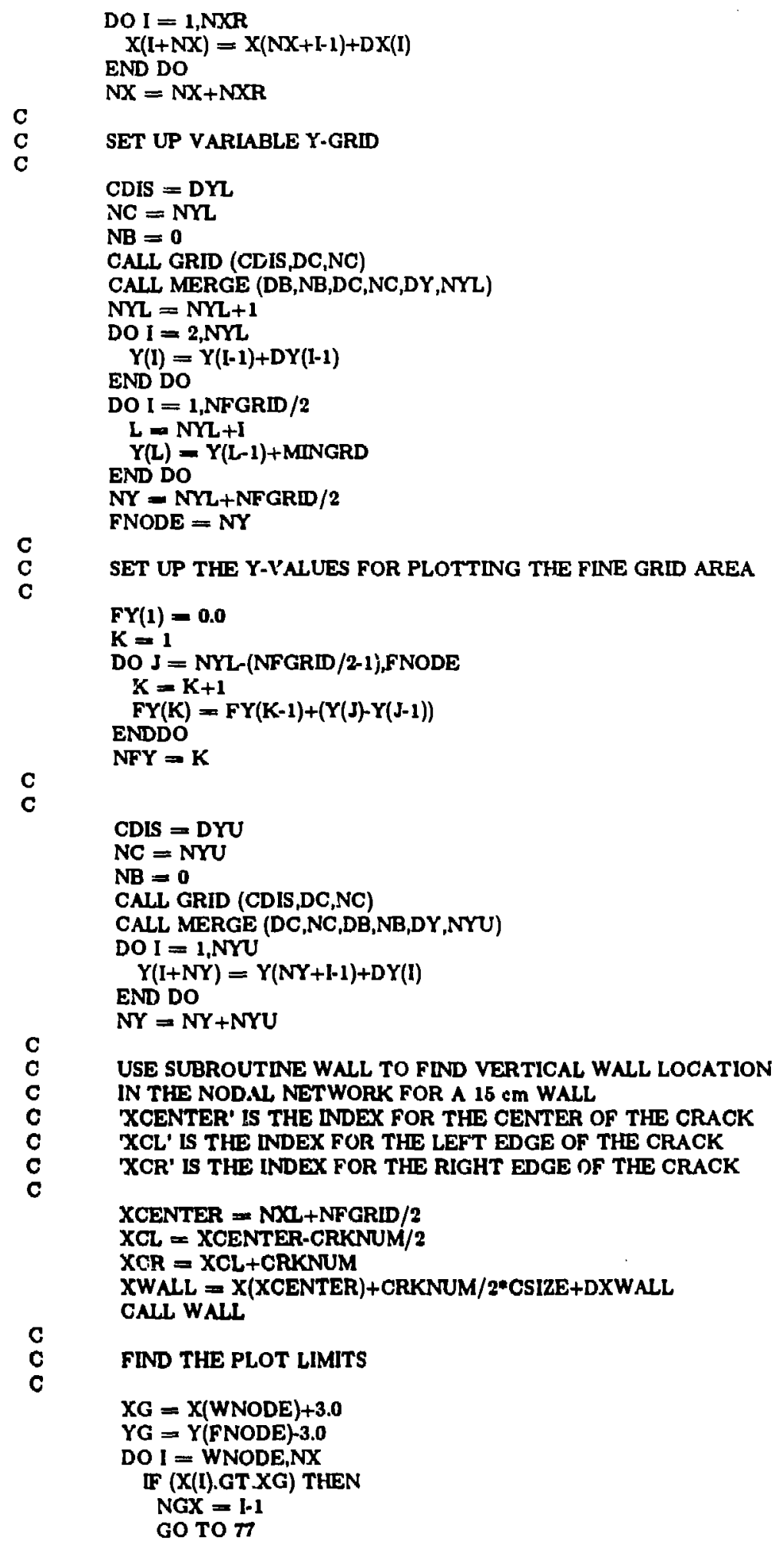




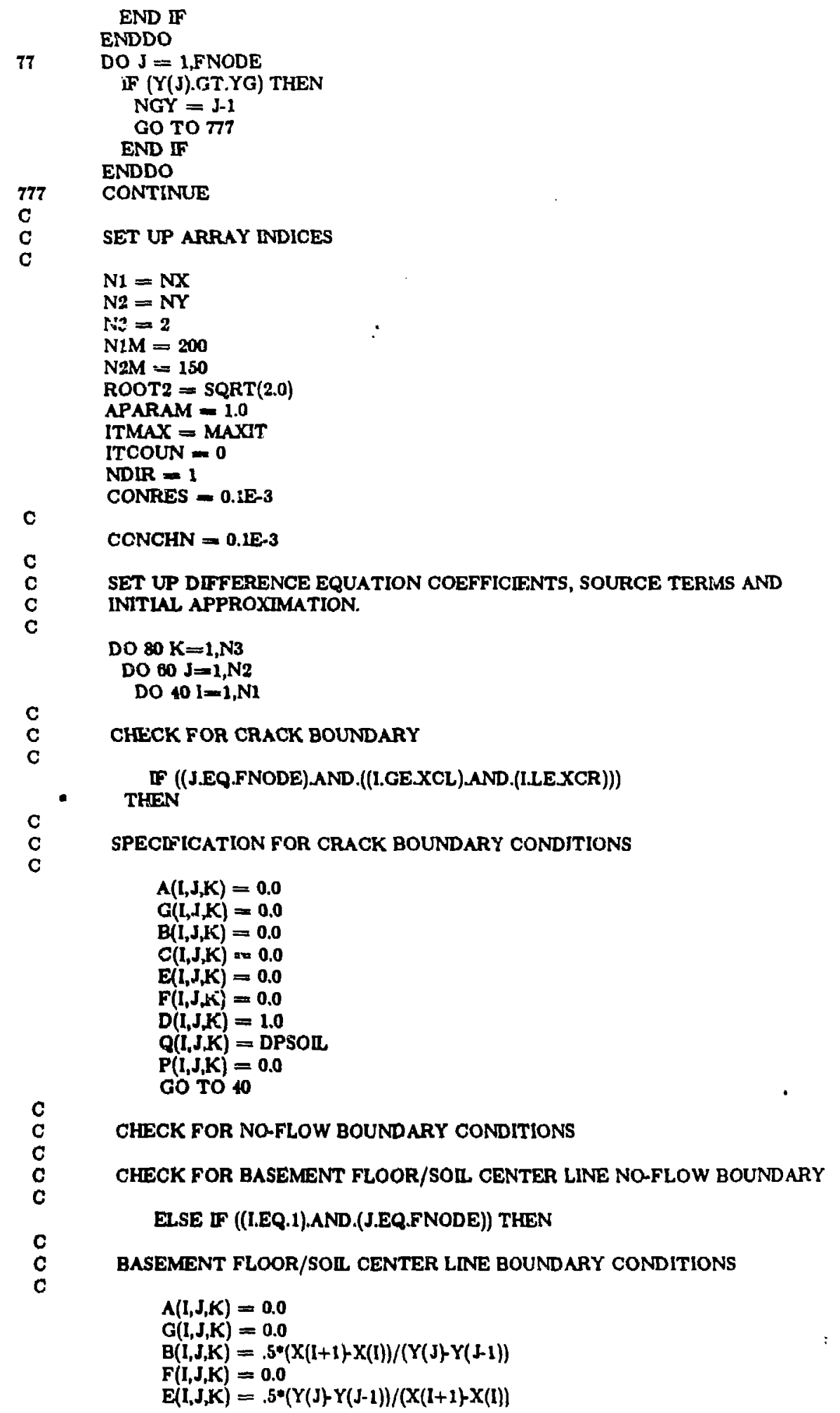




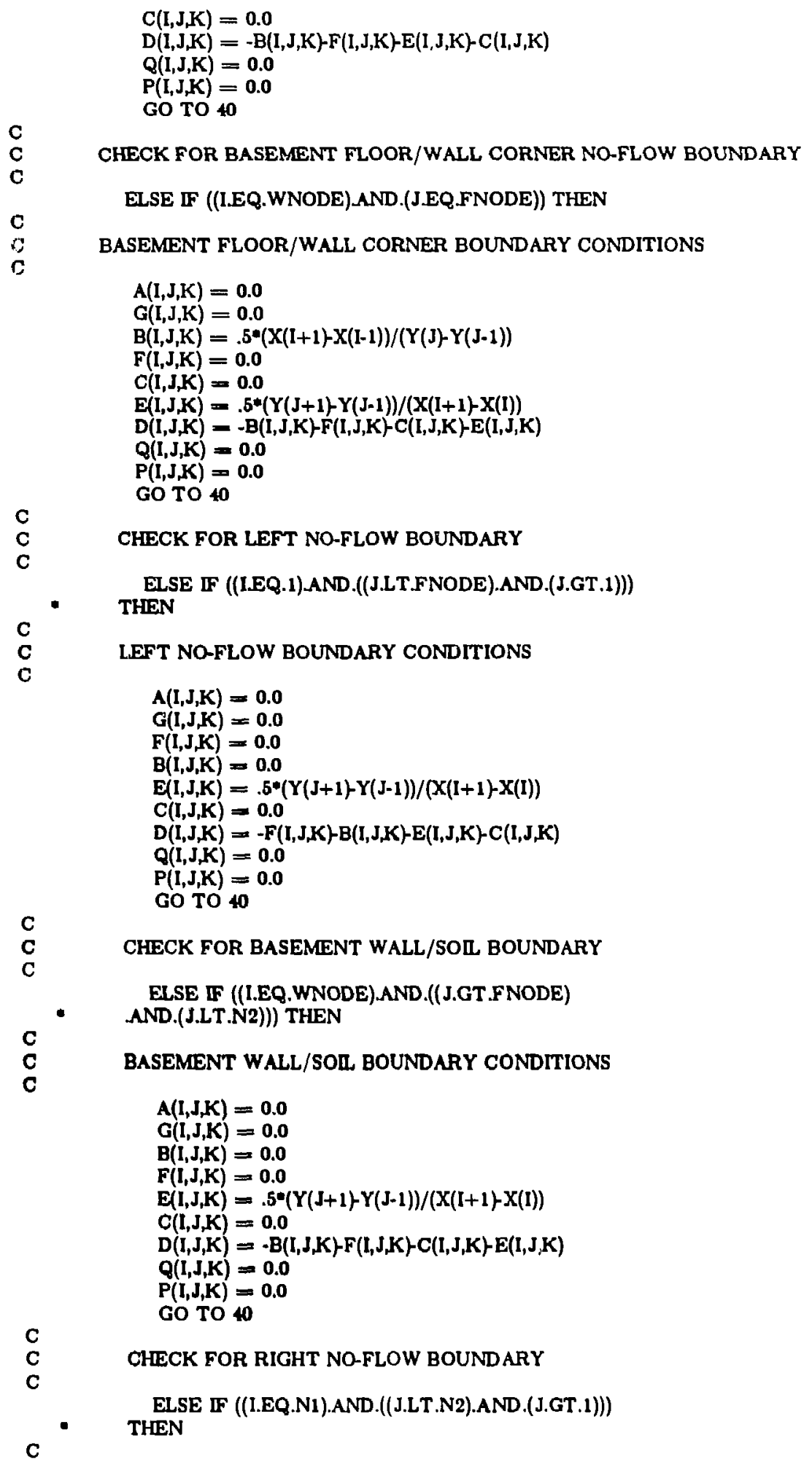




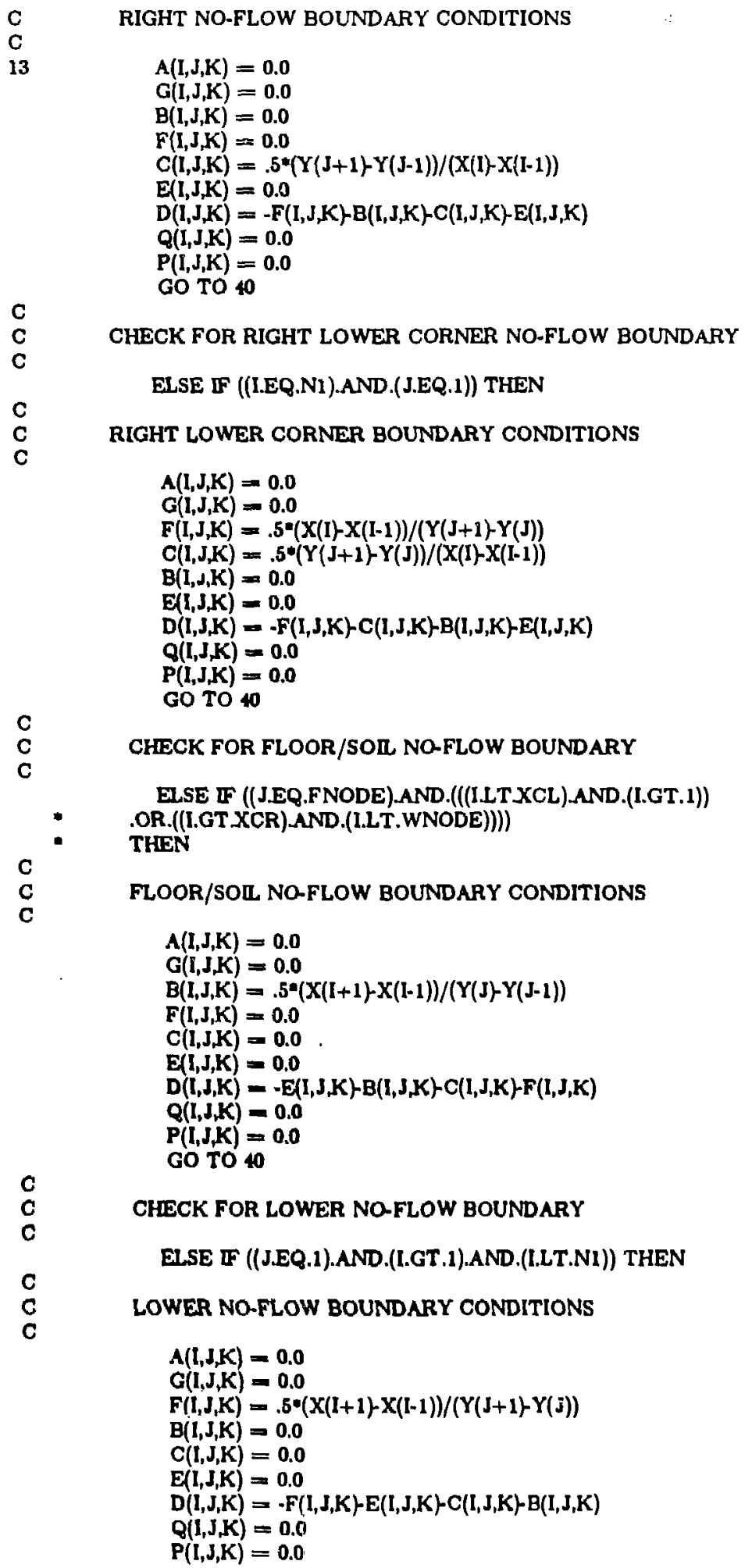


Go TO 40

$\mathrm{C}$

C

CHECK FOR LOWER LEFT CORNER NO-FLOW BOUNDARY

ELSE IF ((1.EQ.1).AND.(J.EQ.1)) THEN

C

LOWER LEFT CORNER BOUNDARY CONDITION

$$
\begin{aligned}
& \mathbf{A}(\mathrm{I}, \mathrm{J}, \mathrm{K})=\mathbf{0 . 0} \\
& \mathrm{G}(\mathrm{I}, \mathrm{J}, \mathrm{K})=0.0 \\
& F(I, J, K)=.5^{*}(X(I+1) X(I)) /(Y(J+1)-Y(J)) \\
& \mathrm{B}(\mathrm{I}, \mathrm{J}, \mathrm{K})=\mathbf{0 . 0} \\
& \mathrm{E}(\mathrm{I}, \mathrm{J}, \mathrm{K})=. \mathrm{s}^{*}(\mathrm{Y}(\mathrm{J}+\mathrm{I})-\mathrm{Y}(\mathrm{J})) /(\mathrm{X}(\mathrm{I}+1)-\mathrm{X}(\mathrm{I})) \\
& C(\mathrm{I}, \mathrm{J}, \mathrm{K})=0.0 \\
& D(\mathbf{I}, \mathbf{J}, \mathbf{K})=-F(\mathbf{I}, \mathrm{J}, \mathrm{K})-\mathrm{E}(\mathbf{I}, \mathrm{J}, \mathrm{K})-\mathrm{B}(\mathbf{I}, \mathrm{J}, \mathrm{K})-\mathrm{C}(\mathbf{I}, \mathrm{J}, \mathrm{K}) \\
& Q(\mathrm{I}, \mathrm{J}, \mathrm{K})=0.0 \\
& P(I, J, K)=0.0
\end{aligned}
$$

c

C

CHECK FOR SOILAIR-INTERFACE BOUNDARY

C

ELSE F ((I.GE.WNODE).AND.(J.EQ.N2))

$$
\text { THEN }
$$

C

C

C

SPECIFICATION FOR SOLL-AIR-INTERFACE BOUNDARY CONDITIONS

$$
\begin{aligned}
& A(I, J, K)=0.0 \\
& G(I, J, K)=0.0 \\
& B(I, J, K)=0.0 \\
& C(I, J, K)=0.0 \\
& E(I, J, K)=0.0 \\
& F(I, J, K)=0.0 \\
& D(I, J, K)=1.0 \\
& Q(I, J, K)=0.0 \\
& F(I, J, K)=0.0 \\
& G(\text { TO } \$ 0
\end{aligned}
$$

CHECIC FOR UNNECESSARY NODES IN THE BASEMENT

AND II THE 2ND INDEX OF THE 2-DIRECTION

ELSE FF ((I.GE.1).AND.(I.LT.WNODE)

- THEN

c

c

SPECIFIOATION FOR THE UNNECESSARY BASEMENT NODES

$$
\begin{aligned}
A(I, J, K)=0.0 \\
B(I, J, K)=0.0 \\
C(I, J, K)=0.0 \\
E(I, J, K)=0.0 \\
F(I, J, K)=0.0 \\
G(I, J, K)=0.0 \\
D(I, J, K)=0.0 \\
Q(I, J, K)=0.0 \\
P(I, J, K)=0.0 \\
G O \quad, T O 40
\end{aligned}
$$

C

c

ELSE CONOITION FOR INTERNAL NODES

ELSE

$\mathrm{C}$

C SPECFICATION FOR INTERNAL NODES

C COEFFICIENTS $A$ AND G ARE SET TO ZERO FOR 2-DIMENSIONS 


$$
\begin{aligned}
& \mathrm{A}(\mathrm{I}, \mathrm{J}, \mathrm{K})=0.0 \\
& G(1, J, K)=0.0 \\
& \mathrm{~B}(\mathrm{I}, \mathrm{J}, \mathrm{K})=.5^{*}(\mathrm{X}(\mathrm{l}+1)-\mathrm{X}(\mathrm{l}-1)) /(\mathrm{Y}(\mathrm{J})-\mathrm{Y}(\mathrm{J}-1)) \\
& F(1, J, K)=.5^{*}(X(1+1)-X(1-1)) /(Y(J+1)-Y(J)) \\
& \mathrm{C}(\mathrm{I}, \mathrm{J}, \mathrm{K})=.5^{*}(\mathrm{Y}(\mathrm{J}+1)-\mathrm{Y}(\mathrm{J}-1)) /(\mathrm{X}(\mathrm{I})-\mathrm{X}(\mathrm{I}-\mathrm{I})) \\
& \mathrm{E}(\mathrm{I}, \mathrm{J}, \mathrm{K})=.5 *(\mathrm{Y}(\mathrm{J}+1)-\mathrm{Y}(\mathrm{J}-1)) /(\mathrm{X}(\mathrm{I}+1) \mathrm{X}(\mathrm{I})) \\
& \mathrm{D}(\mathrm{I}, \mathrm{J}, \mathrm{K})=-\mathrm{B}(\mathbf{I}, \mathrm{J}, \mathrm{K})-\mathrm{F}(\mathbf{I}, \mathrm{J}, \mathrm{K})-\mathrm{C}(\mathbf{I}, \mathrm{J}, \mathrm{K})-\mathrm{E}(\mathbf{I}, \mathrm{J}, \mathrm{K}) \\
& Q(I, J, K)=0.0 \\
& P(I, J, K)=0.0
\end{aligned}
$$

C

END IF

C

10 CONTINUE

60 CONTINUE

80 CONTINUE

PGAP $\Rightarrow$ DELP-DPSOLL

WRITE $(*, 000)$ CSIZE,DPSOIL,PGAP

WRITE $(*, 080)$ NX,NY,MINGRD

WRITE (NOUT, 00908)

FAII $=1$

IDONE $=0$

C

C

C

C

c

C

C

C

C

777 CALL DO3ECF(N1,N2,N3,N1M,N2M,A,B,C,D,E,F,G,Q,P,

- APARAM,ITMAX,ITCOUN,ITUSED,NDR,IXN,IYN,IZN,CONRES,

- CONCHN,RESDS,CHNGS,WRKSP 1, WRKSP 2,WRKSP 3,WRKSP 4, IFAIL)

IF (FFAII.NE.0) WRITE (NOUT, 90997) IFAIL

- ITUSED)

NAG FORTRAN LIBRARY SUBROUTINE DOBECF

the for thesure deld, using

the 2-dimensional system of equetions given

Equation (4.28) in Chapter 4 . The subroutine

approximate LU factorization of the Strongly

Implicit Procedure. Convergence is besed on

the uner supplied variablea CONCHN and CONRES.

C

C

C

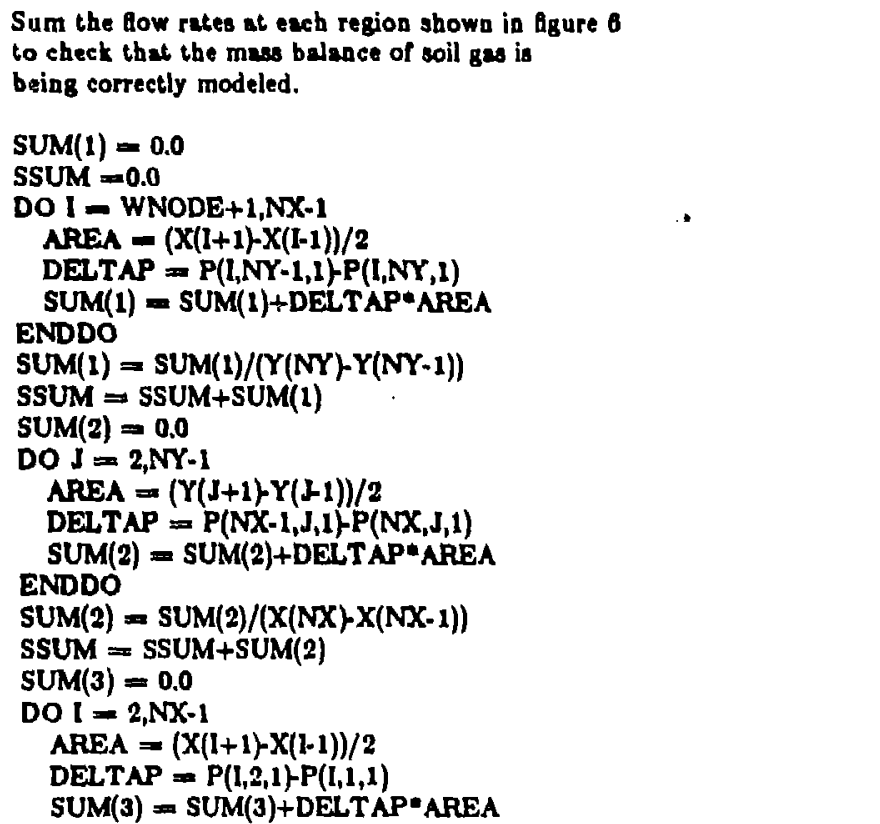




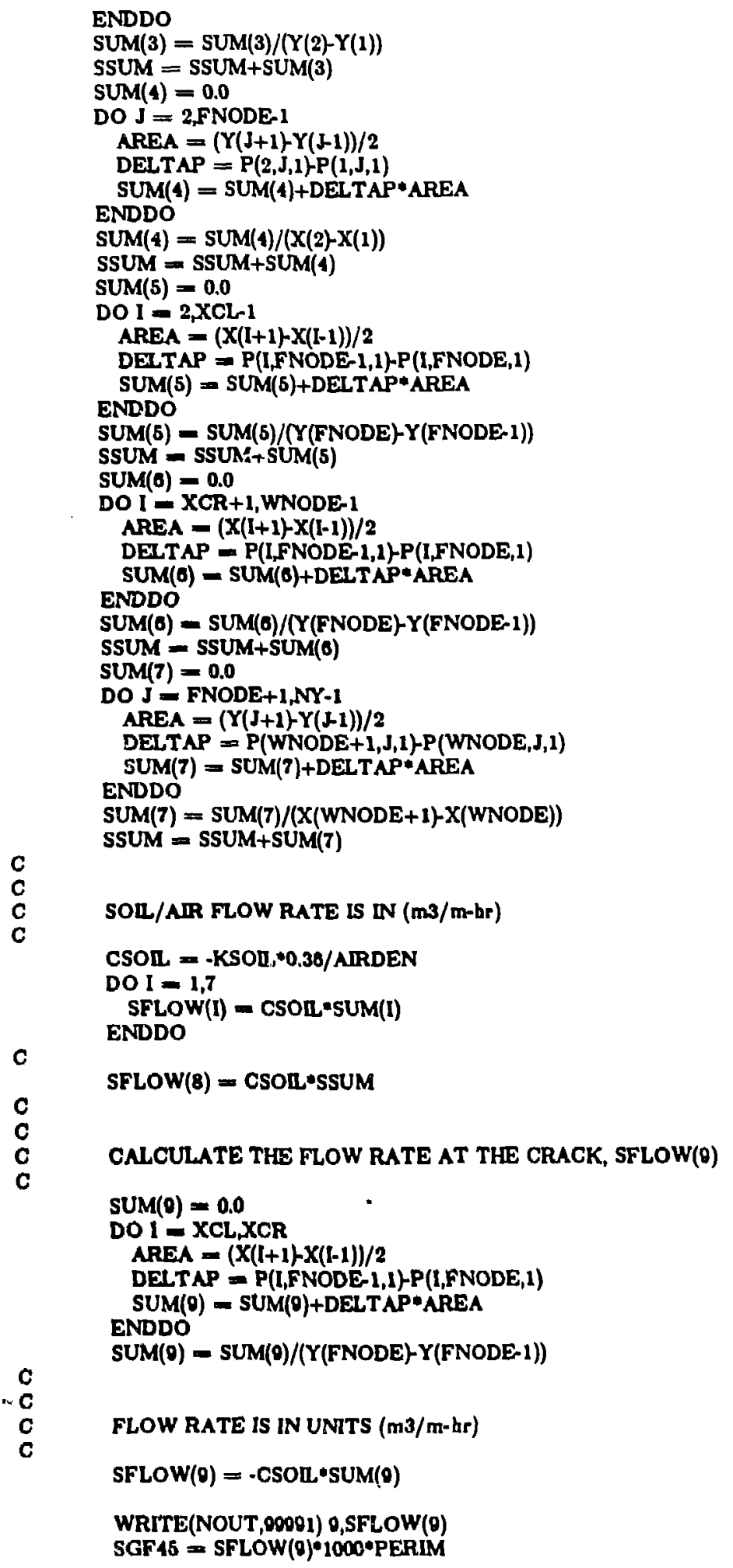




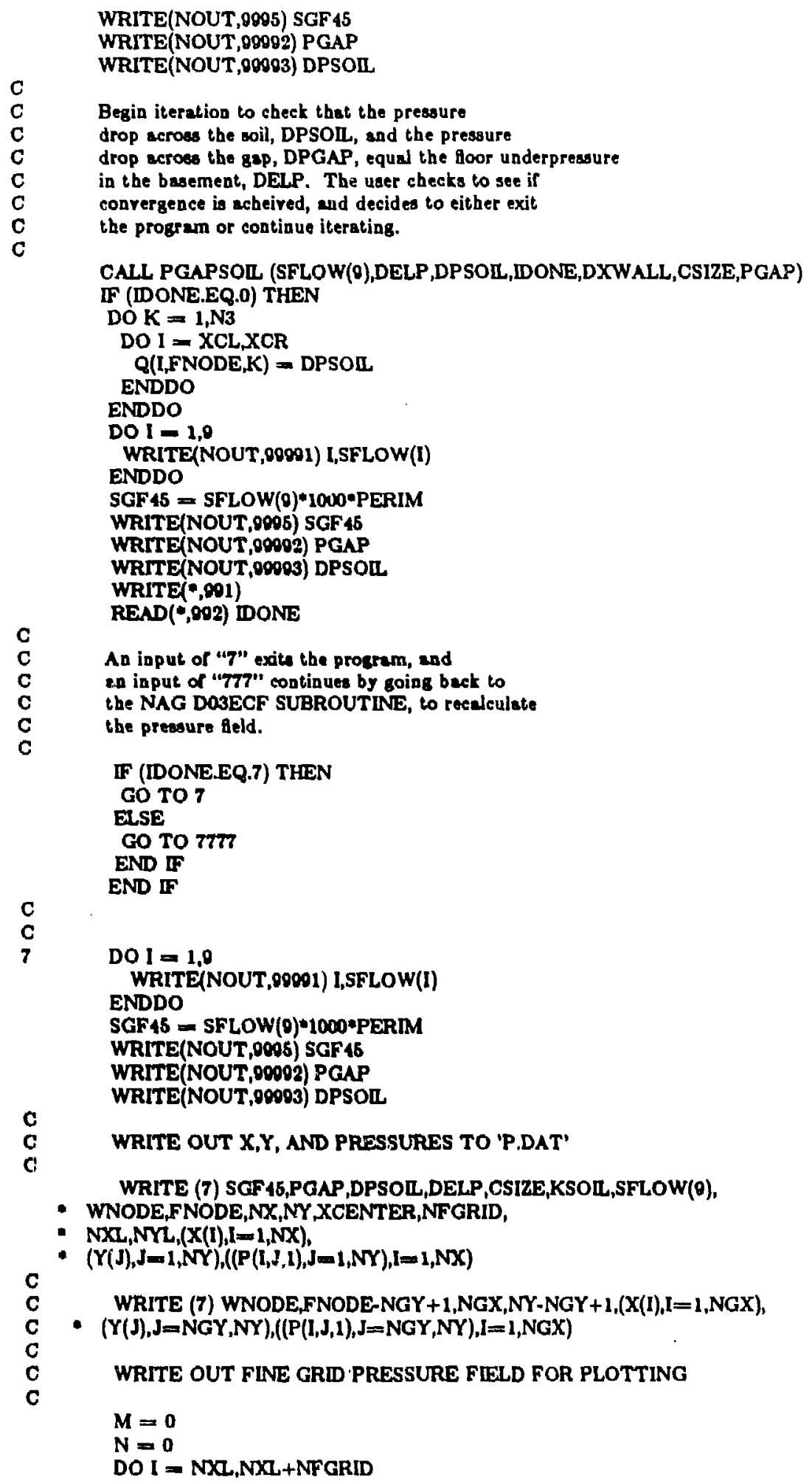




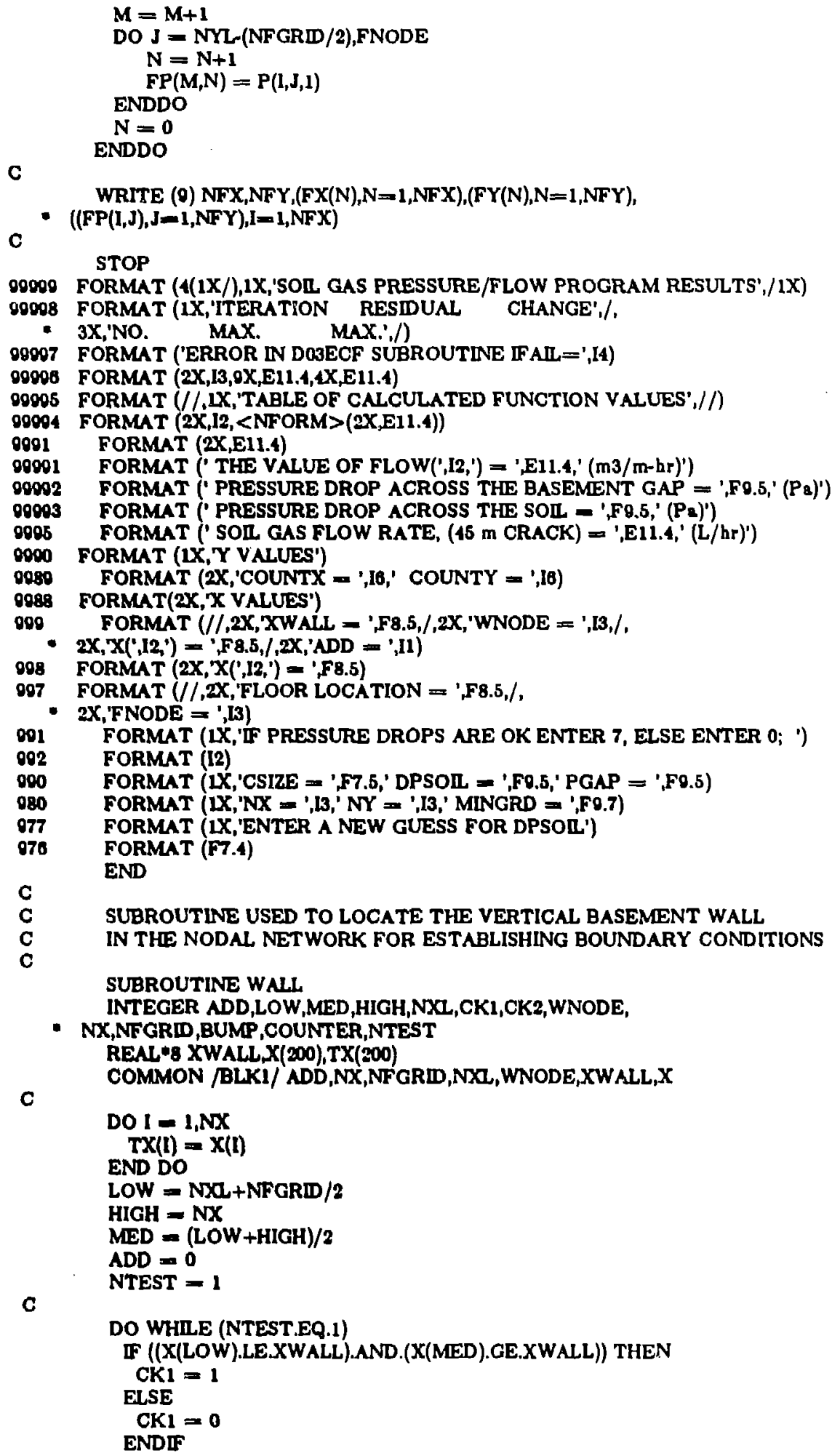




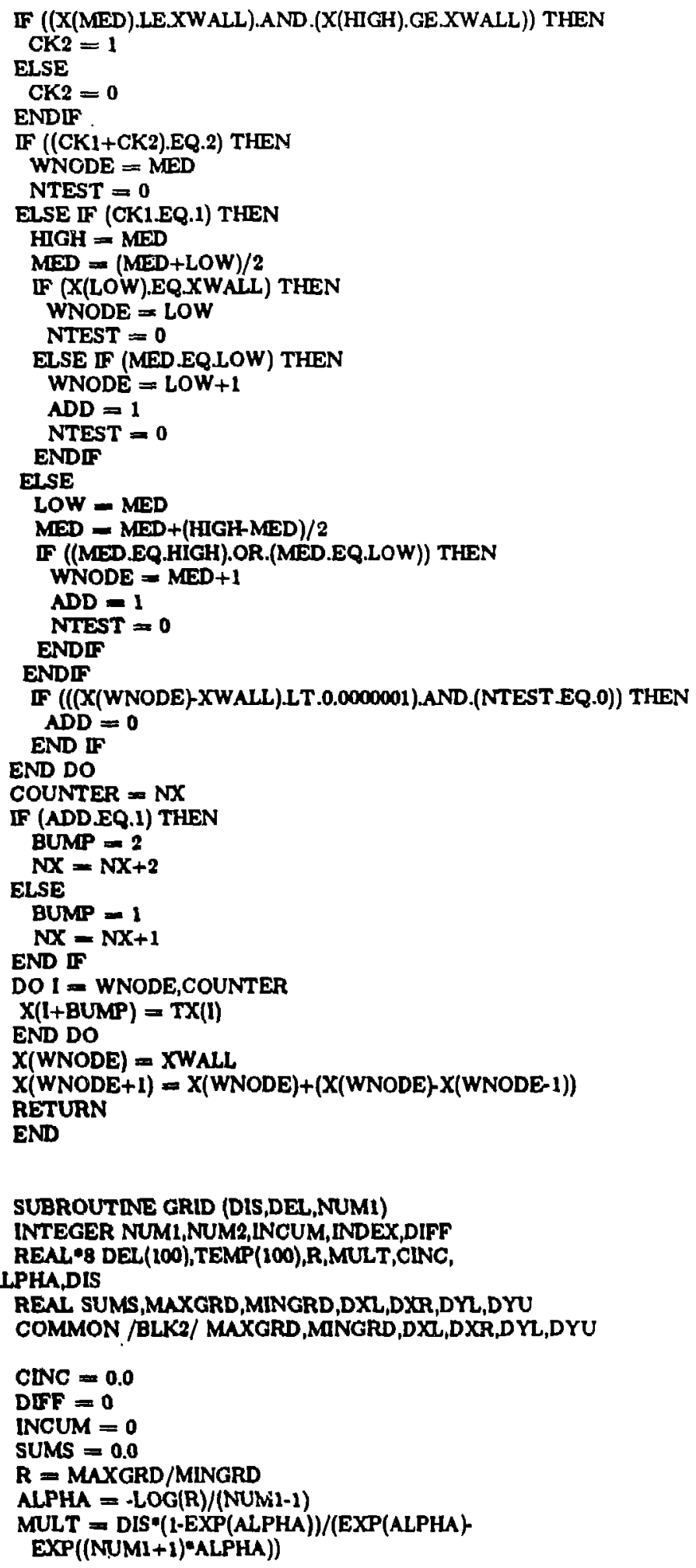




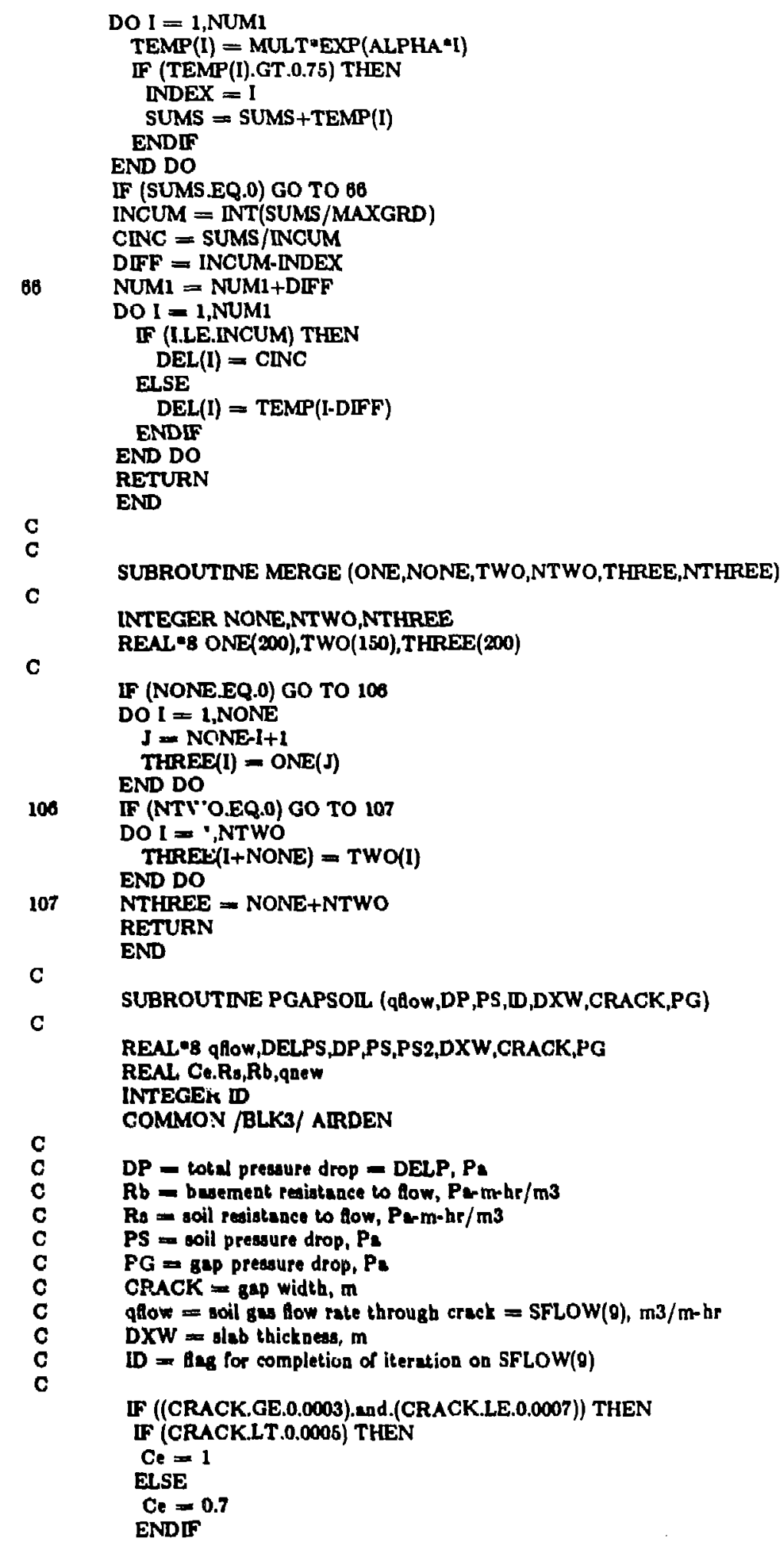


C

C Jergling's relation

$\mathrm{PG}=-((\mathrm{ABS}(\mathrm{q}$ (qlow) $) * \mathrm{CRACK} * 1000 / \mathrm{C} \bullet+1) * * 2-1) /((220 \mathrm{E}+9) *(\mathrm{CRACK} * * 4))$ $\mathrm{Rb}=\mathbf{A B S}\left(\mathrm{PG} / \mathrm{q}_{\text {flow }}\right)$

c ELSE

C Fluid low through tat pipe soalog

C

$\mathrm{Rb}=($ AIRDEN*DXW $) /\left(300^{*}(\mathrm{CRACK} * * 3)\right)$

$\mathrm{PG}=-\mathbf{A B S}($ qflow* $\mathrm{Rb})$

ENDIF

$\mathrm{PS2}=\mathrm{DP}-\mathrm{PG}$

DELPS $=$ PS-PS2

IF (ABS(DELPS).LT.0.05) THEN

$\mathrm{D}=1$

ELSE

ID $=0$

RU = ABS(PS/qRow)

qaew $=\mathrm{ABS}(\mathrm{DP}) /(\mathrm{Rs}+\mathrm{Rb})$

PS = -ABS (quew"Rs)

ENDIF

RETURN

C END 


\section{ERRATA}

The term $\lambda_{,} R n_{0}$ in the mass balance equations (Eq. 2.1 and 2.2) given in Chapter II (page 7) should be corrected to account for air entering the house from gaps or cracks in the foundation of a house with a basement or air entering through the floor of a house with a crawl space. The correct mass balance equations are

$$
\frac{d R n_{i}(t)}{d t}=\sigma_{d}(t)+\sigma_{j}(t)+\left[\lambda_{,}(t)-\lambda_{F}\right] R n_{o}(t)-R n_{i}(t)\left[\lambda_{0}+\lambda_{R n}\right]
$$

where $\sigma_{d}=$ radon entry rate from diffusion $(p C i / l-\dot{h} r), \sigma_{f}=$ radon entry rate from convection or soil gas flow $(p C i / l-h r), \lambda_{V}=$ house ventilation rate $\left(h r^{-1}\right), \lambda_{F}=$ air infiltration rate from the floor due to the soil gas entry rate or crawl space entry rate $\left(h r^{-1}\right), \lambda_{R n}=$ radon decay constant $=0.00756\left(h r^{-1}\right)$, and $R_{n_{0}}=$ outdoor radon concentration $(p C i / l-h r)$. At steady-state Equation (2.1a) may be written as

$$
R n_{i}=\frac{\sigma_{d}+\sigma_{j}+\left[\lambda_{i}-\lambda_{F}\right] R n_{0}}{\lambda_{i}+\lambda_{R a}}
$$

The term $\lambda_{F}$ for a house with a crawl space is given by

$$
\lambda_{F}=\frac{3600}{V o l} E L A_{I}\left[\frac{2\left|\Delta P_{f-t o}\right|}{\rho}\right]^{1 / 2}\left(h r^{-1}\right)
$$

and for a house with a basement

$$
\lambda_{F}=\frac{300 L \Delta P}{\mu V_{0} l}\left[\frac{C_{f} L_{0}}{t^{3}}+\frac{1}{12 \pi k} \cosh ^{-1}\left[\frac{2 z}{l}\right]\right]^{-1}\left(h r^{-1}\right)
$$


The results given in the thesis were calculated without accounting for the above correction in the radon entry rate due to infiltrating outdoor air. For the most part errors in the results presented here are not significant since the outdoor radon concentration is low $\left(R n_{0}=0.25 p C i / \eta\right.$. However, for cases of low permeable soil in the house with a basement the percent of infiltrating air due to soil gas entry may be as large as $20 \%$. For cases of high floor underpressure combined with large floor leakage area in the house with a crawl space the percent of infiltrating air may be as high as $100 \%$. Depending on the case examined, the largest error in predicted indoor radon concentration for the house with a crawl space given in the thesis can be no greater than the outdoor radon concentration, and for the house with a basement the largest error can be no greater than $20 \%$ of the outdcor radon concentration. 
This report was done with support from the Department of Energy. Any tonciusions or opinions expressed in this report represent solely thase of the author(s) and not necessarily those of The Regents of the University of California, the Lawrence Berkeicy Laboralory or the Department of Energy.

Reference to a company or product name does not imply approval or recommendation of the product by the University of Califomia or the U.S. Department of Energy to the exclusion of others that may be suitable. 